UNIVERSIDADE DE SÃO PAULO

FACULDADE DE ECONOMIA, ADMINISTRAÇÃO E CONTABILIDADE DE RIBEIRÃO PRETO

DEPARTAMENTO DE CONTABILIDADE

PROGRAMA DE PÓS-GRADUAÇÃO EM CONTROLADORIA E CONTABILIDADE

\title{
VANESSA SCHAEFER
}

Análise da relação entre os papéis assumidos pelos cooperados (usuário e/ou proprietário) e o desempenho socioeconômico percebido na cooperativa

ORIENTADOR: PROF. DR. AMAURY JOSÉ REZENDE

RIBEIRÃO PRETO 
Prof. Dr. Vahan Agopyan

Reitor da Universidade de São Paulo

Prof. Dr. André Lucirton Costa

Diretor da Faculdade de Economia, Administração e Contabilidade de Ribeirão Preto

Prof. Dr. Fabiano Guasti Lima

Chefe do Departamento de Contabilidade

Prof. Dr. Amaury José Rezende

Coordenador do Programa de Pós-Graduação em Controladoria e Contabilidade 



\section{VANESSA SCHAEFER}

Análise da relação entre os papéis assumidos pelos cooperados (usuário e/ou proprietário) e o desempenho socioeconômico percebido na cooperativa

Dissertação apresentada ao Programa de PósGraduação em Controladoria e Contabilidade da Faculdade de Economia, Administração e Contabilidade de Ribeirão Preto da Universidade de São Paulo para obtenção do título de Mestre em Ciências. Versão Corrigida. A original encontra-se disponível na FEA-RP/USP.

Área de concentração: Controladoria e

Contabilidade

Orientador: Prof. Dr. Amaury José Rezende

\section{RIBEIRÃO PRETO}


Autorizo a reprodução e divulgação total ou parcial deste trabalho, por qualquer meio convencional ou eletrônico, para fins de estudo e pesquisa, desde que citada a fonte.

O presente trabalho foi realizado com apoio da Coordenação de Aperfeiçoamento de Pessoal de Nível Superior Brasil (CAPES) - Código de Financiamento 001.

\section{Schaefer, Vanessa}

Análise da relação entre os papéis assumidos pelos cooperados (usuário e/ou proprietário) e o desempenho socioeconômico percebido na cooperativa. Ribeirão Preto, 2020.

104 f.: il.; $30 \mathrm{~cm}$

Dissertação de Mestrado, apresentada à Faculdade de Economia, Administração e Contabilidade de Ribeirão Preto/USP. Área de concentração: Controladoria e Contabilidade

Orientador: Rezende, Amaury José.

1. Desempenho socioeconômico. 2. Cooperativa agropecuária. 3. Papéis. 4. Comprometimento. 5. Confiança 


\section{FOLHA DE APROVAÇÃO}

Schaefer, Vanessa. (2020). Análise da relação entre os papéis assumidos pelos cooperados (usuário e/ou proprietário) e o desempenho socioeconômico percebido na cooperativa. (Dissertação de Mestrado em Controladoria e Contabilidade). Faculdade de Economia, Administração e Ciências Contábeis de Ribeirão Preto, Universidade de São Paulo, Ribeirão Preto.

Aprovado em:

\section{Banca Examinadora}

Prof. Dr.

Instituição:

Julgamento:

Prof. Dr.

Instituição:

Julgamento:

Prof. Dr.

Instituição:

Julgamento: 


\section{AGRADECIMENTOS}

Não vivemos só. Em cada avanço na escadaria da vida, percebo que as minhas conquistas não são só minhas. Elas são resultado de um esforço conjunto. E, por isso, hoje, eu agradeço a todos que, de uma forma ou de outra, me impulsionaram a subir esse degrau, chamado mestrado. E, de maneira especial, cito os agradecimentos a seguir.

A Deus, agradeço pela oportunidade de viver cada dia como um novo aprendizado.

Agradeço aos meus pais, Lídio e Vera, pela dádiva da vida, pela educação, pelos incentivos, pelo abraço carinhoso, pelos "puxões de orelha", por me mostrar que o simples é belo e por serem o meu porto-seguro.

Agradeço à minha irmã, Vitória, por abrilhantar os meus dias com a beleza da sua infância e por ser um dos motivos para que eu busque ser cada dia uma pessoa melhor. Obrigada, Vi!

Agradeço ao Jones, meu noivo e companheiro. Obrigada por me ouvir, por acalmar os meus choros e por ser minha fonte de energia e alegria. Seu apoio e companheirismo foram essenciais.

Agradeço aos meus sogros, Marta e Lauri, que sempre me apoiaram, demonstrando preocupação e interesse, perguntando como é o mestrado e, em cada despedida desejando boa sorte.

Agradeço a todos os meus amigos por entenderem a minha ausência. Em especial, agradeço à Kátia, Gianne e Dirlei, que durante as férias, sempre me recebiam com um bom papo e chimarrão. Esses momentos revigoravam minhas energias.

Agradeço à minha amiga, Anna Bárbara, por me acolher em Ribeirão Preto, por me oferecer um ombro amigo nos momentos difíceis e por partilhar os almoços e jantas da sua família. Sempre me senti em casa. Obrigada!

Agradeço à minha amiga Gislaine, por partilhar comigo sua experiência, pela companhia nas atividades diárias e pelos conselhos. Com você, a caminhada se tornou mais leve. Obrigada! Agradeço aos colegas de mestrado, em especial, Lucas, João Paulo e Bia. Obrigada por compartilharem as angústias, incertezas, aprendizados e conquistas. Contar com vocês nessa caminhada foi muito importante!

Agradeço ao meu orientador, Amaury por cada orientação, por compartilhar comigo os seus conhecimentos e me proporcionar oportunidades de aprendizado. Obrigada!

Aos demais colegas e professores do PPGCC, sou grata por cada experiência e aprendizado compartilhado.

Agradeço aos funcionários da FEA-RP, em especial, aqueles do Serviço de Pós-Graduação e as meninas do Departamento de Contabilidade. Obrigada pelo profissionalismo e eficiência.

Por fim, agradeço à CAPES, pela bolsa-auxílio durante os 24 meses. 
“Ando devagar porque já tive pressa

E levo esse sorriso

Porque já chorei demais

Hoje me sinto mais forte

Mais feliz, quem sabe

Só levo a certeza

De que muito pouco sei

Ou nada sei"

(Almir Sater, 1992) 


\section{RESUMO}

Schaefer, Vanessa. (2020). Análise da relação entre os papéis assumidos pelos cooperados (usuário e/ou proprietário) e o desempenho socioeconômico percebido na cooperativa. (Dissertação de Mestrado) Faculdade de Economia, Administração e Ciências Contábeis de Ribeirão Preto, Universidade de São Paulo, Ribeirão Preto.

Na relação contratual entre o cooperado e a cooperativa agropecuária, os cooperados podem assumir os papéis de usuário e proprietário. O primeiro pressupõe atividades de compra, venda e utilização de serviços, e o segundo de participação na tomada de decisão e prestação de contas. Não há obrigatoriedade contratual para que ele assuma os dois papéis na relação, o que ocasiona distintos perfis dentro da mesma organização e influencia o seu desempenho, tanto de maneira positiva quanto negativa. Neste contexto, este estudo buscou explicar como os papéis assumidos pelo cooperado (usuário e proprietário) relacionam-se com a comunicação efetiva, confiança, comprometimento e a percepção sobre o desempenho socioeconômico da cooperativa agropecuária. A estratégia de pesquisa compreendeu a coleta de dados por meio de um questionário e a análise dos dados pela modelagem de equações estruturais com estimação por mínimos quadrados parciais, no software SmartPLS3. A amostra é composta por 210 cooperados de uma cooperativa agropecuária brasileira. Os principais resultados indicam que a comunicação efetiva influencia positivamente a confiança e o comprometimento, os quais influenciam positivamente o comportamento do cooperado como usuário e proprietário e, este comportamento influencia positivamente a percepção deles sobre o desempenho socioeconômico. Portanto, os resultados mostram que quanto mais o cooperado manter relações, seja como usuário ou proprietário, melhor é o desempenho socioeconômico percebido por ele. Além disso, a análise do mapa importância-desempenho (IPMA) demonstra que a dimensão de usuário apresenta uma influência positiva maior sob o desempenho socioeconômico percebido do que o comportamento dele como proprietário. Para a literatura, este estudo contribui ao trazer evidências empíricas sobre a relação entre os papéis que o cooperado escolhe assumir na sua relação com a cooperativa, o seu comportamento e a forma como ele percebe o desempenho socioeconômico da organização. De forma prática, estes aspectos contribuem para que a gestão da cooperativa atue de maneira mais efetiva nas ações que envolvem o cooperado e os seus papéis.

Palavras-chave: Usuário. Proprietário. Desempenho Socioeconômico. Cooperativa Agropecuária. 


\begin{abstract}
Schaefer, Vanessa. (2020). Analysis of the relationship between the members' role (patron and /or owner) and their perception about cooperative's socioeconomic performance. (Dissertation) School of Economics, Business Administration and Accounting at Ribeirão Preto, University of São Paulo, Ribeirão Preto.

The members could be patron and owner in the contractual relationship with the agricultural cooperative. As patron, he purchases, sales and uses services from cooperative, and as patron, he participates in decision making and accountability. There is no contractual obligation for the member act as the both roles in the relationship, which causes different profiles in the same organization and influences its performance, positively or negatively. In this context, our aim was explaining how the members' role (patron and owner) are related to effective communication, trust, commitment and members' perception of the agricultural cooperative socioeconomic performance. We collected the data by a questionnaire and we analyzed them by Partial Least Square-Structural Equation Modeling, in the SmartPLS3 software. Our sample was 210 members from a Brazilian agricultural cooperative. The main results indicate that effective communication positively influences trust and commitment, which positively influence the member's behavior as patron and owner, and this behavior positively influences their perception of socioeconomic performance. Therefore, the results show that as more member act, as a patron or owner, better is the socioeconomic performance perceived by him. In addition, the analysis of the importance-performance map (IPMA) demonstrates that the patron has a greater positive influence on perceived socioeconomic performance than his behavior as owner. For the literature, our main contribution is providing empirical evidence about the relationship between the members' role, their behavior and how they perceive the organization's socioeconomic performance. In practical terms, these aspects contribute to the cooperative's management to act more effectively in actions that involve the member and its roles.
\end{abstract}

Keywords: Patron. Owner. Socioeconomic Performance. Agricultural Cooperative. 


\section{LISTA DE FIGURAS}

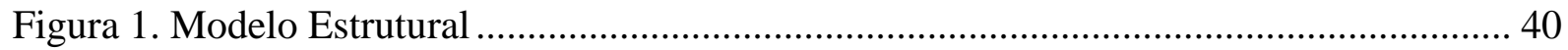

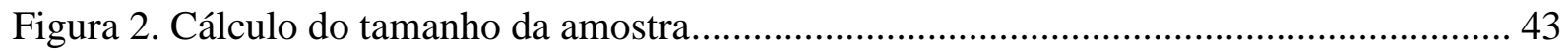

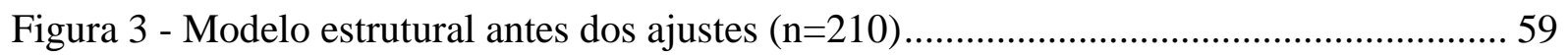

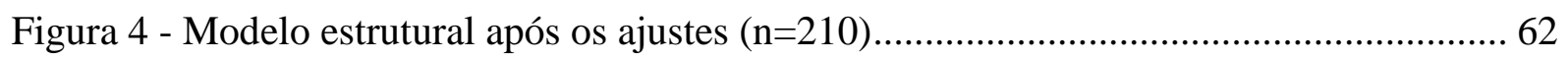

Figura 5 - Modelo estrutural com as variáveis de controle e a variável endógena ................... 64

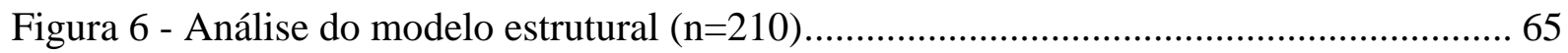




\section{LISTA DE GRÁFICOS}

Gráfico 1 - Frequência relativa "Desempenho Socioeconômico Percebido"- Parte 1 .............50

Gráfico 2 - Frequência relativa "Desempenho Socioeconômico Percebido" - Parte 2 ............51

Gráfico 3 - Frequência relativa "Comunicação Efetiva" - Parte 1 ...........................................52

Gráfico 4 - Frequência relativa "Comunicação Efetiva" - Parte 2 ..........................................53

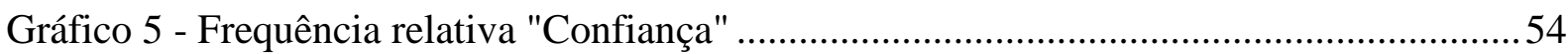

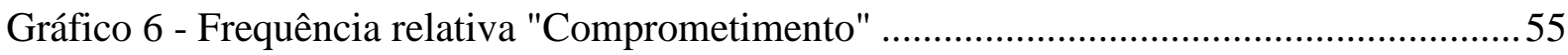

Gráfico 7 - Frequência relativa "Intensidade da Participação como Proprietário"....................58

Gráfico 8 - Mapa importância-desempenho “Desempenho Socioeconômico Percebido" ........71 


\section{LISTA DE TABELAS}

Tabela 1 - Papéis do cooperado na relação contratual ......................................................... 26

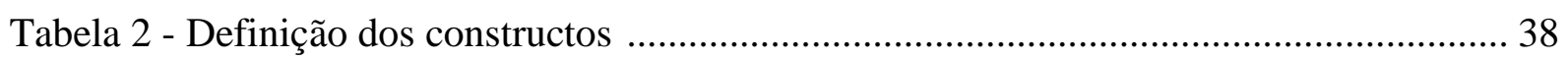

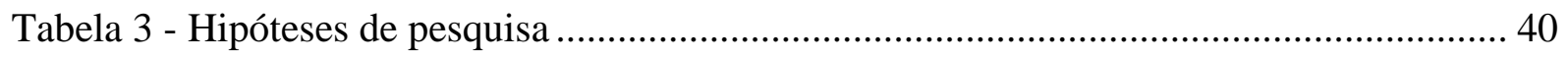

Tabela 4 - Efeito esperado das variáveis de controle sob o desempenho socioeconômico

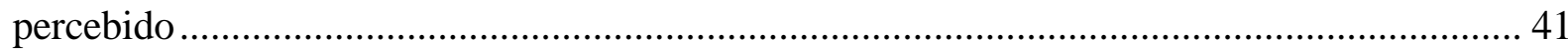

Tabela 5 - Mensuração das variáveis de controle .................................................................. 41

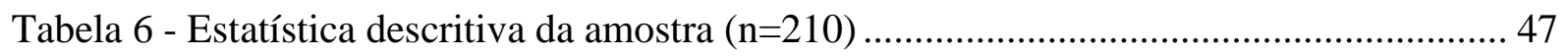

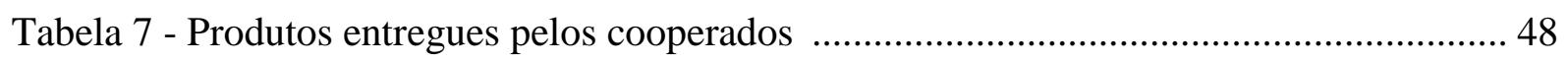

Tabela 8 - Estatística descritiva "Desempenho Socioeconômico Percebido".......................... 50

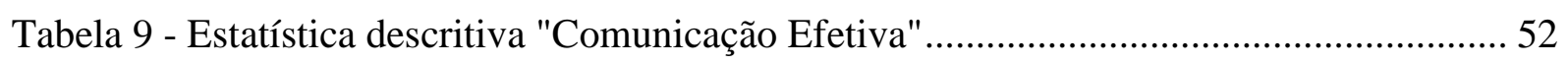

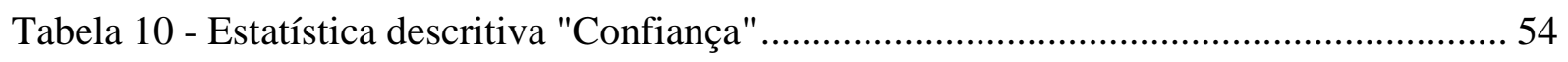

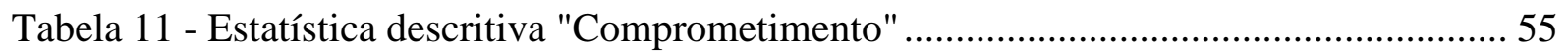

Tabela 12 - Frequência do Volume de Transação como Usuário ............................................ 57

Tabela 13 - Estatística descritiva "Intensidade da Participação como Proprietário" ............... 58

Tabela 14 - Matriz de correlação entre as variáveis latentes antes dos ajustes $(n=210) \ldots \ldots \ldots . . .60$

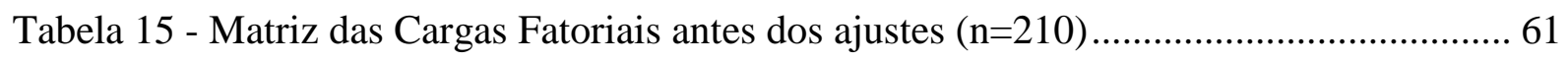

Tabela 16 - Matriz de correlação entre as variáveis latentes depois dos ajustes do modelo

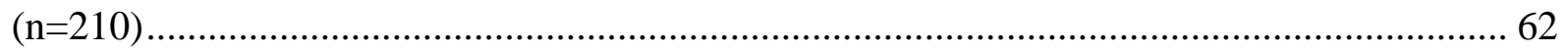

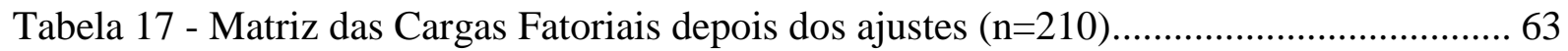

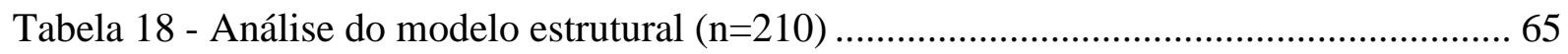

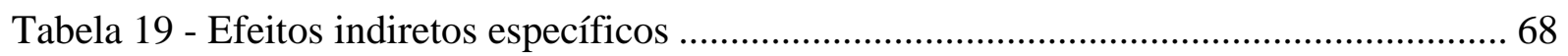

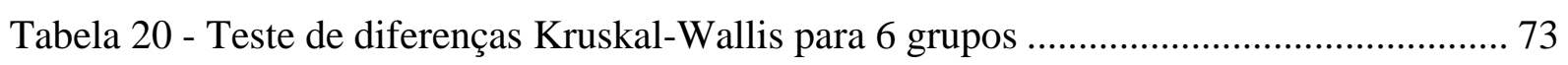

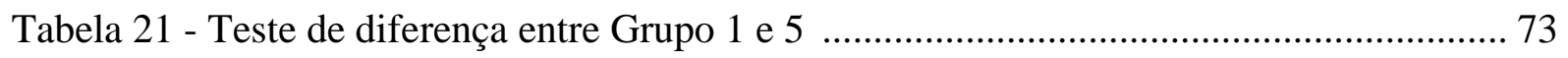

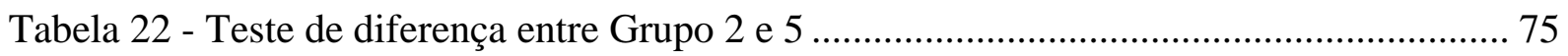

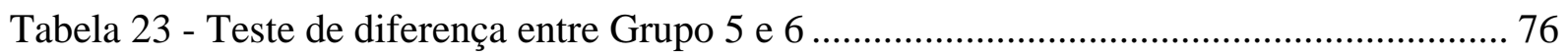




\section{SUMÁRIO}

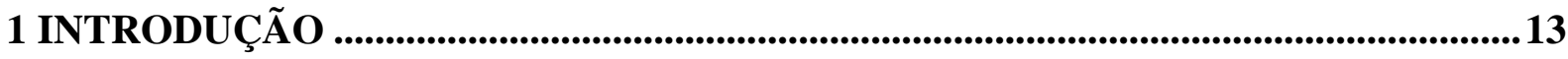

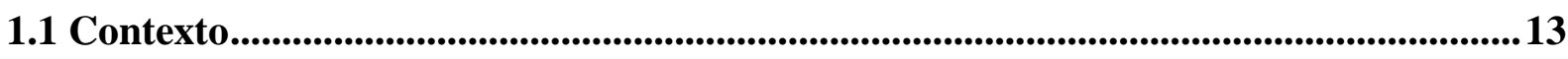

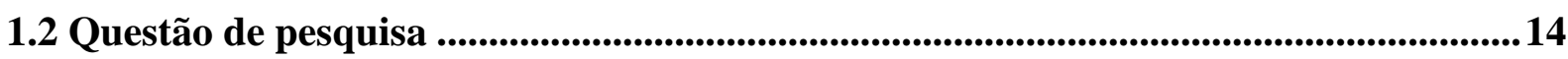

1.3 Objetivo e estratégia de pesquisa ....................................................................................14

1.4 Justificativa e contribuições....................................................................................................... 14

2 REFERENCIAL TEÓRICO E FORMULAÇÃO DE HIPÓTESES................................. 17

2.1 Teoria dos Custos de Transação e Contratos Relacionais .................................................. 17

$2.2 \mathrm{O}$ desempenho socioeconômico percebido pelos cooperados...........................................21

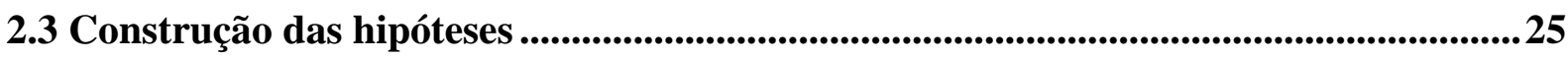

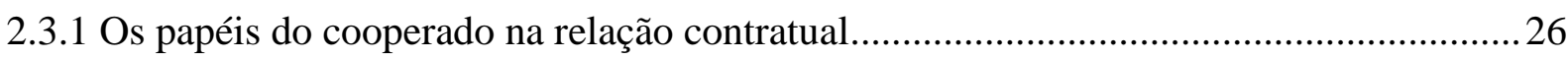

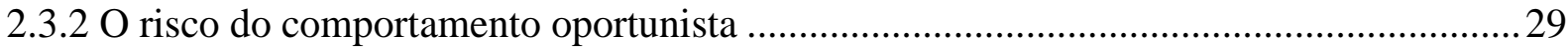

3 PROCEDIMENTOS METODOLÓGICOS .................................................................37

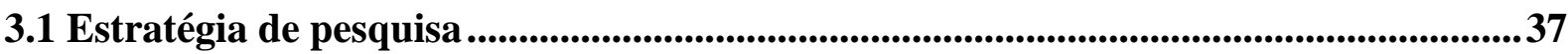

3.2 Modelo estrutural, modelo de mensuração e instrumento de coleta de dados .............37

3.3 Variáveis de controle ................................................................................................4

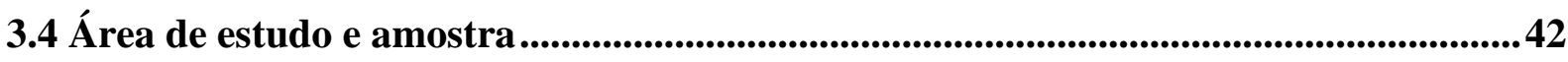

3.5 Técnicas de análise dos dados..................................................................................................45

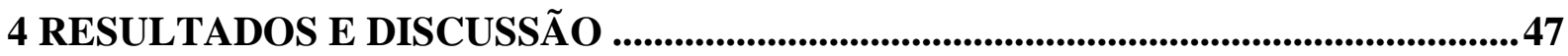

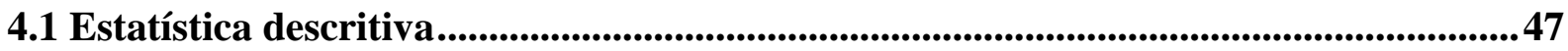

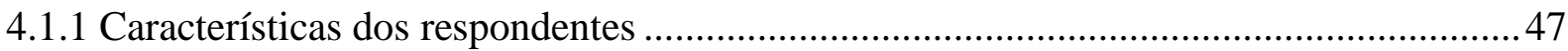

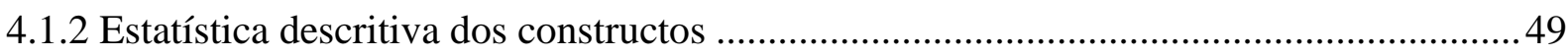

4.2 Validação do modelo de mensuração..............................................................................59

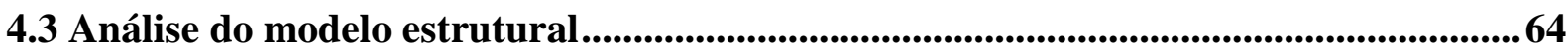

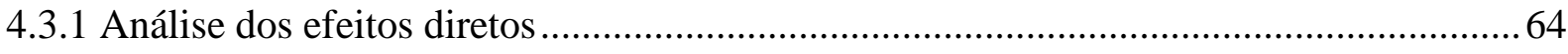

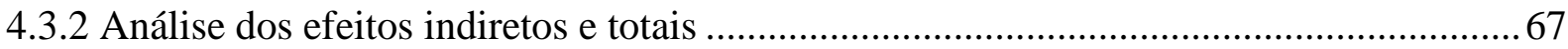

4.4 Análise entre o papel do cooperado e o desempenho socioeconômico percebido ........71

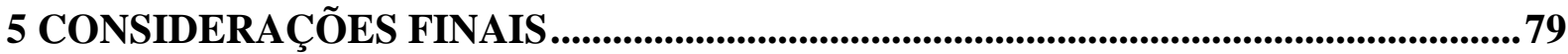

REFERÊNCIAS ...........................................................................................................8 81

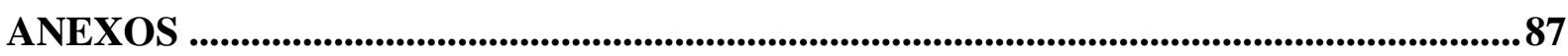

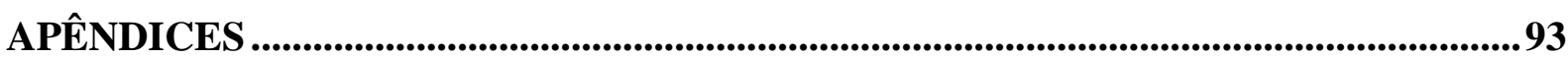





\section{INTRODUÇÃO}

\subsection{Contexto}

Nas cooperativas agropecuárias, os cooperados podem assumir papéis como usuário (cliente e fornecedor) e proprietário da organização (Nilsson, 2001), o que permite que haja dois tipos de relação contratual entre eles: de mercado, e de propriedade e controle. $\mathrm{Na}$ relação de mercado, o cooperado exerce o seu papel como usuário, entregando sua produção na cooperativa, comprando insumos e usufruindo dos serviços oferecidos (Cechin, Bijman, Pascucci, \& Omta, 2013). Na relação de propriedade e controle, o cooperado exerce seu papel como proprietário ao participar das atividades referentes a tomada de decisão e prestação de contas da gestão (Limnios, Mazzarol, Soutar, \& Siddique, 2018). Estas relações são mantidas por meio de um ambiente de cooperação entre os membros e a cooperativa. Entretanto, Nilsson (2001) argumente que o produtor rural pode se tornar sócio da cooperativa e não agir como proprietário e nem como usuário, assim como atribuir pesos diferentes para cada papel. Esta combinação pode influenciar o desempenho da cooperativa, tanto de maneira positiva como negativa (Nilsson, 2001).

Como não há um contrato formal que obrigue os cooperados a manter estas relações com a cooperativa (Cechin, Bijman, Pascucci, Zylbersztajn, \& Omta, 2013a) e esta não consegue prever como será o comportamento deles no futuro (Williamson, 2010b), há um risco de comportamento oportunista (Cechin, Bijman, Pascucci, Zylbersztajn, et al., 2013a), que prejudicaria o desempenho da organização. Em cooperativas italianas, Pascucci, Gardebroek, \& Dries (2012) evidenciam que os cooperados se tornam sócios, mas nem sempre entregam a produção na cooperativa. Para evitar que ele haja desta maneira oportunista, a literatura aponta que a gestão deve investir em ações que incentivem o comprometimento e a confiança (Hakelius \& Hansson, 2016a; Lui, Wong, \& Liu, 2009). Nesse sentido, Graca \& Arnaldo (2016), Hansen, Morrow Jr., \& Batista (2002) e Susanty, Bakhtiar, Jie, \& Muthi (2017) demonstram que há uma relação positiva entre confiança, comprometimento e o desempenho das cooperativas. Além disso, em cooperativas australianas, Limnios et al. (2018) aborda que as dimensões de usuário e proprietário são consideradas pela gestão quando pensam em estratégias para fortalecer engajamento e o comprometimento dos cooperados. 


\subsection{Questão de pesquisa}

Ao considerar que, os cooperados podem assumir distintos papéis na sua relação com a cooperativa, e que esta configuração influencia o seu comportamento e o desempenho da organização, este estudo buscou responder a seguinte questão de pesquisa: Como os papéis assumidos pelo cooperado (usuário e proprietário) relacionam-se com a comunicação efetiva, confiança, comprometimento e a sua percepção sobre o desempenho socioeconômico da cooperativa agropecuária?

\subsection{Objetivo e estratégia de pesquisa}

O objetivo geral desta pesquisa é explicar como os papéis assumidos pelo cooperado (usuário e proprietário) relacionam-se com a comunicação efetiva, confiança, comprometimento e a percepção sobre o desempenho socioeconômico da cooperativa agropecuária.

Para atingir o objetivo proposto, formulou-se um modelo teórico que foi analisado por meio do método PLS-SEM (Partial Least Square-Structural Equation Modeling), ou seja, modelagem de equações estruturais com estimação por mínimos quadrados parciais. Os dados foram coletados por meio de um questionário aplicado a 210 cooperados de uma cooperativa agropecuária brasileira.

\subsection{Justificativa e contribuições}

Dentro de uma organização, as pessoas tomam decisões e realizam transações entre si, por isso, as suas ações e os seus comportamentos são determinantes do desempenho organizacional (Milgrom \& Roberts, 1992). Quando se trata de organizações cooperativas, o estudo de como o comportamento influencia o desempenho organizacional justifica-se por dois motivos. Primeiro, as cooperativas são organizações nas quais o cooperado se torna sócio, mas não tem uma obrigação formal para realizar transações com ela. Assim, a cooperativa precisa buscar formas de fortalecer a relação entre esses agentes a fim de que haja uma cooperação mútua e, dessa forma, alcance o desempenho esperado. Segundo, o cooperado pode realizar transações com a cooperativa tanto como proprietário quanto como usuário, bem como atribuir pesos diferentes para essas relações. Esta configuração pode 
causar uma heterogeneidade de perfis dentro do quadro social, tornando-se um desafio para a gestão da cooperativa (Höhler \& Kühl, 2017).

Estudos anteriores evidenciam a importância da confiança e do comprometimento no desempenho da organização (Graca \& Arnaldo, 2016; Hakelius \& Hansson, 2016a; Susanty et al., 2017), bem como dos papéis do cooperado na relação com a cooperativa (Limnios et al., 2018; Nilsson, 2001; Pascucci, Gardebroek, \& Dries, 2012). No entanto, muito pouco se sabe sobre como os papéis do cooperado se relacionam com o seu comportamento e o desempenho da cooperativa. Desta forma, a análise proposta neste estudo contribui com a literatura ao trazer evidências empíricas sobre o efeito da comunicação efetiva, da confiança e do comprometimento no comportamento dos cooperados como usuários e proprietários, e, deste comportamento no desempenho percebido por eles.

Em aspectos práticos, argumenta-se que este tipo análise contribui com o entendimento de como ocorre as relações contratuais entre cooperativa e cooperado e de como as diferenças contratuais, oriundas da pluralidade de papéis, dentro de uma mesma organização podem interferir o comportamento e as percepções dos indivíduos. Para a gestão, este tipo de análise auxilia na implementação de ações e estratégias que mantenham os cooperados comprometidos com a organização, contribuindo, portanto, com o desempenho dela. 


\section{REFERENCIAL TEÓRICO E FORMULAÇÃO DE HIPÓTESES}

\subsection{Teoria dos Custos de Transação e Contratos Relacionais}

A abordagem contratual para a teoria das organizações enfatiza a natureza voluntária do envolvimento das pessoas (Milgrom \& Roberts, 1992). Na cooperativa, os membros aderem voluntariamente à sociedade, a qual é considerada uma organização intermediária posta a serviço das necessidades das suas economias particulares (Bialoskorski Neto, 2012). A Aliança Cooperativa Internacional (ACI, 2013), define cooperativa como uma "associação autônoma de pessoas que se unem voluntariamente, para satisfazer aspirações e necessidades econômicas, sociais e culturais comuns, através de uma empresa de propriedade comum e democraticamente gerida".

As cooperativas podem ser criadas para atender demandas na área da saúde, do trabalho, do turismo, do mercado financeiro, da agricultura, dentre outros. Para cada um desses casos, as motivações e necessidades dos indivíduos podem ser diferentes. No contexto do agronegócio, geralmente a cooperativa é formada para suprir uma falha de mercado e proporcionar serviços indisponíveis na região (Nilsson, 2001; Valentinov \& Iliopoulos, 2013) ou em condições comerciais melhores do que aquelas existentes até então. Os agricultores inseridos num mercado monopolista resolvem unir esforços e criar uma organização cooperativa a fim de reduzir seus custos de transação (Bijman, 2018; Giagnocavo, GaldeanoGómez, \& Pérez-Mesa, 2018; Hansmann, 1996; Valentinov \& Iliopoulos, 2013), por meio da redução de risco de mercado, aumento do poder de barganha e ganho de economia de escala (Bijman, 2018; Valentinov \& Iliopoulos, 2013).

Os custos de transação são "aqueles próprios do desenvolvimento da transação, ou seja, aquilo que se gasta ao efetivar a transferência de um bem" (Coase, 1937). Coase (1937), ao investigar o motivo do surgimento das firmas, conclui que elas surgem devido aos custos de transação, ou seja, aqueles custos que existem no mercado para os agentes negociarem produtos e serviços. Para o produtor rural os custos de transação referem-se aos custos e riscos de produzir e vender sua produção agrícola. No momento de produzir ele tem custos para negociar a aquisição de insumos, máquinas e novas tecnologias, além da incerteza da qualidade e da quantidade que será colhida devido a condições climáticas e outras adversidades ambientais (Nilsson, 2001). Na venda da produção, dependendo da localização geográfica, é possível que ele tenha apenas uma opção de comprador e, devido ao baixo volume, não tenha condições de barganhar os melhores preços (Nilsson, 2001). 
As incertezas relacionadas à produção, à falta de opção de comprador e baixa economia de escala levam os produtores rurais a se organizar em uma sociedade cooperativa, a fim de se beneficiar de menores custos de transação comparado ao que teriam barganhando sozinhos no mercado (Staatz, 1987). Desta maneira, a cooperativa surge porque os produtores rurais percebem e acreditam que ela é a estrutura organizacional mais eficiente para este fim (Alho, 2015; Hendrikse \& Veerman, 2003; Valentinov \& Iliopoulos, 2013).

A abordagem contratual adotada por Coase (1937) trouxe a oportunidade de investigar a firma como um arranjo institucional que rege as transações por meio de contratos formais e informais (Zylbersztajn, 2005). Oliver E. Williamson deu seguimento à pesquisa de Ronald Coase, partindo do seguinte questionamento: Dada a constituição da firma, "quais fatores de eficiência levam ela a produzir um produto ou serviço para suas necessidades ao invés de negociá-lo no mercado? "(Coase, 1937). Assim, Oliver E. Williamson passou a investigar quais fatores conduzem ao alinhamento eficiente das transações dentro da firma (Williamson, 2010b).

Os estudos de Williamson levaram ao desenvolvimento da Teoria dos Custos de Transação (TCT), uma das ramificações da visão da firma como um "nexo de contratos" (Zylbersztajn, 2005). Qualquer organização que pode ser conjecturada pela lente dos contratos pode ser estudada pela TCT, a qual comporta uma análise interdisciplinar (Williamson, 2010b). A preocupação central da TCT está nas estruturas de governança ex-post das relações contratuais, a fim de manter a continuidade e eficiência das transações (Bijman, Muradian, \& Cechin, 2011; Williamson, 2010b). Como eficiência entende-se o alcance do objetivo da organização (Milgrom \& Roberts, 1992). No caso das cooperativas agropecuárias, o objetivo é reduzir os custos de transação dos seus cooperados (Alho, 2015; Nilsson, 2001) e atender as suas necessidades econômicas e sociais (Benos, Kalogeras, Verhees, Sergaki, \& Pennings, 2016; Cook, 2018), ao proporcionar uma relação contratual mais rentável do que eles teriam negociando sozinhos no mercado (Staatz, 1987).

O pressuposto da TCT é que as transações ocorrem entre dois agentes e são regidas por leis contratuais, as quais estabelecem a estrutura que sustenta esta relação de troca sob uma gama ampla de distúrbios, exigindo adaptações e modelos de governança diferentes (Hendrikse \& Veerman, 2003; Williamson, 2010b). Assim, para compreender quais aspectos conduzem a eficiência das transações entre cooperado e cooperativa e, portanto, ao desempenho organizacional é necessário discutir as características dessa transação, as leis contratuais, os possíveis distúrbios que podem ocorrer e as possíveis adaptações e modelos de governança adotados na relação. 
“As transações são uma unidade de análise fundamental na teoria organizacional devido ao seu papel na alocação e monitoramento de direitos entre as partes que combinam esforços ou recursos”(Ménard, 2018). Para Williamson $(1979$; 2010) três fatores caracterizam as transações: especificidade dos ativos, frequência e incerteza. A especificidade dos ativos representa quão relevante é a continuidade da relação para que as partes invistam nela (Williamson, 2010b). A cooperativa investe na estrutura de armazenamento e/ou beneficiamento dos grãos de acordo com o portfólio dos cooperados, esperando que eles entreguem e vendam sua produção para ela (Bialoskorski Neto, 2012; Bijman et al., 2011). Já os investimentos do cooperado dependem das condições de mercado do produto. Quanto mais específico e perecível é o produto (por exemplo, vinho), mais ele investirá em ativos específicos para atender a qualidade exigida e maior a probabilidade de ele entregar o produto na cooperativa (Pascucci et al., 2012).

Em relação a frequência e a incerteza, quanto mais frequente é a transação, menor é o custo de organizá-la e quanto maior a incerteza, maiores são os custos da transação (Ménard, 2018). Assim, uma alta frequência das transações contribui positivamente com o desempenho da relação, enquanto uma incerteza alta o influencia negativamente. A incerteza da transação pode surgir de fatores externos (por exemplo, clima e regulação) ou internos (por exemplo, o comportamento oportunista) (Ménard, 2018). Nas cooperativas, em geral, a frequência das transações é alta e há uma incerteza na relação devido as flutuações climáticas (Nilsson, 2001) e o risco do comportamento oportunista oriundo da incompletude contratual (Bialoskorski Neto, 2012). Em virtude destas características, as transações são reguladas pela relação contratual firmada entre os agentes.

Na cooperativa, a relação contratual começa quando o produtor rural assina o livro matrícula e concorda com as cláusulas do estatuto social, o qual baseia-se nos princípios do cooperativismo $^{1}$ e na legislação brasileira (Lei 5.764/71). Ao se tornar cooperado, o produtor rural pode exercer distintos papéis na sua relação com a organização: proprietário, investidor e usuário (Mazzarol, Simmons, \& Limnios, 2014; Nilsson, 2001). Este papéis permitem que o cooperado mantenha relações contratuais de propriedade e controle e de mercado (Cechin, Bijman, Pascucci, Zylbersztajn, \& Omta, 2013b), realizando transações como proprietário/investidor e usuário (fornecedor e/ou cliente).

\footnotetext{
${ }^{1}$ São sete princípios do cooperativismo compartilhados mundialmente: adesão voluntária e livre; gestão democrática; participação econômica dos membros; autonomia e independência; educação, formação e informação; intercooperação; interesse pela comunidade. Recuperado de: https://www.ocb.org.br/o-que-ecooperativismo.
} 
Como usuário, o membro vende sua produção agrícola para a cooperativa e usufrui dos produtos e serviços oferecidos por ela (Limnios et al., 2018). Em geral, este é um dos principais motivos pelo qual a cooperativa surge e pelo qual o produtor rural se torna cooperado (Nilsson, 1996). Em alguns casos, o cooperado pode apenas vender ou comprar (Mazzarol et al., 2014). No Brasil é comum que ele realize as duas transações com a cooperativa (Bialoskorski Neto, 2012).

Como proprietário o membro possui direitos de propriedade, os quais lhe proporcionam o controle de decisão sobre o uso dos ativos da cooperativa, assim como o direito de receber as sobras no final do exercício (Hansmann, 1996). Na assembleia geral, os cooperados exercem o seu poder de decisão através do voto. O voto, nas cooperativas tradicionais, é baseado no princípio democrático "um membro, um voto" e as sobras são distribuídas conforme o volume de transações (compra e/ou venda) do cooperado (Chaddad \& Cook, 2004). Já nas cooperativas que se assemelham ao modelo de sociedades de capital, a configuração dessa relação é diferente, pois o percentual de quotas-partes de cada membro define o peso do voto e a forma da distribuição de sobras (Chaddad \& Cook, 2004).

No Brasil, as cooperativas podem adotar apenas o modelo tradicional, de acordo com a Lei 5.764/71 (Bialoskorski Neto, 2012). Esta legislação e o estatuto formam o contrato formal entre cooperado e cooperativa (Hansmann, 1996). Pelo contrato formal, o cooperado não é obrigado a participar do processo decisório (como proprietário) nem a transacionar (como usuário) com a cooperativa, enquanto que ela é obrigada a comprar e negociar a produção dele, oferecer serviços de assistência técnica e insumos e permitir sua participação na assembleia geral (Bialoskorski Neto, 2012). Esta configuração cria um ambiente de incerteza em relação ao comportamento dos cooperados, permitindo que eles ajam de maneira oportunista (Hendrikse \& Veerman, 2003). Há, portanto, uma incompletude contratual, pois o cooperado adere à relação contratual, mas não é possível prever como será o seu comportamento e atitudes ex-post (Williamson, 2010b).

Como as transações são realizadas pelos indivíduos, as suas ações determinam o comportamento e o desempenho das organizações (Milgrom \& Roberts, 1992). Os indivíduos, por sua vez, são dotados de limitações cognitivas, interesse próprio e outros atributos humanos, os quais podem gerar distúrbios na relação, como o comportamento oportunista (Williamson, 2010b). Para Williamson (2010) a incompletude contratual e os distúrbios da relação conduzem as partes para fora da curva do alinhamento contratual e, por isso, podem prejudicar o desempenho organizacional. 
Por causa da incompletude contratual e dos possíveis distúrbios, a gestão da organização precisa coordenar as adaptações ao longo da execução do contrato, a fim de mitigar comportamentos que podem prejudicar o desempenho da relação (Williamson, 2010c). Como as cooperativas são consideradas organizações híbridas, essa coordenação acontece por meio de contratos relacionais (Ménard, 2018) e informais (Williamson, 2010b).

Organizações híbridas são formas de governança intermediárias entre mercado e hierarquia (Williamson, 2010b). Isto significa que nem o preço dos produtos/serviços nem a alocação hierárquica de tarefas define a direção da transação (Ménard, 2004). Neste tipo de organização, as partes decidem compartilhar alguns direitos e ativos, enquanto que cada uma mantém controle sobre seus direitos de propriedade ou a maioria dos ativos estratégicos (Ménard, 2018). Nas cooperativas, a firma controla os direitos e ativos compartilhados interagindo com cada cooperado, que permanece autônomo e compete com os outros no mercado (Ménard, 2018). Assim, os contratos relacionais desempenham um papel nas negociações e barganhas dentro da firma, em que as capacidades da gestão são centrais para superar os distúrbios e manter a relação estável (Deng \& Hendrikse, 2015).

Como alguns aspectos não são tratados no contrato formal e não há coação por juízes ou árbitros, as partes têm incentivos para fazerem escolhas alinhadas ao seu próprio interesse sem considerar os aspectos implícitos do contrato (Ménard, 2018). Neste contexto, os contratos relacionais permitem a coordenação da auto regulação do acordo (Ménard, 2018), ao fortalecer a relação entre os agentes, gerar confiança mútua e maior probabilidade de que as partes cumpram as regras implícitas do contrato (Bialoskorski Neto, 2006), o que estruturaria a continuidade e a eficiência das transações dentro da organização (Williamson, 2010b) e o desempenho organizacional (Milgrom \& Roberts, 1992). Quando se trata de cooperativas, o fortalecimento dessa relação pode ser mais fácil devido ao elo social estabelecido pelos princípios e valores do cooperativismo (Bialoskorski Neto, 2012; Nilsson, 1996).

\subsection{O desempenho socioeconômico percebido pelos cooperados}

O desempenho é um indicador da efetividade da firma (Richard, Devinney, Yip, \& Johnson, 2009), alcançado a partir das ações e comportamentos dos indivíduos, pois estes são tomadores de decisões e atores organizacionais que realizam transações entre si (Milgrom \& Roberts, 1992). A continuidade e a eficiência da gestão da transações entre os agentes refletem o desempenho organizacional (Milgrom \& Roberts, 1992; Williamson, 2010a). 
No contexto das cooperativas agropecuárias, a definição sobre as formas de mensuração dos indicadores de desempenho ainda permanece em aberto (Benos, Kalogeras, Wetzels, Ruyter, \& Pennings, 2018; Soboh, Lansink, Giesen, \& van Dijk, 2009). As principais discussões perpassam a dualidade dos objetivos da cooperativa como modelo de negócio econômico, em que se avalia o desempenho com base em indicadores econômicos financeiros (Lauermann, Moreira, Souza, \& Piccoli, 2018; Soboh et al., 2009), e como modelo de negócio social, no qual se avalia a adequabilidade das ações da cooperativa aos interesses de seus membros (Benos et al., 2018; Soboh et al., 2009) por meio de indicadores socioeconômicos (Lauermann et al., 2018). A escolha do uso de apenas uma abordagem ou de ambas na pesquisa empírica envolve a análise: i) das vantagens e desvantagens de cada uma, ii) dos objetivos da pesquisa (Benos et al., 2018), e iii) do objetivo da(s) cooperativa(s) em estudo (Cook, 2018; Soboh et al., 2009).

A vantagem de usar o desempenho econômico-financeiro é que os indicadores utilizam dados financeiros, os quais são objetivos e permitem a comparabilidade entre as firmas (Benos et al., 2018). Por outro lado, Grashuis \& Su (2018) reconhecem que nem sempre estes dados estão disponíveis ${ }^{2}$ ou são confiáveis. Há também trabalhos que utilizam a percepção dos gestores para mensurar o desempenho econômico-financeiro (por exemplo, Benos et al., 2016; Tana, Mesquita, Gonçalves, \& Martins, 2017). A percepção torna a medida subjetiva e sujeita a vieses cognitivos, mas ainda permite a comparabilidade entre as firmas (Benos et al., 2018).

Soboh et al. (2009) argumentam que uma das desvantagens do desempenho econômico-financeiro é que ele não considera a estrutura organizacional específica da cooperativa nem o seu objetivo como organização, qual seja atender as necessidades de seus membros. Entretanto, Benos et al. (2018) em uma revisão da literatura sobre desempenho das cooperativas agropecuárias, destacam que o estudo do desempenho socioeconômico tem se intensificado numa tentativa de suprir essa lacuna apontada por Soboh et al. (2009).

A vantagem de analisar o desempenho socioeconômico reside no fato de que ele busca mensurar o sucesso da cooperativa por meio dos benefícios que os cooperados recebem (Benos et al., 2018). No entanto, é uma abordagem difícil de mensurar devido ao conceito inconclusivo na literatura e a dificuldade de acesso aos dados (Grashuis \& Su, 2018), os quais podem exigir informações internas da organização, como o percentual de entrega da produção

\footnotetext{
${ }^{2}$ Não há uma base de dados com informações financeiras sobre cooperativas agropecuárias como existe para empresas de capital aberto em nível mundial (exemplo, Thomson Reuters e Compustat) e nacional (exemplo, Economática).
} 
de cada membro, ou a coleta de informações direto com o cooperado (Benos et al., 2018). No primeiro caso utiliza-se medidas objetivas e no segundo a percepção dos membros ou dos gestores (Benos et al., 2018).

Conforme verificado por Benos et al. (2018), o uso de medidas objetivas, como o preço pago pela produção dos membros e percentual de fidelidade, é mais comum dentre aqueles estudos que analisam o desempenho socioeconômico. No Brasil, por exemplo, Lauermann et al. (2018) após entrevistas com gestores de grandes cooperativas, selecionaram quatro medidas objetivas: capital social por membro, sobras por membro, entrega versus compra de insumos (fidelidade), quantidade de membros versus técnicos agrícolas. Para os autores, esses itens identificam o cumprimento das relações econômicas e sociais da cooperativa com o cooperado. Como desvantagem desse tipo de medida, Benos et al. (2018) apontam que ela não reflete a natureza dual da cooperativa, nem todos os benefícios dos membros (por exemplo, satisfação dos membros com a sociedade), o que exige cautela no momento de interpretá-las e compará-las com outras cooperativas.

Já o uso de medidas subjetivas envolve a análise da satisfação dos membros em relação aos benefícios proporcionados pela cooperativa, por meio da percepção dos gestores (por exemplo, Benos et al., 2016; Franken \& Cook, 2015; Sisay, Verhees, \& van Trijp, 2017; Tana, Mesquita, Gonçalves, \& Martins, 2017; Yang \& Chaddad, 2014) ou dos membros (por exemplo, Alho, 2015; Arcas-Lario et al., 2014; Feng, Friis, \& Nilsson, 2016; Figueiredo \& Franco, 2018; Grashuis \& Cook, 2020; Hernández-Espallardo, Arcas-Lario, \& Marcos-Matas, 2013; Susanty et al., 2017). Grashuis e Cook (2020) defendem que o uso da satisfação como medida de desempenho é relevante por que ela reflete "o impacto positivo da cooperativa na utilidade do membro, seja pela melhora do preço, qualidade do produto, acesso a insumos ou alguma outra variável. ". Contudo, Richard et al. (2009) advertem que essa medida é subjetiva e sujeita a vieses cognitivos e psicológicos.

Franken e Cook (2013), na análise de desempenho de 367 cooperativas agropecuárias americanas, utilizaram dados financeiros e a percepção dos gestores sobre 05 itens componentes do índice Cooperative Health, quais sejam: satisfação do membro, posição competitiva na indústria, rentabilidade, habilidade para alcançar visão organizacional e desempenho geral. Os principais resultados apontaram que as correlações são mais significativas entre a rentabilidade e outras medidas financeiras do que com o índice Cooperative Health. Com isso, os autores concluem que o desempenho financeiro nem sempre está relacionado à satisfação das necessidades dos membros (Franken \& Cook, 2013). 
Yang e Chaddad (2014), com base nos conceitos de Franken e Cook (2013), mensuraram o desempenho das cooperativas agropecuárias americanas pela percepção dos gestores, considerando o desempenho como um constructo (variável latente). Por meio da técnica de equações estruturais relacionaram o constructo de desempenho com o constructo de governança. Os autores concluíram que as medidas que remetem a "satisfação do membro" e a "habilidade para alcançar a visão organizacional" apresentam maior significância no constructo de desempenho (Yang \& Chaddad, 2014).

Hernández-Espallardo et al. (2013) e Arcas-Lario et al. (2014) analisaram a satisfação pela percepção dos cooperados de cooperativas espanholas de frutas e vegetais. Os primeiros concluíram que o preço pago pela produção e o menor custo de transação explicam a satisfação dos cooperados, bem como o desejo de continuar na cooperativa. Os segundos afirmam que a satisfação é uma medida de sucesso da relação entre cooperativa e seus associados e exerce uma influência positiva sobre o desejo dos produtores rurais em continuarem na sociedade.

Feng et al. (2016) investigaram a satisfação por meio da percepção dos cooperados de três cooperativas de grãos na Suíça, considerando dois aspectos: i) cooperativa como um parceiro de negócio (preços, acessibilidade e receptividade), e ii) cooperativa como associação (atividades, informações, amizades). Os principais resultados apontaram que a satisfação dos membros é maior em cooperativas menores. Para os autores, cooperativas menores tendem a ser mais homogêneas no seu quadro social e focam sua estratégia nas necessidades dos membros, o que garante mais envolvimento e satisfação deles.

Uma das limitações de estudos como o de Feng et al. (2016) e Hernández-Espallardo et al. (2013) é definir até que ponto os achados podem ser generalizados, por se basear em uma ou poucas cooperativas de uma indústria em um país (Feng et al., 2016). Por outro lado, embora a comparação entre países seja desejável, estes dados podem ser difíceis de coletar e interpretar devido as particularidades de cada contexto em análise (Feng et al., 2016). Por isso, Benos et al. (2018) afirmam que o pesquisador "deve selecionar as métricas de acordo com o contexto e objetivos da pesquisa”. Para Grashuis \& Cook (2019) a somatória dos estudos em diferentes tipos de cooperativas agropecuárias e diferentes países contribui para confirmar ou não as relações em análise.

Em relação ao contexto de pesquisa, Cook (2018) destaca que a métrica de desempenho é definida pelos membros na fase de estruturação da cooperativa e varia conforme o modelo e objetivo da organização. No Brasil, as cooperativas agropecuárias são consideradas tradicionais com multipropósito (Bialoskorski Neto, 2012). Tradicional significa 
que o capital social é restrito aos cooperados, os quais recebem as sobras com base no percentual de uso (compra e venda de produtos e serviços) (Chaddad \& Cook, 2004). Multipropósito significa que o objetivo principal da cooperativa é receber os diferentes produtos dos membros e agregar valor, assim como possuir lojas de insumos e oferecer assistência técnica e outros serviços (Bialoskorski Neto, 2012). Logo, estas características devem ser consideradas na definição e análise dos indicadores de desempenho socioeconômico.

Além dos diferentes produtos, os múltiplos papéis que o cooperado pode assumir na relação com a cooperativa como proprietário e usuário e o crescimento do quadro social ao longo do tempo podem ocasionar uma heterogeneidade de perfis dos cooperados (Benos et al., 2018; Cook, 2018; Kalogeras, Pennings, van der Lans, Garcia, \& Van Dijk, 2009). A heterogeneidade dos membros provavelmente resultará em diferentes comportamentos e preferencias referentes à estrutura organizacional, aos seus objetivos com a cooperativa, à distribuição das sobras (Höhler \& Kühl, 2017) e às métricas de desempenho (Cook, 2018).

Para a gestão da cooperativa é desafiador equilibrar as divergências que podem existir, e garantir que todos se mantenham comprometidos com a relação contratual estabelecida com a cooperativa (Kalogeras et al., 2009), assim como se sintam satisfeitos com os resultados alcançados (Höhler \& Kühl, 2017). No entanto, Cook (2018) argumenta que não é possível assumir uma correlação direta entre a heterogeneidade do quadro social e os resultados da cooperativa, pois a diversidade pode estimular o desenvolvimento de propostas únicas e soluções criativas para os problemas. Para analisar estas relações, a abordagem contratual da teoria dos custos de transação e dos contratos relacionais fornece pressupostos que auxiliam no entendimento de como as transações acontecem e como a organização pode gerenciar e equilibrar os distúrbios do comportamento humano que podem surgir ex-post, a fim de garantir a continuidade e eficiência das relações e o desempenho organizacional.

\subsection{Construção das hipóteses}

Com base nos pressupostos da TCT e dos contratos relacionais, pesquisas vem investigando como os agentes e as organizações coordenam os distúrbios da relação contratual. Entre a cooperativa agropecuária e os cooperados, há, pelo menos, dois aspectos do comportamento humano que podem provocar distúrbios na relação contratual e prejudicar o desempenho organizacional: a diversidade de papéis que o cooperado pode assumir na sua 
relação com a cooperativa e o risco do comportamento oportunista. Estas relações embasam a construção das hipóteses de pesquisa.

\subsubsection{Os papéis do cooperado na relação contratual}

Ao se tornar cooperado, o membro pode assumir os papéis de proprietário, investidor e usuário (cliente e/ou fornecedor) (Hansmann, 1996; Nilsson, 2001). Mazzarol et al. (2014) argumenta que ele também pode desempenhar o papel de membro da comunidade. Neste estudo, será analisado apenas as relações de proprietário, investidor e usuário, pois estas são as relações que a abordagem contratual fornece subsídios teóricos para análise. Na Tabela 1, evidencia-se os papéis do cooperado, a respectiva relação contratual e o resultado esperado por ele.

Tabela 1 - Papéis do cooperado na relação contratual

\begin{tabular}{|c|c|c|c|}
\hline Papel & Relação Contratual & Resultado esperado & Autores \\
\hline 1.Proprietário & $\begin{array}{l}\text { Relação de propriedade e controle } \\
\text { Refere-se ao direito de controle do membro, } \\
\text { exercido através dos direitos de voto na } \\
\text { tomada de decisão, frequentando a } \\
\text { assembleia geral, permanecendo ativamente } \\
\text { informado dos assuntos da cooperativa e } \\
\text { assumindo posições nos conselhos ou } \\
\text { participando em comitês. }\end{array}$ & $\begin{array}{l}\text { Retorno sobre o } \\
\text { investimento: } \\
\text { - juros sobre capital } \\
\text { próprio } \\
\text { - sobras }\end{array}$ & $\begin{array}{l}\text { (Chaddad \& } \\
\text { Iliopoulos, 2013; } \\
\text { Limnios et al., } \\
\text { 2018; Mazzarol } \\
\text { et al., 2014) }\end{array}$ \\
\hline 2.Investidor & $\begin{array}{l}\text { Surge a partir do momento em que o membro } \\
\text { adquire quotas-partes da cooperativa. Ele } \\
\text { deseja investir e receber remuneração pelo } \\
\text { seu capital. }\end{array}$ & $\begin{array}{l}\text { Retorno sobre o } \\
\text { investimento }\end{array}$ & $\begin{array}{l}\text { (Mazzarol et al., } \\
\text { 2014; Nilsson, } \\
\text { 2001) }\end{array}$ \\
\hline 3. Usuário & $\begin{array}{l}\text { Relação de mercado } \\
\text { Refere-se ao relacionamento de cadeia de } \\
\text { suprimentos que existe entre a cooperativa e } \\
\text { o cooperado. Como fornecedor ele vende sua } \\
\text { produção para a cooperativa, e como cliente } \\
\text { ele compra máquinas e insumos agrícolas e } \\
\text { obtém empréstimos com a cooperativa. }\end{array}$ & $\begin{array}{l}\text { Sobras distribuídas com } \\
\text { base no percentual de } \\
\text { operações (venda e } \\
\text { compra), preço justo } \\
\text { pela produção entregue, } \\
\text { preço baixo pelo } \\
\text { insumo e armazenagem } \\
\text { preços, qualidade e } \\
\text { disponibilidade de } \\
\text { produtos e serviços. }\end{array}$ & $\begin{array}{l}\text { (Limnios et al., } \\
\text { 2018; Mazzarol } \\
\text { et al., 2014; } \\
\text { Morfi, Ollila, } \\
\text { Nilsson, Feng, \& } \\
\text { Karantininis, } \\
\text { 2014; Nilsson, } \\
\text { 2001) }\end{array}$ \\
\hline $\begin{array}{l}\text { 4.Membro da } \\
\text { comunidade }\end{array}$ & $\begin{array}{l}\text { Refere-se ao fato de que a cooperativa pode } \\
\text { gerar benefícios e serviços à comunidade que } \\
\text { estão inseridas. }\end{array}$ & $\begin{array}{l}\text { Benefícios oferecidos à } \\
\text { comunidade em que a } \\
\text { cooperativa } \\
\text { inserida. }\end{array}$ & $\begin{array}{l}\text { (Limnios et al., } \\
\text { 2018; Mazzarol } \\
\text { et al., 2014) }\end{array}$ \\
\hline
\end{tabular}

Fonte: Elaborado pelos autores (2020).

Além da definição dos papéis do cooperado há outros aspectos que auxiliam na compreensão dos tipos de relação contratual que podem existir entre cooperado e cooperativa, 
são eles: a estrutura organizacional, o contexto legal e as condições de mercado da cooperativa. Dependendo da estrutura organizacional e do contexto legal em que a cooperativa está inserida, a relação como proprietário pode ser semelhante ou não à de investidor (Mazzarol et al., 2014). Por exemplo, nos Estados Unidos, Suécia e Finlândia, a legislação permite que as cooperativas negociem todo ou parte do seu capital social no mercado de ações (Chaddad \& Iliopoulos, 2013), logo nem todos os investidores são considerados proprietários com direitos de controle e de distribuição dos resultados (Mazzarol et al., 2014). No Brasil, as cooperativas não podem abrir seu capital social para investidores externos (Lei 5.764/71) e, portanto, adotam a estrutura organizacional tradicional (Bialoskorski Neto, 2012). Neste caso, os investidores são também os proprietários com direito ao controle, as sobras e ao retorno sobre o investimento (Mazzarol et al., 2014). Portanto, neste estudo ambos serão tratados como proprietários.

O proprietário mantém uma relação de propriedade e controle, a qual refere-se a alocação dos direitos de propriedade e do uso dos ativos da cooperativa (Pascucci et al., 2012; Sykuta \& Cook, 2001). Ela é uma relação exercida coletivamente em um processo de tomada de decisão democrático (Cechin, Bijman, Pascucci, Zylbersztajn, et al., 2013b). Ao manter relações como proprietário o membro procura participar de atividades relacionadas a tomada de decisão e prestação de contas (Limnios et al., 2018), bem como almeja o sucesso da sua cooperativa ao longo do tempo (Borgström, 2013). Como cliente e/ou fornecedor, o membro mantém uma relação de usuário. Ela é uma relação individual, em que o cooperado entrega sua produção na cooperativa, compra insumos e usufrui dos serviços proporcionados (Cechin, Bijman, Pascucci, Zylbersztajn, et al., 2013b), bem como espera obter boas condições de preço e qualidade dos serviços (Mazzarol et al., 2014; Nilsson, 2001).

A configuração das relações de usuário e proprietário é afetada pelo contex to legal e as condições de mercado da cooperativa. Na China, por exemplo, Jia \& Huang (2011) com base na legislação do país, distinguiram os cooperados entre "membros clientes" e "membros formais", os últimos se diferenciam dos primeiros por estarem registrados e possuírem direitos de voto. Os autores concluem que quanto mais "membros formais" a cooperativa tem, mais difícil é para ela conseguir contratos com compradores do seu produto, pois eles acreditam que as divergências entre os membros com direito à voto implicarão na ineficiência da cooperativa em cumprir o contrato (Jia \& Huang, 2011). Assim, há um incentivo de mercado para que as cooperativas tenham em seu quadro social mais "membros clientes", os quais mantêm apenas relações de usuário (Jia \& Huang, 2011). 
Na Itália, Pascucci et al. (2012) separaram os cooperados entre: i) "associação forte", produtores rurais que são associados e entregam a produção na cooperativa; ii) "associação fraca", produtores rurais que são associados e não entregam a produção na cooperativa. Os resultados do estudo mostraram que "associação fraca" é mais comum em cooperativas tradicionais e multipropósito, em que os membros se beneficiam por controlar a organização e manter a reputação de pertencer a uma rede coletiva. Já a "associação forte" ocorre mais em cooperativas altamente especializadas, como de vinhos e leite, nas quais os membros precisam realizar investimentos altos em ativos específicos para atender a qualidade exigida do produto.

A configuração de "associação fraca" abordada por Pascucci et al. (2012) é semelhante àquela que pode ser encontrada nas cooperativas brasileiras, as quais são tradicionais e multipropósito. Como não há um contrato formal que exija que o membro mantenha relações de propriedade e controle e de mercado, ele pode ser associado e não realizar transações como proprietário e usuário. Pascucci et al. (2012) não analisaram se os membros desempenhavam o seu papel como proprietário, apenas verificaram se ele era sócio ou não.

Nilsson (2001) argumenta que o produtor rural pode se tornar sócio da cooperativa e não agir como proprietário/investidor. Quando isso acontece, o membro deixa de se preocupar com o monitoramento e os gestores podem ter um comportamento oportunista (Nilsson, 2001). No curto prazo, se o membro continua comprando e vendendo com a cooperativa, nem sempre haverá prejuízo para o desempenho financeiro dela (Nilsson, 2001). No longo prazo, a falta de sentimento de propriedade prejudica a motivação e engajamento dos membros para manter uma relação de usuário e proprietário (Borgström, 2013), o que prejudicaria o desempenho e a sobrevivência da cooperativa ao longo do tempo (Jensen-Auvermann, Adams, \& Doluschitz, 2018). Portanto, para a cooperativa é interessante que todos os membros atuem como usuários e como proprietários (Nilsson, 2001).

Bialoskorski Neto (2005) destaca que no cenário brasileiro a lógica econômica favorece que o membro opte por manter a relação de usuário quando lhe convém, pois ela gera apenas benefícios. Na relação de propriedade e controle, embora o cooperado incorra em custos de participação, de incerteza e de tempo, ele pode obter benefícios por sua influência nas decisões sobre o uso dos ativos e dos resultados da cooperativa, o que seria um incentivo para a sua participação como proprietário (Bialoskorski Neto, 2005). Ao direcionar o uso dos ativos e dos resultados ele é capaz de definir, de acordo com as suas necessidades, a forma como os produtos e serviços serão oferecidos pela cooperativa, o que incentivaria o seu 
volume de transação como usuário. Por isso, este estudo propõe-se a investigar a seguinte hipótese de pesquisa:

H1a: A intensidade da participação como proprietário está relacionada positivamente com o volume de transação como usuário do cooperado na cooperativa.

Pela ótica da Teoria dos Custos de Transação, em um arranjo contratual, quanto mais frequente são as transações, melhor é o desempenho da relação contratual (Williamson, 2010b). No caso das cooperativas agropecuárias, espera-se que quanto mais o cooperado mantiver relações como usuário e como proprietário com a cooperativa, melhor será o desempenho socioeconômico percebido por ele. Como o membro pode escolher qual relação estabelecer com a cooperativa (Nilsson, 2001), propõe-se as seguintes hipóteses de pesquisa:

H1b: A intensidade da participação como proprietário está relacionada positivamente com a percepção do cooperado acerca do desempenho socioeconômico.

H2a: O volume de transação como usuário está relacionado positivamente com a percepção do cooperado acerca do desempenho socioeconômico.

\section{$\underline{\text { 2.3.2 O risco do comportamento oportunista }}$}

Pela lógica contratual é importante para o desempenho da cooperativa que o cooperado realize transações como usuário e participe como proprietário (Nilsson, 2001). No entanto, devido a incompletude contratual (Williamson, 1979) e a concorrência do mercado (Susanty et al., 2017) há o risco de que ele haja de maneira oportunista, ou seja, não participe das atividades como proprietário e não transacione com a cooperativa. Este comportamento oportunista é negativamente relacionado com o desempenho da relação, uma vez que o sucesso dela depende do esforço conjunto das partes (Lui et al., 2009; Williamson, 2010b). Por isso, é importante que a gestão crie mecanismos para fortalecer as relações com os cooperados e mantê-los comprometidos com a relação estabelecida (Susanty et al., 2017).

O fortalecimento da relação advém da capacidade dos gestores fazerem cumprir as regras implícitas do contrato relacional (Deng \& Hendrikse, 2015), as quais incluem a manutenção das relações do cooperado como proprietário e usuário. Ao afetar o comportamento dos indivíduos dentro da organização (Baker, Gibbons, \& Murphy, 2002), o contrato relacional permite que a gestão coordene a ação dos cooperados a fim de reduzir o 
risco do comportamento oportunista (Hendrikse \& Veerman, 2003). Conforme Hakelius e Hansson (2016) a confiança e o comprometimento são aspectos que podem reduzir significativamente tais riscos, e que, portanto, devem ser incentivados pela gestão da cooperativa.

A confiança é uma dimensão relacional do capital social que facilita a cooperação (Liang et al., 2015). Ela evidencia o quanto uma parte acredita que a outra parte é confiável e íntegra a ponto de cumprir com o seu compromisso na relação contratual (Fischer, 2013; Morgan \& Hunt, 1984) e, por isso, incentiva os membros a cooperarem com a organização (Tadesse \& Kassie, 2017). Como os membros não possuem um contrato formal para comprar, vender e participar da cooperativa, a confiança pode reduzir significativamente os riscos de um comportamento oportunista (Bachmann \& Inkpen, 2011; Bhuyan, 2007; Graca \& Arnaldo, 2016; Hakelius \& Hansson, 2016b; Tadesse \& Kassie, 2017) e atuar como como um facilitador das relações (Fischer, 2013).

Devido aos custos para escrever um contrato formal que preveja todos os comportamentos ex-post num ambiente de incerteza e instabilidade institucional (Bialoskorski Neto, 2005), a confiança pode ser um substituto ou complementar do contrato formal (Bialoskorski Neto, 2005; Fischer, 2013). Quando há confiança na relação o indivíduo é capaz de responder positivamente as incertezas e riscos percebidos (Pesämaa, Pieper, Vinhas da Silva, Black, \& Hair Jr, 2013), mas não representa uma obrigação para o membro comprar e vender com a cooperativa, pois o contrato formal ainda permite que ele busque preços no mercado e faça o negócio que minimiza os seus custos de transação (Bialoskorski Neto, 2005).

Já os membros comprometidos são menos prováveis de sair da cooperativa ou negociar com outras empresas (Cechin, Bijman, Pascucci, \& Omta, 2013). Morgan \& Hunt (1984) definem que o comprometimento existe quando a parte acredita que a continuidade da relação é tão importante que justifica o esforço máximo para mantê-la. Em uma cooperativa, o comprometimento é uma medida de quão bem ela se diferencia de uma empresa de capital, de forma que os membros mantêm a cooperação e o volume de negócios mesmo quando há outras oportunidades no mercado (Fulton, 1999). Desta forma, o comprometimento aumenta a probabilidade de que o membro faça um esforço para o sucesso da organização e não venda sua produção no mercado paralelo (Cechin, Bijman, Pascucci, \& Omta, 2013), assim como exerça seus direitos como proprietário e influencie as estratégias da cooperativa em relação aos produtos e serviços que serão oferecidos (Bialoskorski Neto, 2005). 
Tanto o comprometimento quanto a confiança contribuem com o bom desempenho da relação contratual. Morgan e Hunt (1994) apontam três benefícios da confiança e comprometimento para a eficiência das relações: i) auxiliam na preservação dos investimentos da relação através da cooperação com as partes; ii) as partes resistem à alternativas de curto prazo em detrimento dos benefícios de longo prazo esperados por manter a relação atual; iii) as partes veem potencialmente ações de alto risco como sendo prudentes, pois acreditam que a outra parte não agirá oportunisticamente. Estas relações promovem um comportamento cooperativo que conduz a eficiência, produtividade e eficácia da relação (Morgan \& Hunt, 1984).

Empiricamente, alguns estudos vêm investigando como relações de confiança, comprometimento estão relacionadas ao desempenho das relações contratuais, mensuradas pela percepção (Graca \& Arnaldo, 2016; Hansen et al., 2002; Hernández-Espallardo et al., 2013; Pesämaa et al., 2013; Susanty et al., 2017) ou por medidas objetivas (Liang, Huang, Lu, \& Wang, 2015).

Em cooperativas americanas de algodão e grãos, Hansen et al. (2002) identificaram que a confiança entre os membros e entre os membros e a gestão são determinantes importantes da coesão do grupo, a qual é uma medida de desejo do membro permanecer na sociedade e comprometido com ela. Pesäma et al. (2013) ao analisarem pequenas cooperativas de turismo americanas, concluíram que as cooperativas devem investir em estratégias que aumentam a confiança, pois ela constrói comprometimento interpessoal e, então, ajuda a fortalecer o comprometimento organizacional.

Em cooperativas de leite na Península Ibérica, Graça e Arnaldo (2016) encontraram que a reputação corporativa e a confiança têm um impacto positivo sobre a fidelidade, e esta tem efeito positivo sobre a percepção dos membros em relação ao desempenho. Da mesma forma, Susanty et al. (2017), ao investigarem cooperativas de leite da Indonésia encontraram que a confiança tem um efeito positivo na fidelidade e esta tem efeito positivo sobre a percepção dos membros em relação desempenho financeiro e não financeiro do negócio.

Com base nas premissas expostas acima, considera-se que a confiança pode estar positivamente relacionada com o comprometimento dos cooperados. Se eles têm confiança entre si e na cooperativa, eles serão mais comprometidos com as metas e propósitos da entidade (Hansen et al., 2002, Tadessie \& Kassie, 2017). Ao demonstrarem mais confiança e serem mais comprometidos, espera-se que os cooperados mantenham mais relações com a cooperativa (Morgan \& Hunt, 1984), demonstrem preocupação com a longevidade da 
organização e com a qualidade e quantidade da produção entregue (Peng, Hendrikse, \& Deng, 2016). À vista disso, este estudo propõe-se a investigar as seguintes hipóteses de pesquisa:

$H_{3}$ : A confiança do cooperado está relacionada positivamente com o seu comprometimento. $\boldsymbol{H}_{b}$ : A confiança do cooperado está relacionada positivamente com a sua intensidade de participação como proprietário.

H3 : A confiança do cooperado está relacionada positivamente com o seu volume de transação como usuário.

H4a: O comprometimento do cooperado está relacionado positivamente com a sua intensidade de participação como proprietário.

$H_{4}$ : O comprometimento do cooperado está relacionado positivamente com o seu volume de transação como usuário.

Considerando que a confiança e o comprometimento estimulam o cooperado a manter relações de usuário e proprietário com a cooperativa, como a gestão pode influenciar os membros a sentirem mais confiança e serem mais comprometidos? Pela abordagem contratual no contexto de cliente e fornecedor, alguns estudos revelam que a comunicação influencia positivamente a confiança, comprometimento, satisfação e o desempenho da relação (Brown, Crosno, \& Tong, 2018; Chen et al., 2017; Morgan \& Hunt, 1984; Palmatier, Dant, Grewal, \& Evans, 2006; Reynolds, Fischer, \& Hartmann, 2009). No contexto das cooperativas, Hendrikse e Veerman (2003) argumentam que, como elas são gerenciadas por contratos relacionais, as diversas formas de comunicação também podem ser capazes de influenciar confiança e comprometimento entre as partes.

Em uma cooperativa, a comunicação pode ocorrer de maneira horizontal e vertical (Peng et al., 2016), por meio de diferentes técnicas de comunicação como assembleias, jornais, websites, aplicativos, rede social, eventos desportivos e dias de campo (Tadesse \& Kassie, 2017). As informações compartilhadas podem ser em relação a gestão do negócio, a produção do cooperado ou assuntos diversos, como família, esporte, entre outros. Qualquer atitude da cooperativa que vise o compartilhamento de informações reduz a assimetria de informação e aumenta a satisfação e comprometimento dos membros (Arcas-Lario et al., 2014).

A comunicação horizontal ocorre quando os cooperados compartilham informações entre si (Peng et al., 2016). A relação próxima e a troca de informações e experiências gera confiança e comprometimento entre eles e contribui para melhorar a qualidade dos produtos 
entregues na cooperativa (Peng et al., 2016), além de fortalecer a relação do grupo como um todo (Hendrikse \& Veerman, 2003).

A comunicação vertical é aquela que acontece entre a cooperativa e os cooperados sobre assuntos da gestão, da produção, da comunidade, dentre outros (Peng et al., 2016). A comunicação sobre informações da gestão é pautada no princípio de gestão democrática e estruturada de acordo com o modelo de governança adotado pela cooperativa. Naquelas em que há um Conselho de Administração (CA) e uma Diretoria Executiva (DE), em geral, o CA comunica as decisões da DE para os cooperados, bem como levanta informações sobre as necessidades dos cooperados e repassa para a DE. Já nas cooperativas apenas com CA, a ligação da gestão com os cooperados é direta.

O modelo democrático requer compromisso e participação dos membros nas assembleias e reuniões (Nilsson, 2001), bem como responsabilidade e prestação de contas do Conselho de Administração (Susanty et al., 2017). O processo de prestação de contas visa garantir que o CA esteja envolvido em estratégias que atendam os interesses de todos (Bijman et al., 2014). Independentemente da estrutura de gestão, a comunicação vertical e a legitimidade das decisões através desse processo participativo tem o papel de equilibrar o conhecimento do gestor e dos membros, estabelecer uma relação de confiança (Hendrikse \& Veerman, 2003) e aumentar o comprometimento dos membros (Bijman et al., 2011).

Wolnni e Fischer (2014) destacam que reuniões regulares onde os membros recebem informações sobre as condições de mercado e desempenho da cooperativa, promovem interações sociais entre os membros e a gestão, o que aumenta a transparência e confiança. A participação dos membros em assembleias gerais também está relacionada positivamente com o desempenho da cooperativa, conforme estudo de Franken e Cook (2015) em cooperativas americanas. Na Etiópia, Tadessie e Kassie (2017) evidenciam que há aumento da confiança quando os membros participam na governança da cooperativa.

Östeberg e Nilsson (2009) ao investigarem produtores rurais na Suíça, concluíram que a percepção dos membros em participar do controle democrático é o fator com maior peso para explicar o comprometimento dos membros e sua confiança no Conselho de Administração. Também em cooperativas suíças, Hakelius e Hansson (2016) observaram que a percepção do cooperado em relação a gestão da cooperativa relaciona-se positivamente com seu nível de confiança e comprometimento. No Brasil, Cechin, Bijman, Pascucci, e Omta (2013) evidenciam que os membros que observam a cooperativa como uma democracia são mais comprometidos com a ação coletiva. 
Além da comunicação a respeito das informações da gestão, os membros podem manter relações com a cooperativa por meio de outros canais e discutir outros assuntos. Por exemplo, os serviços de assistência técnica permitem uma relação próxima com o cooperado e, junto com a tecnologia, contribui para o aumento da produtividade e entrega da produção, o que consequentemente aumenta a relação de troca com os membros e o desempenho organizacional (Lauermann et al., 2018). Peng et al. (2016) ao investigarem cooperativas de queijo e vegetais constataram que a comunicação horizontal e vertical sobre inovação e qualidade dos processos e dos produtos melhora o desempenho da organização. Com base nisto, os autores destacam que a comunicação também pode ser utilizada para estudar outros contextos, como por exemplo, envolvimento, comprometimento e confiança entre os membros e a cooperativa.

A comunicação pode contribuir com o comprometimento e a confiança entre os cooperados e o desempenho socioeconômico ao transmitir conhecimento, resolver conflitos e alinhar expectativas (Hendrikse \& Veerman, 2003; Peng et al., 2016). Primeiro, o conhecimento transmitido através da assistência técnica e entre conversas dos cooperados, pode fazer com que eles melhorem a qualidade e a produtividade do seu produto, proporcionando melhores resultados para a propriedade rural e para a cooperativa (Peng et al., 2016). Segundo, a comunicação auxilia na compreensão e cumprimento dos acordos informais entre cooperado e cooperativa, o que contribui para alinhar as expectativas entre as partes (Hendrikse \& Veerman, 2003). Terceiro, como os gestores e os membros podem ter conhecimentos diferentes entre si, a comunicação tem um papel intermediário de equipará-los, resolver os conflitos que surgem, estabelecer e manter a confiança entre eles (Hendrikse \& Veerman, 2003).

Fischer (2013) e Susanty et al. (2013) argumentam que a comunicação contribui com o estabelecimento da confiança quando as partes estão satisfeitas com a qualidade e a frequência da troca de informações. Fischer (2013) analisou a relação entre 1.430 produtores rurais (fornecedores de matéria-prima) e agroindústrias (clientes processadores de matériaprima) de 06 países diferentes (Alemanha, Inglaterra, Espanha, Polônia, Irlanda e Finlândia) e encontrou que a comunicação efetiva ${ }^{3}$ é um dos determinantes da confiança das partes na relação. Da mesma forma, Susanty et al. (2017) verificaram que, em cooperativas lácteas da

${ }^{3}$ Fischer (2013) utilizou o constructo de comunicação efetiva definido pela qualidade (relevância, acurácia, confiabilidade e tempestividade) e a frequência da informação compartilhada. 
Indonésia, a comunicação colaborativa ${ }^{4}$ está relacionada positivamente com a confiança entre produtores rurais e a cooperativa. Embora Fischer (2013) e Susanty et al.(2013) utilizem nomenclaturas diferentes, ambas atribuem o mesmo significado para comunicação ( comunicação colaborativa = comunicação efetiva), a qual é determinada pela qualidade e frequência da troca de informação. Adiante, utilizar-se-á apenas o termo comunicação efetiva.

Com base nas premissas expostas acima, espera-se que a comunicação efetiva esteja relacionada positivamente com a confiança, como demonstrado nos estudos de Fischer (2013) e Susanty et al. (2017), e também contribua com o comprometimento dos cooperados (Hendrikse \& Veerman, 2003). O argumento central desta proposição considera que, como as as transações entre cooperado e cooperativa são geridas por contratos relacionais (Bialoskorski Neto, 2005) e cooperativas têm melhores canais de informação e comunicação do que outras empresas (Cook, 1994). Desta maneira, a comunicação efetiva contribuiria com o cumprimento das regras formais e informais ao fomentar relações de confiança e comprometimento (Hendrikse \& Veerman, 2003). Por isso, propõem-se as seguintes hipóteses de pesquisa:

H5a: A comunicação efetiva está relacionada positivamente com a confiança do cooperado.

H5b: A comunicação efetiva está relacionada positivamente com o comprometimento do cooperado.

${ }^{4}$ Susanty et al. (2017) utilizaram o constructo de comunicação colaborativa definido por (Boniface, Gyau, Stringer, \& Umberger, 2010), no qual a comunicação é determinada em termos de qualidade e frequência da informação compartilhada entre as partes. 


\section{PROCEDIMENTOS METODOLÓGICOS}

\subsection{Estratégia de pesquisa}

Esta pesquisa tem por objetivo explicar como os papéis assumidos pelo cooperado (usuário e proprietário) relacionam-se com a comunicação efetiva, confiança, comprometimento e a percepção sobre o desempenho socioeconômico da cooperativa agropecuária. O papel do cooperado como usuário é mensurado pela variável "Volume de Transação como Usuário" e o papel como proprietário é mensurado pela variável "Intensidade da Participação como Proprietário".

Para atingir o objetivo proposto, foi realizado um levantamento com aplicação de questionário aos cooperados de uma cooperativa agropecuária brasileira. $\mathrm{Na}$ análise dos dados utilizou-se: i) o método do PLS-SEM (Partial Least Square-Structural Equation Modeling), ou seja, modelagem de equações estruturais com estimação por mínimos quadrados parciais, no software SmartPLS 3, para análise do modelo estrutural e ii) o teste Mann-Whitney e Kruskall-Wallis para análise das diferenças de percepção do desempenho socioeconômico entre os grupos conforme os papéis assumidos pelos cooperados.

Dada a complexidade das relações entre cooperado e cooperativa, é difícil identificar relações de causa e efeito, especialmente no que diz respeito ao comportamento e percepção desses indivíduos, pois as variáveis são correlacionadas (Cechin et al., 2013). Nesse sentido, Chin (2010) destaca que o PLS é indicado para modelos complexos que capturam fatores relacionados à atitude, opiniões e comportamentos ao longo do tempo. Por isso, estudos sobre a percepção do desempenho nas cooperativas agropecuárias (Graca \& Arnaldo, 2016; Grashuis \& Cook, 2020; Susanty et al., 2017; Yang \& Chaddad, 2014) têm utilizado e sugerido o uso do PLS na investigação dos fenômenos.

\subsection{Modelo estrutural, modelo de mensuração e instrumento de coleta de dados}

A aplicação do PLS-SEM exige a elaboração de um modelo de mensuração e um modelo estrutural (Chin, 2004). O modelo de mensuração mostra as relações entre os indicadores e o constructo, e o modelo estrutural apresenta as relações entre os constructos, ou seja, testa as hipóteses de pesquisa (Hair Jr. et al., 2014).

Para o modelo de mensuração, adotou-se um modelo com medidas reflexivas, uma vez que considera-se que os indicadores são uma amostra representativa de todos os itens 
possíveis dentro do domínio conceitual de cada constructo do modelo (Hair Jr, Hult, Ringle, \& Sarstedt, 2016; Nunnally \& Bernstein, 1994). Os constructos são as variáveis latentes não observáveis e os indicadores são as variáveis observáveis, ou seja, as questões do questionário (Hair Jr, Hult, Ringle, \& Sarstedt, 2014). Na escala reflexiva cada indicador contribui com o constructo (Fornell \& Larcker, 1981), assim o peso de cada indicador forma o melhor score que maximiza a variância extraída (Chin, 2010).

Na Tabela 2 apresenta-se a definição de cada construto que serviu de base para a elaboração do questionário, conforme demonstra o Apêndice B e C. A mensuração de cada indicador (assertiva) segue uma escala Likert de 1 a 10, em que 1 representa a menor nota atribuída e 10 a maior. Para elaborar as perguntas, além da revisão bibliográfica, foram realizadas entrevistas com os 3 gestores e 10 cooperados a fim de adequar os conceitos a realidade do objeto de estudo (DeVellis, 2016; Hernández-Espallardo et al., 2013). As entrevistas com os gestores foram não-estruturadas com o intuito de conhecer a estrutura de governança da cooperativa e a relação dela com os cooperados. As entrevistas com os cooperados foram semiestruturadas (Apêndice A) com o objetivo de compreender as suas relações com a cooperativa e o seu entendimento sobre desempenho socioeconômico. Por meio das entrevistas também foi possível observar o vocabulário utilizado por eles, auxiliando na construção do questionário.

Tabela 2 - Definição dos constructos (continua)

\begin{tabular}{|c|c|c|}
\hline Constructo & Definição & $\begin{array}{l}\text { Quantidade } \\
\text { de questões }\end{array}$ \\
\hline Comunicação efetiva & $\begin{array}{l}\text { - Provê informação relevante e de qualidade (Fischer, 2013; } \\
\text { Susanty et al., 2017) } \\
\text { - Frequência da comunicação é adequada (Fischer, 2013; } \\
\text { Susanty et al., 2017) } \\
\text { - Provê informações da gestão, assistência técnica e assuntos } \\
\text { diversos (Peng et al., 2016) }\end{array}$ & 7 \\
\hline Confiança & $\begin{array}{l}\text { - Evidencia o quanto uma parte acredita que a outra parte é } \\
\text { confiável e íntegra (Morgan \& Hunt, 1984) } \\
\text { - Quanto os cooperados confiam na gestão (Hakelius \& } \\
\text { Hansson, 2016b; Östeberg \& Nilsson, 2009) e nos demais } \\
\text { membros da cooperativa (Hakelius \& Hansson, 2016b) }\end{array}$ & 5 \\
\hline Comprometimento & $\begin{array}{l}\text { - Sentimento que existe quando a parte acredita que a } \\
\text { continuidade da relação é tão importante que justifica o esforço } \\
\text { máximo para mantê-la (Morgan \& Hunt, 1984) } \\
\text { - Comprometimento com a estratégia de mercado: atitude } \\
\text { positiva em relação a uma estratégia orientada para o cliente, } \\
\text { com maior coordenação vertical da transação entre cooperados. } \\
\text { Comprometimento com a ação coletiva: vontade de fazer um } \\
\text { esforço e sacrificar ganhos econômicos de curto prazo em prol } \\
\text { do sucesso de longo prazo da cooperativa (Cechin, Bijman, } \\
\text { Pascucci, \& Omta, 2013) }\end{array}$ & 5 \\
\hline
\end{tabular}




\begin{tabular}{|c|c|c|}
\hline Constructo & Definição & $\begin{array}{l}\text { Quantidade } \\
\text { de questões }\end{array}$ \\
\hline $\begin{array}{l}\text { Volume de transação } \\
\text { como usuário }\end{array}$ & $\begin{array}{l}\text { - Refere-se ao relacionamento de cadeia de suprimentos que } \\
\text { existe entre a cooperativa e o cooperado. (Limnios et al., 2018; } \\
\text { Nilsson, 2001) }\end{array}$ & 3 \\
\hline $\begin{array}{l}\text { Intensidade da } \\
\text { participação como } \\
\text { proprietário }\end{array}$ & $\begin{array}{l}\text { - Refere-se ao direito de controle do membro (Limnios et al., } \\
\text { 2018; Mazzarol et al., 2014). } \\
\text { - Surge a partir do momento em que o membro adquire quotas- } \\
\text { partes da cooperativa (Limnios et al., 2018; Nilsson, 2001). }\end{array}$ & 4 \\
\hline $\begin{array}{l}\text { Desempenho } \\
\text { socioeconômico } \\
\text { percebido }\end{array}$ & $\begin{array}{l}\text { - Desempenho referente a execução das relações econômicas e } \\
\text { sociais com os cooperados, considerando crescimento, } \\
\text { desenvolvimento, assistência e satisfação com os resultados } \\
\text { financeiros obtidos (Lauermann et al., 2018) } \\
\text { - Produtos e serviços recebidos pelos membros (Cook, 2018; } \\
\text { Franken \& Cook, 2017) } \\
\text { - Satisfazer os objetivos dos membros (Benos et al., 2016; } \\
\text { Hakelius \& Hansson, 2016b; Yang \& Chaddad, 2014) }\end{array}$ & 9 \\
\hline
\end{tabular}

Fonte: Elaborado pelos autores (2020)

Após esta fase, o questionário foi submetido a testes de validade de conteúdo e validade de face. Primeiro, o conteúdo foi validado por meio de especialistas (pesquisadores da área de cooperativismo e pós-graduandos). Após, a validade de face foi realizada por meio de um pré-teste aplicado à vinte e nove (29) cooperados. O objetivo destas validações é identificar falhas e inconsistências e assim, aumentar a confiabilidade e validade do instrumento (Martins \& Theóphilo, 2016). Com base nos resultados obtidos em cada fase foram realizados ajustes no instrumento de coleta de dados. A versão final do questionário encontra-se no Apêndice C.

O modelo estrutural estabelece as relações entre os constructos, as quais são testadas no teste de hipóteses. Na Figura 1 apresenta-se o modelo estrutural e na Tabela 3 as hipóteses de pesquisa. 


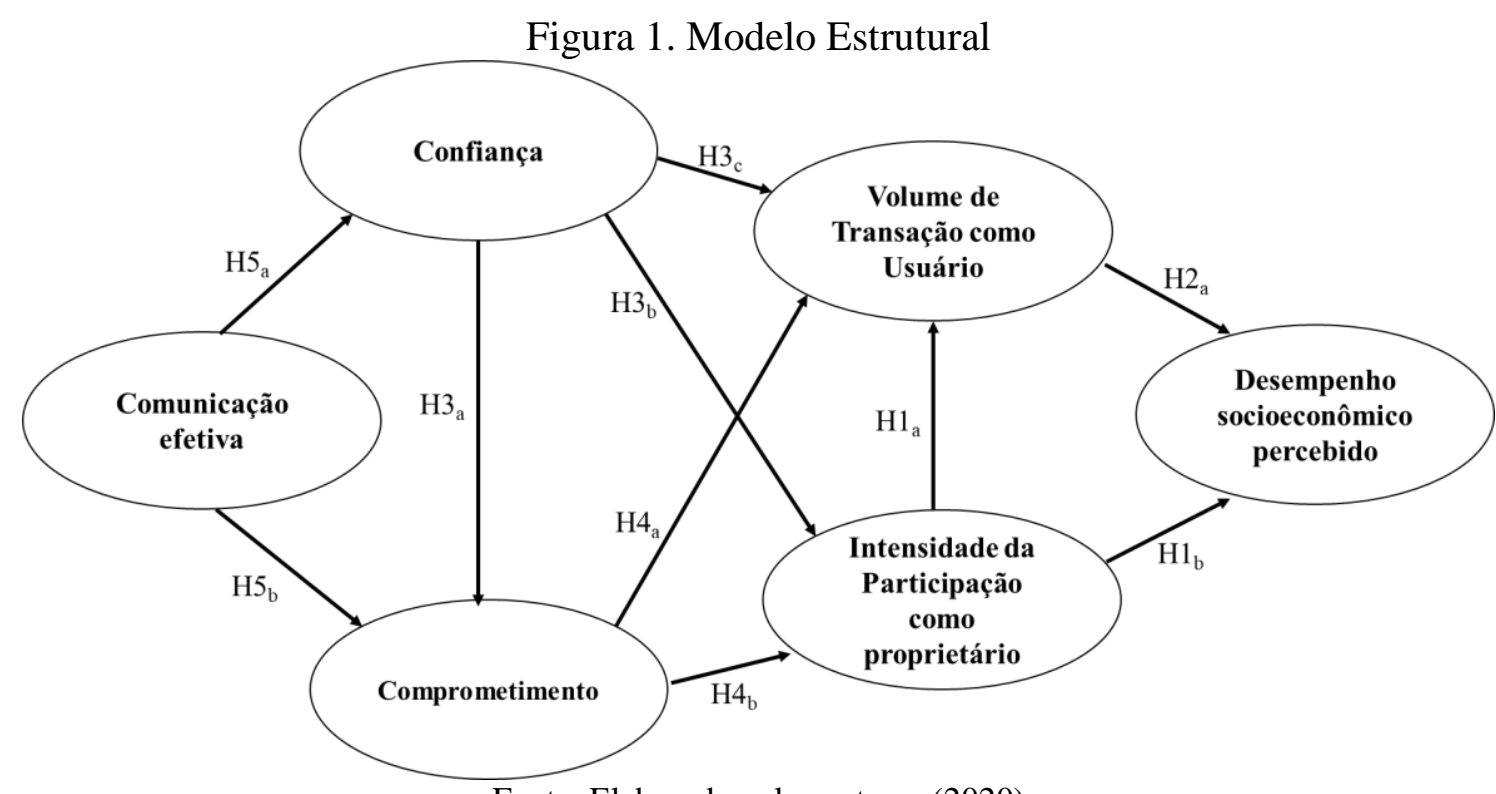

Fonte: Elaborado pelos autores (2020)

Tabela 3 - Hipóteses de pesquisa

\begin{tabular}{|c|c|c|c|}
\hline Hipóteses & Variáveis & $\begin{array}{c}\text { Coeficiente } \\
\text { esperado }\end{array}$ & Autores \\
\hline H1a & $\begin{array}{l}\text { Intensidade da Participação como Proprietário } \\
\rightarrow \text { Volume de Transação como Usuário }\end{array}$ & + & (Bialoskorski Neto, 2005) \\
\hline $\mathrm{H} 1_{\mathrm{b}}$ & $\begin{array}{l}\text { Intensidade da Participação como Proprietário } \\
\rightarrow \text { Desempenho Socioeconômico Percebido }\end{array}$ & + & $\begin{array}{l}\text { (Bhuyan, 2007; Franken \& Cook, } \\
\text { 2015; Limnios et al., 2018; Nilsson, } \\
\text { 2001) }\end{array}$ \\
\hline $\mathrm{H} 2 \mathrm{a}$ & $\begin{array}{l}\text { Volume de Transação como Usuário } \rightarrow \\
\text { Desempenho Socioeconômico Percebido }\end{array}$ & + & $\begin{array}{l}\text { (Lauermann et al., 2018; Peng et al., } \\
\text { 2016; Williamson, 2010b) }\end{array}$ \\
\hline $\mathrm{H} 3 \mathrm{a}$ & Confiança $\rightarrow$ Comprometimento & + & $\begin{array}{l}\text { (Brown, Crosno, \& Tong, 2018; } \\
\text { Cechin, Bijman, Pascucci, \& Omta, } \\
\text { 2013; Graca \& Arnaldo, 2016; } \\
\text { Hansen et al., 2002; Susanty et al., } \\
\text { 2017; Tadesse \& Kassie, 2017; } \\
\text { Wollni \& Fischer, 2015) }\end{array}$ \\
\hline $\mathrm{H} 3_{\mathrm{b}}$ & $\begin{array}{c}\text { Confiança } \rightarrow \text { Intensidade da Participação como } \\
\text { Proprietário }\end{array}$ & + & (Bhuyan, 2007) \\
\hline $\mathrm{H} 3_{\mathrm{c}}$ & $\begin{array}{c}\text { Confiança } \rightarrow \text { Volume de Transação como } \\
\text { Usuário }\end{array}$ & + & $\begin{array}{c}\text { (Morgan \& Hunt, 1984; Williamson, } \\
\text { 2010b) }\end{array}$ \\
\hline $\mathrm{H} 4_{\mathrm{a}}$ & $\begin{array}{c}\text { Comprometimento } \rightarrow \text { Volume de Transação } \\
\text { como Usuário }\end{array}$ & + & $\begin{array}{l}\text { (Cechin, Bijman, Pascucci, } \\
\text { Zylbersztajn, et al., 2013a; Morgan \& } \\
\text { Hunt, 1984; Peng et al., 2016) }\end{array}$ \\
\hline $\mathrm{H} 4_{b}$ & $\begin{array}{l}\text { Comprometimento } \rightarrow \text { Intensidade da } \\
\text { Participação como Proprietário }\end{array}$ & + & $\begin{array}{c}\text { (Borgström, 2013; Morgan \& Hunt, } \\
\text { 1984) }\end{array}$ \\
\hline $\mathrm{H} 5 \mathrm{a}$ & Comunicação efetiva $\rightarrow$ Comprometimento & + & $\begin{array}{l}\text { (Fischer, 2013; Hendrikse \& } \\
\text { Veerman, 2003; Östeberg \& Nilsson, } \\
\text { 2009; Peng et al., 2016) } \\
\text { (Arcas-Lario et al., 2014; Bijman et } \\
\text { al., 2011; Östeberg \& Nilsson, 2009; } \\
\text { Peng et al., 2016; Trechter, King, \& } \\
\text { Walsh, 2002; Wollni \& Fischer, } \\
\text { 2015) }\end{array}$ \\
\hline
\end{tabular}




\subsection{Variáveis de controle}

Neste estudo, o objetivo é explicar como os papéis assumidos pelo cooperado, como usuário e proprietário, relacionam-se com o seu comportamento e a sua percepção acerca do desempenho socioeconômico. Entretanto, é possível que outras características do cooperado, da propriedade rural e do produto exerçam influência sobre o desempenho socioeconômico percebido. Estudos anteriores informam que as diferenças de percepção estão relacionadas ao tempo de associação, idade do membro, tamanho da propriedade rural, distância geográfica, nível educacional, tipo de produto (por exemplo, Alho, 2015; Benos et al., 2016; Bhuyan, 2007; Cechin, Bijman, Pascucci, Zylbersztajn, et al., 2013b; Ferraz et al., 2018; JensenAuvermann et al., 2018; Kalogeras et al., 2009; Zheng, Wang, \& Awokuse, 2012). Portanto, a fim de controlar estes efeitos serão analisadas as variáveis de controle listadas na Tabela 4: tempo de associação, idade, tamanho da propriedade rural, distância geográfica, nível educacional, quantidade e tipo de produto entregue.

Tabela 4 - Efeito esperado das variáveis de controle sob o desempenho socioeconômico percebido

\begin{tabular}{|c|c|c|}
\hline Variável & $\begin{array}{c}\text { Efeito } \\
\text { esperado }\end{array}$ & Base teórica \\
\hline Tempo de associação & + & (Cechin, Bijman, Pascucci, \& Omta, 2013) \\
\hline Idade & + & (Alho, 2015; Bhuyan, 2007; Jensen-Auvermann et al., 2018) \\
\hline Tamanho da propriedade rural & - & $\begin{array}{c}\text { (Alho, 2015; Cechin, Bijman, Pascucci, \& Omta, 2013; } \\
\text { Kalogeras et al., 2009) }\end{array}$ \\
\hline Distância geográfica & - & (Alho, 2015) \\
\hline Nível Educacional & + & (Bhuyan, 2007; Cechin, Bijman, Pascucci, \& Omta, 2013) \\
\hline Quantidade de produto entregue & - & (Alho, 2015; Cechin, Bijman, Pascucci, \& Omta, 2013) \\
\hline Tipo de produto entregue & $\begin{array}{c}\text { Há } \\
\text { diferença }\end{array}$ & (Alho, 2015; Cechin, Bijman, Pascucci, \& Omta, 2013) \\
\hline
\end{tabular}

Fonte: Elaborado pelos autores (2020)

As variáveis de controle foram mensuradas e analisadas conforme a Tabela 5:

Tabela 5 - Mensuração das variáveis de controle

\begin{tabular}{|c|c|c|c|}
\hline Variável de Controle & Mensuração & Descrição & Sigla \\
\hline Tipo de Produto & Categórica & $\begin{array}{l}\text { Entrega soja e/ou milho e/ou trigo }=1 \\
\text { Entrega soja e/ou milho e/ou trigo e outro produto }=0\end{array}$ & PC1 \\
\hline Quantidade de Produto & $\begin{array}{l}\text { Ordinal de } \\
\quad 1 \text { a } 5\end{array}$ & $\begin{array}{l}\text { Quantidade do tipo de produtos que entrega na } \\
\text { cooperativa }\end{array}$ & $\mathrm{PC} 2$ \\
\hline Tamanho da Propriedade & $\begin{array}{l}\text { Ordinal de } \\
\quad 1 \text { a } 4\end{array}$ & $\begin{array}{l}1=\text { Menos que } 10 \text { hectares; } 2=\text { Entre } 11 \text { e } 50 \text { hectares; } \\
3=\text { Entre } 51 \text { e } 100 \text { hectares; } 4=\text { Mais que } 100 \text { hectares }\end{array}$ & TAM \\
\hline Distância & $\begin{array}{l}\text { Ordinal de } \\
\quad 1 \text { a } 7\end{array}$ & $\begin{array}{l}1=\text { Menos que } 5 \mathrm{~km} ; 2=\text { Entre } 5 \mathrm{~km} \text { e } 10 \mathrm{~km} ; 3=\text { Entre } 11 \\
\mathrm{~km} \text { e } 15 \mathrm{~km} ; 4=\text { Entre } 16 \mathrm{~km} \text { e } 20 \mathrm{~km} ; 5=\text { Entre } 21 \mathrm{~km} \text { e } \\
25 \mathrm{~km} ; 6=\text { Entre } 26 \mathrm{~km} \text { e } 30 \mathrm{~km} ; 7=\text { Mais que } 30 \mathrm{~km}\end{array}$ & DIST \\
\hline
\end{tabular}


Tabela 5 - Mensuração das variáveis de controle

(conclusão)

\begin{tabular}{|c|c|c|c|}
\hline Variável de Controle & Mensuração & Descrição & Sigla \\
\hline Idade & $\begin{array}{l}\text { Ordinal de } \\
\quad 1 \text { a } 5\end{array}$ & $\begin{array}{l}1=18 \text { a } 30 \text { anos; } 2=\text { De } 31 \text { a } 40 \text { anos; } 3=\text { De } 41 \text { a } 50 \text { anos; } \\
4=\text { De } 51 \text { a } 60 \text { anos; } 5=\text { Mais de } 60 \text { anos }\end{array}$ & IDA \\
\hline Tempo de Associação & $\begin{array}{l}\text { Ordinal de } \\
\quad 1 \text { a } 5\end{array}$ & $\begin{array}{l}1=\text { Menos de } 2 \text { anos; } 2=2 \text { a } 5 \text { anos; } 3=6 \text { a } 11 \text { anos; } 4=12 \\
\text { a } 20 \text { anos; } 5=\text { mais de } 20 \text { anos }\end{array}$ & TA \\
\hline Escolaridade & $\begin{array}{l}\text { Ordinal de } \\
\quad 1 \text { a } 7\end{array}$ & $\begin{array}{l}\text { 1=Ensino Fundamental Incompleto; } 2=\text { Ensino } \\
\text { Fundamental Completo; } 3=\text { =nsino Médio Incompleto; } \\
\text { 4=Ensino Médio Completo; 5=Ensino Superior } \\
\text { Incompleto; } 6=\text { Ensino Superior Completo; } 7=\text { Pós } \\
\text { Graduação }\end{array}$ & ESCO \\
\hline
\end{tabular}

Nota 1: A definição da mensuração das variáveis de controle foi realizada com base em Chen, Chen, \& Wu (2017) e Munoz \& Mallin (2019).

Nota 2: Na variável "Tipo de produto", 186 cooperados foram classificados na Categoria 1 e 24 cooperados na Categoria 2.

Nota 3: Na variável "Quantidade de produto" houve a seguinte classificação: 19 cooperados entregam 1 tipo de produto, 141 entregam 2 tipos de produto, 41 cooperados entregam 3 tipos de produto e 9 entregam 4 tipos de produto.

Fonte: Elaborado pelos autores (2020)

\section{4 Área de estudo e amostra}

Esta pesquisa foi conduzida em uma cooperativa agropecuária de grande porte com notável desempenho econômico-financeiro ${ }^{5}$. A cooperativa recebe, beneficia, industrializa e comercializa soja, milho, algodão, canola, café, laranja, girassol e trigo além de fornecer insumos agrícolas e agropecuários, bem como disponibilizar assistência técnica para os produtores. Ela possui cerca de 14.000 cooperados distribuídos em 3 estados do Brasil. O Anexo A demonstra as principais características do quadro social disponibilizadas pela cooperativa. Além das informações do anexo A, a cooperativa também informou o perfil dos cooperados por unidade (cidade), o que serviu de guia para a estratégia de coleta de dados.

A escolha desta cooperativa para análise justifica-se pelos seguintes motivos:

i) Bialoskorski Neto (2012) argumenta que é esperado que cooperativas com bom desempenho econômico-financeiro proporcionem uma maior oferta de benefícios aos membros. Por outro lado, o estudo de Lauermann et al., (2018) em cooperativas agropecuárias brasileira demonstra que isto nem sempre ocorre. Assim, a análise do desempenho socioeconômico percebido pelos membros em cooperativas que possuem bom desempenho econômicofinanceiro torna-se interessante para verificar se os membros estão realmente satisfeitos com os benefícios proporcionados por ela.

\footnotetext{
${ }^{5}$ A cooperativa está presente no ranking das Maiores e Melhores (2018) (EXAME, 2018).
} 
ii) A cooperativa possui mais de 50 anos de fundação. Ao longo dos anos, ela modificou o portfólio de produtos e expandiu a sua área de atuação adquirindo o patrimônio de outras cooperativas e construindo novas unidades. Com isto, houve expansão do seu quadro de associados. Cook (2018) explica que esta expansão incorre na diversidade de perfil dos cooperados. No anexo A, observa-se a partir das informações repassadas pela cooperativa, que há uma diversidade no portfólio de seus produtos, no tamanho da propriedade rural e na idade dos cooperados. Estas características de heterogeneidade dos membros podem impactar na relação e na percepção dos cooperados (Kalogeras et al., 2009; Hohler \& Kuhl, 2017).

iii) Estudos de caso permitem uma avaliação detalhada dos fatores que afetam o comportamento dos membros e talvez proporcione maior compreensibilidade do fenômeno, contribuindo para as análises mais agregadas (Kalogeras et al., 2009).

O levantamento na cooperativa foi realizado por meio da aplicação de questionário aos cooperados. No PLS-SEM, a amostra mínima deve ser determinada por meio de análise de poder baseadas na parte do modelo com o maior número de preditores. (Hair Jr, Hult, Ringle, $\&$ Sarstedt, 2016). Assim, realizou-se o cálculo da amostra por meio do software G*Power (Faul, Erdfelder, Lang, \& Buchner, 2007), conforme mostra a Figura 2.

Figura 2. Cálculo do tamanho da amostra

\begin{tabular}{|c|c|c|c|c|}
\hline Test family & \multicolumn{4}{|l|}{ Statistical test } \\
\hline F tests $\quad \checkmark$ & \multicolumn{3}{|c|}{ Linear multiple regression: Fixed model, $\mathrm{R}^{2}$ deviation from zero } & $\checkmark$ \\
\hline \multicolumn{5}{|c|}{ Type of power analysis } \\
\hline \multicolumn{4}{|c|}{ A priori: Compute required sample size - given $\alpha$, power, and effect size } & $\checkmark$ \\
\hline \multicolumn{3}{|l|}{ Input Parameters } & \multicolumn{2}{|l|}{ Output Parameters } \\
\hline Determine $=>$ & \multirow{2}{*}{$\begin{array}{r}\text { Effect size } f^{2} \\
\alpha \text { err prob }\end{array}$} & 0.15 & \multirow{2}{*}{$\begin{array}{r}\text { Noncentrality parameter } \lambda \\
\text { Critical F }\end{array}$} & 13.8000000 \\
\hline \multirow{2}{*}{\multicolumn{2}{|c|}{$\begin{array}{r}\alpha \text { err prob } \\
\text { Power }(1-\beta \text { err prob) }\end{array}$}} & 0.05 & & 2.3205293 \\
\hline & & 0.80 & Numerator df & 5 \\
\hline \multicolumn{2}{|c|}{ Number of predictors } & \multirow[t]{3}{*}{5} & Denominator df & 86 \\
\hline & & & Total sample size & 92 \\
\hline & & & Actual power & 0.8041921 \\
\hline
\end{tabular}

Fonte: Software G*Power (Faul et al., 2007). 
Para o cálculo, considerou-se a variável latente "Desempenho socioeconômico percebido", a qual tem o maior número de preditores (cinco), o poder do teste (1$\left.\beta_{\text {erro prob.II }}=0,80\right)$ e o tamanho do efeito $\left(\mathrm{f}^{2}=0,15\right)$ (Hair Jr et al., 2014). Para definir o número de preditores analisou-se o modelo com as variáveis de controle (veja na Seção 4.3). Como nenhuma variável de controle foi estatisticamente significativa $(\mathrm{p}<0,05)$, o cálculo da amostra mínima considerou apenas os indicadores do modelo principal (Comunicação Efetiva, Confiança, Comprometimento, Volume de Transação como Usuário e Intensidade da Participação como Proprietário). O cálculo resultou em uma amostra de 92 observações (Figura 2), no entanto, para garantir um modelo mais consistente buscou-se utilizar mais do que o dobro (Ringle, Silva, \& Bido, 2014).

Para a coleta de dados utilizou-se Mixed Mode Survey (Mooi, Sarstedt, \& Mooi-Reci, 2018), no qual os cooperados responderam ao questionário presencialmente e via Whatsapp. Esta estratégia foi utilizada visando alcançar um maior número de respondentes. As coletas presenciais foram realizadas em dois momentos. A primeira, durante assembleias, nos dias 10 e 11 de julho de 2019, em 6 cidades diferentes. A segunda foi realizada entre os dias 30 de setembro de 2019 e 04 de outubro de 2019. Neste período, a pesquisadora visitou 5 unidades de diferentes cidades e coletou presencialmente as respostas dos cooperados durante o horário de funcionamento da unidade ( $8 \mathrm{~h}$ às $17 \mathrm{~h} 30 \mathrm{~min}$ ). $\mathrm{O}$ critério para escolha das cidades foi o tamanho do quadro social, optando-se por aquelas com maior quantidade de cooperados. A coleta via Whatsapp foi realizada pelo aplicativo TypeForm, no período de 5 de agosto de 2019 a 20 de agosto de 2019. O controle da duplicidade de respostas foi feito pelo número do telefone, o qual era a senha de acesso ao questionário por Whatsapp ${ }^{6}$ e foi informado no questionário impresso. A participação dos cooperados foi voluntária e anônima, sendo entregue a todos os participantes um Termo de Consentimento Livre e Esclarecido (Apêndice F).

A amostra inicial coletada foi de 223 questionários, dos quais treze foram eliminados porque os dados faltantes excediam a $15 \%$ das questões e/ou porque havia uma proporção alta de dados faltantes em um único construto (Hair Jr et al., 2016). Portanto, a amostra final é composta por 210 questionários.

${ }^{6} \mathrm{O}$ aplicativo TypeForm permite que o mesmo número de celular envie apenas uma resposta. 


\subsection{Técnicas de análise dos dados}

A primeira etapa de análise dos dados, consiste no teste de confiabilidade e validade do modelo de mensuração e estrutural através do software SmartPLS3. Primeiro, no modelo de mensuração analisou-se: i) a validade convergente (AVE - Average Variance Extracted $\geq$ 0,50) (Henseler, Ringle \& Sinkovics, 2009); ii) a consistência interna (Confiabilidade Composta > 0,70) (Hair Jr. et al, 2014); iii) a validade discriminante pelo critério de cargas cruzadas (Chin, 2004) e critério de Fornell e Larcker (1981). Segundo, no modelo estrutural analisou-se: i) o coeficiente de determinação de Pearson (Efeito Pequeno: $\mathrm{R}^{2}=2 \%$, Efeito Médio: $\mathrm{R}^{2}=13 \%$, Efeito Grande: $\mathrm{R}^{2}=26 \%$ ) (Cohen, 1988); ii) a significância das relações pela técnica de reamostragem (bootstrapping), a qual compara os resultados com o parâmetro da distribuição $t$ de Student $(t \geq 1,96)$ e valor-p ( $\mathrm{p}<0,05)$; e iii) o tamanho do efeito (Pequeno: $\mathrm{f}^{2}$ $=0,02$, Médio: $\mathrm{f}^{2}=0,15$, Grande: $\left.\mathrm{f}^{2}=0.35\right)$ (Cohen, 1988).

Após a avaliação da qualidade de ajuste do modelo, interpretou-se os resultados através dos coeficientes de caminho, os quais são considerados como betas ( $\beta$ ) das regressões lineares simples ou ordinárias (Hair Jr et al., 2014). Por fim, como análise adicional realizouse os testes Mann-Whitney e Kruskall-Wallis para analisar as diferenças de respostas no constructo "Desempenho Socioeconômico Percebido" entre os cooperados que exercem papéis diferentes na cooperativa. 


\section{RESULTADOS E DISCUSSÃO}

\subsection{Estatística descritiva}

\section{$\underline{\text { 4.1.1 Características dos respondentes }}$}

A amostra deste estudo compreende 210 cooperados de uma cooperativa agropecuária. As Tabelas 6 e 7 apresentam as principais características dos respondentes.

Tabela 6 - Estatística descritiva da amostra $(\mathrm{n}=210)$

\begin{tabular}{|c|c|c|c|c|c|}
\hline $\begin{array}{l}\text { Meios de comunicação } \\
\text { utilizados pelos cooperados }\end{array}$ & FA & FR & Tamanho da propriedade rural & FA & FR \\
\hline Site & 20 & $9,52 \%$ & Familiar (Menos que 10 hectares) & 9 & $4,3 \%$ \\
\hline TV & 20 & $9,52 \%$ & Pequeno (Entre 11 e 50 hectares) & 79 & $37,6 \%$ \\
\hline Whatsapp & 139 & $66,19 \%$ & Médio (Entre 51 e 100 hectares) & 42 & $20,0 \%$ \\
\hline Aplicativo & 31 & $14,76 \%$ & Grande (Mais que 100 hectares) & 75 & $35,7 \%$ \\
\hline Facebook ou Instagram & 24 & $11,43 \%$ & Não responderam & 5 & $2,38 \%$ \\
\hline Jornal de Serviços & 64 & $30,48 \%$ & & & \\
\hline Telefone & 40 & $19,05 \%$ & Distância geográfica & $\mathbf{F A}$ & FR \\
\hline Pessoalmente & 11 & $5,24 \%$ & Menos que $5 \mathrm{~km}$ & 48 & $22,86 \%$ \\
\hline Idade & FA & FR & Entre $5 \mathrm{~km} \mathrm{e} 10 \mathrm{~km}$ & 65 & $30,95 \%$ \\
\hline 18 a 30 anos & 6 & $2,86 \%$ & Entre $11 \mathrm{~km} \mathrm{e} 15 \mathrm{~km}$ & 47 & $22,38 \%$ \\
\hline De 31 a 40 anos & 18 & $8,57 \%$ & Entre $16 \mathrm{~km} \mathrm{e} 20 \mathrm{~km}$ & 21 & $10,00 \%$ \\
\hline De 41 a 50 anos & 26 & $12,38 \%$ & Entre $21 \mathrm{~km}$ e $25 \mathrm{~km}$ & 6 & $2,86 \%$ \\
\hline De 51 a 60 anos & 65 & $30,95 \%$ & Entre $26 \mathrm{~km}$ e $30 \mathrm{~km}$ & 5 & $2,38 \%$ \\
\hline Mais de 60 anos & 93 & $44,29 \%$ & Mais que $30 \mathrm{~km}$ & 11 & $5,24 \%$ \\
\hline Não responderam & 2 & $0,95 \%$ & Não responderam & 7 & $3,33 \%$ \\
\hline Tempo de associação & FA & FR & & & \\
\hline Menos de 2 anos & 10 & $4,76 \%$ & Nível Educacional & FA & FR \\
\hline 2 a 5 anos & 14 & $6,67 \%$ & Ensino Fundamental Incompleto & 42 & $20,00 \%$ \\
\hline 6 a 11 anos & 67 & $31,90 \%$ & Ensino Fundamental Completo & 39 & $18,57 \%$ \\
\hline 12 a 20 anos & 32 & $15,24 \%$ & Ensino Médio Incompleto & 11 & $5,24 \%$ \\
\hline mais de 20 anos & 85 & $40,48 \%$ & Ensino Médio Completo & 61 & $29,05 \%$ \\
\hline Não responderam & 2 & $0,95 \%$ & Ensino Superior Incompleto & 11 & $5,24 \%$ \\
\hline Outro familiar é cooperado? & FA & FR & Ensino Superior Completo & 34 & $16,19 \%$ \\
\hline Não & 45 & $21.43 \%$ & Pós Graduação & 11 & $5,24 \%$ \\
\hline Sim & 165 & $78.57 \%$ & Não Responderam & 1 & $0,48 \%$ \\
\hline
\end{tabular}

Legenda: FA = Frequência Absoluta; FR = Frequência Relativa

Fonte: Dados da pesquisa (2020)

A amostra da pesquisa compreende, em sua maioria indivíduos com mais de 50 anos $(75,24 \%)$. Esta também é uma característica do quadro social da cooperativa, pois, segundo informações disponibilizadas, 78,30\% dos cooperados possuem mais do que 45 anos (Anexo A). Pesquisas anteriores evidenciam que é comum as cooperativas agropecuárias terem associados acima de 50 anos (Arcas-Lario et al., 2014; Feng et al., 2016). Possíveis 
explicações para este quadro permeiam o fenômeno da não permanência do jovem no campo e, conforme relatado pelos cooperados, alguns filhos que permaneceram na propriedade rural não se tornam sócio porque o pai ou a mãe já são associados, o que permite que a produção seja movimentada por apenas uma conta (quota-parte).

Além da média alta da idade dos cooperados, nota-se que a maior parte da amostra possui mais do que 11 anos de associação $(55,72 \%)$ e tem algum outro membro da família que também é cooperado (78,57\%). Quanto ao nível de escolaridade, 20\% dos respondentes não tem o ensino fundamental completo, $29,05 \%$ tem o ensino médio completo e $21,91 \%$ possuem pelo menos o ensino superior completo.

No que diz respeito ao tamanho da propriedade rural, na amostra, os pequenos produtores compreendem $37,6 \%$ dos respondentes, os médios $20 \%$ e os grandes $35,7 \%$. Esta configuração é parecida com aquela apresentada pelas informações da cooperativa (Anexo A), pois no total do quadro social ${ }^{7}, 41,17 \%$ dos cooperados são pequenos produtores, $16,13 \%$ são médios e $26,81 \%$ são grandes. Ou seja, a maioria são pequenos e médios produtores. Ademais, 76,19\% dos cooperados moram em até 15 quilômetros de distância da unidade mais próxima da cooperativa e 66,19\% utilizam o Whatsapp para se comunicar com ela.

Por fim, a Tabela 7 informa sobre quais produtos os cooperados entregam na cooperativa.

\begin{tabular}{lcc} 
Tabela 7 - Produtos entregues pelos cooperados & (continua) \\
\hline Descrição & 134 & Quantidade \\
\hline Soja e Milho & 37 & $63.81 \%$ \\
Soja, Milho e Trigo & 12 & $5.71 \%$ \\
Soja & 6 & $2.86 \%$ \\
Café & 4 & $1.90 \%$ \\
Soja, Milho, Café e Trigo & 3 & $1.43 \%$ \\
Soja e Café & 3 & $1.43 \%$ \\
Soja, Milho e Café & 2 & $0.95 \%$ \\
Soja e Trigo & 2 & $0.95 \%$ \\
Soja, Milho, Laranja e Trigo & 1 & $0.48 \%$ \\
Soja e Canola & 1 & $0.48 \%$ \\
Soja e Laranja & 1 & $0.48 \%$ \\
Milho & 1 & $0.48 \%$ \\
Soja, Canola, Milho e Trigo & 1 & $0.48 \%$ \\
Soja, Canola, Café e Trigo &
\end{tabular}

${ }^{7}$ A informação sobre o tamanho da propriedade rural é autodeclarada pelo cooperado para a cooperativa. Com estes dados, a cooperativa faz a estimativa de produção da safra dos cooperados e cria índices de fidelidade. 
Tabela 7 - Produtos entregues pelos cooperados (conclusão)

\begin{tabular}{lcc}
\hline Descrição & Quantidade & \% \\
\hline Soja, Milho e Laranja & 1 & $0.48 \%$ \\
Soja, Milho, Café e Aveia & 1 & $0.48 \%$ \\
Total & $\mathbf{2 1 0}$ & $\mathbf{1 0 0 . 0 0 \%}$ \\
\hline
\end{tabular}

Fonte: Dados da pesquisa (2020)

Na descrição das suas atividades, a cooperativa tem diversos produtos no seu portfólio, sendo eles: soja, milho, algodão, canola, café, laranja, girassol e trigo. Na amostra, no entanto, nota-se que a maior parte dos cooperados entregam soja e/ou milho. Há também aqueles que, além destes itens, entregam café e/ou canola e/ou laranja e/ou aveia e/ou trigo. Na conversa com alguns cooperados durante a aplicação do questionário, eles relatam que o foco da cooperativa é a soja e o milho, sendo os itens em que há melhor assistência técnica e condições comerciais de venda. Tal fator justifica o fato da maior parte deles concentrarem a sua produção nestes dois itens. Um produtor de café, por exemplo, relatou que a assistência técnica demonstra pouco conhecimento sobre este cultivo e são oferecidos poucos eventos técnicos sobre café. Ele também relatou que dificilmente consegue vender o seu produto para a cooperativa porque o preço oferecido fica abaixo do que ele encontra em outras empresas.

\subsubsection{Estatística descritiva dos constructos}

Além de questões sobre as características do respondente, o questionário compõe questões que mensuram cada constructo do modelo estrutural: desempenho socioeconômico percebido, comunicação efetiva, confiança, comprometimento, volume de transação como usuário e intensidade da participação como proprietário. Analisou-se a estatística das questões que compõe cada um desses constructos, a fim de compreender o comportamento geral das respostas.

O constructo "Desempenho Socioeconômico Percebido" buscou mensurar se os membros estão satisfeitos com o desempenho das relações econômicas e sociais mantidas com a cooperativa, por meio dos produtos, serviços e eventos oferecidos por ela. Na Tabela 8 evidencia-se os resultados da estatística descritiva para tal constructo e nos Gráficos 1 e 2 a frequência relativa das respostas de cada pergunta. 
Tabela 8 - Estatística descritiva "Desempenho Socioeconômico Percebido"

Item

DES3

Os serviços de assistência técnica oferecidos pela cooperativa.

DES7 Os eventos e programas educacionais e sociais oferecidos pela cooperativa.

DES9 No geral, eu estou satisfeito com a minha relação com a cooperativa.

DES6 A qualidade do serviço para o armazenamento de grãos.

DES1 O preço pago pela cooperativa por sua produção agrícola.

DES2 preço pago por você pelos insumos agrícolas adquiridos na cooperativa.

DES4 O valor das sobras distribuídas anualmente pela cooperativa.

DES5 A política de preço adotada pela cooperativa para armazenagem do grão.

DES\& A minha participação na cooperativa tem proporcionado um aumento na minha renda familiar.

\begin{tabular}{|c|c|c|c|c|c|c|}
\hline 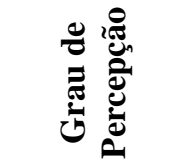 & $\frac{\pi}{\mathscr{C}}$ & 苞 & 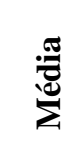 & 兽 & 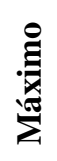 & 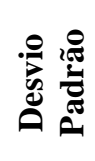 \\
\hline $\begin{array}{c}\text { Muito } \\
\text { satisfeito }\end{array}$ & 10.00 & 9.00 & 8.14 & 1 & 10 & 1.83 \\
\hline $\begin{array}{c}\text { Muito } \\
\text { satisfeito }\end{array}$ & 10.00 & 9.00 & 8.18 & 1 & 10 & 1.96 \\
\hline $\begin{array}{l}\text { Concordo } \\
\text { Totalmente }\end{array}$ & 10.00 & 9.00 & 8.14 & 1 & 10 & 2.10 \\
\hline $\begin{array}{l}\text { Muito } \\
\text { satisfeito }\end{array}$ & 9.00 & 9.00 & 8.39 & 1 & 10 & 1.62 \\
\hline Satisfeito & 8.00 & 8.00 & 7.21 & 1 & 10 & 1.78 \\
\hline Satisfeito & 8.00 & 7.00 & 6.56 & 1 & 10 & 1.98 \\
\hline Satisfeito & 8.00 & 8.00 & 7.48 & 1 & 10 & 2.05 \\
\hline Satisfeito & 8.00 & 7.00 & 6.65 & 1 & 10 & 2.35 \\
\hline Concordo & 8.00 & 7.00 & 7.00 & 1 & 10 & 2.27 \\
\hline
\end{tabular}

Fonte: Dados da Pesquisa (2020)

Gráfico 1 - Frequência relativa "Desempenho Socioeconômico Percebido"- Parte 1

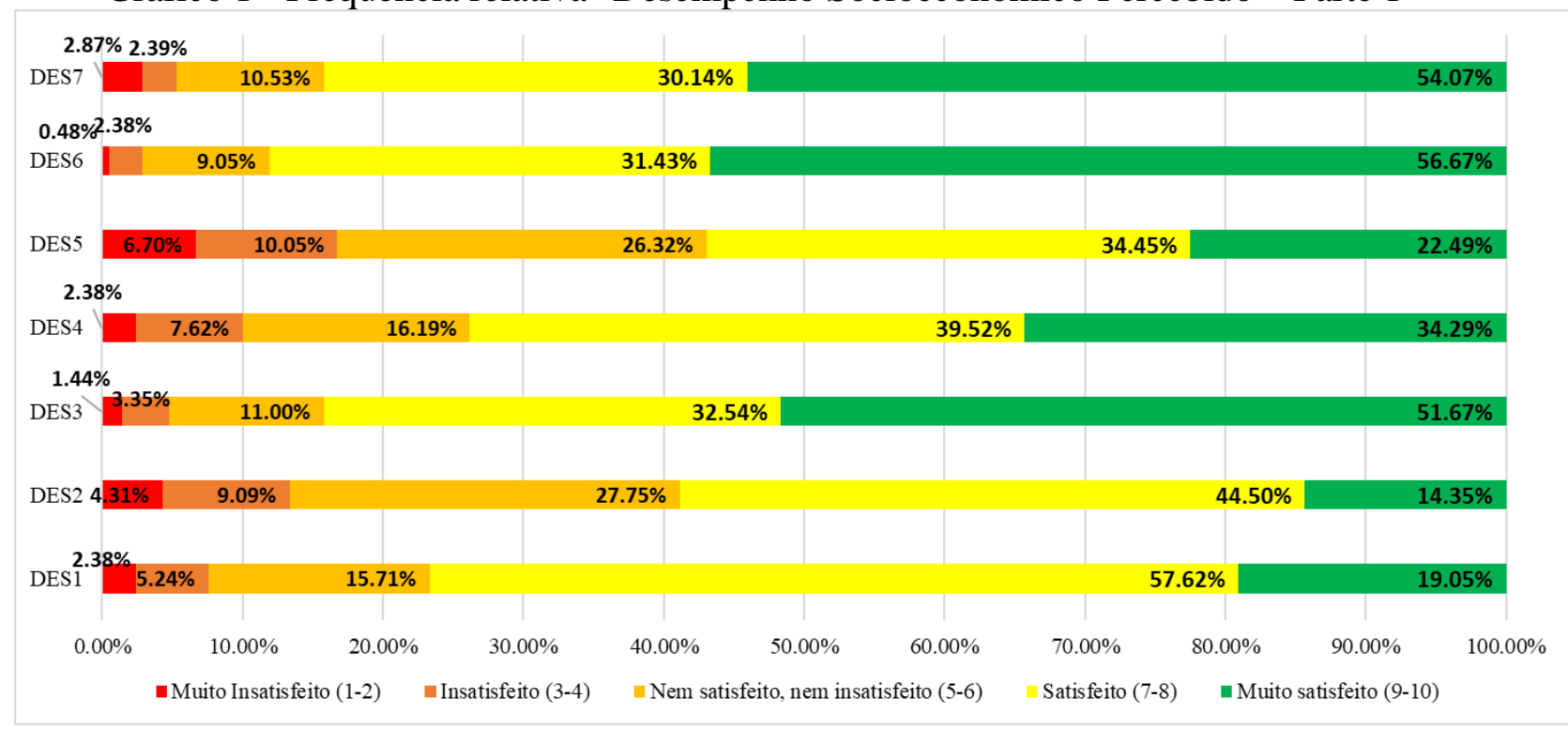

Fonte: Dados da Pesquisa (2020) 
Gráfico 2 - Frequência relativa "Desempenho Socioeconômico Percebido" - Parte 2

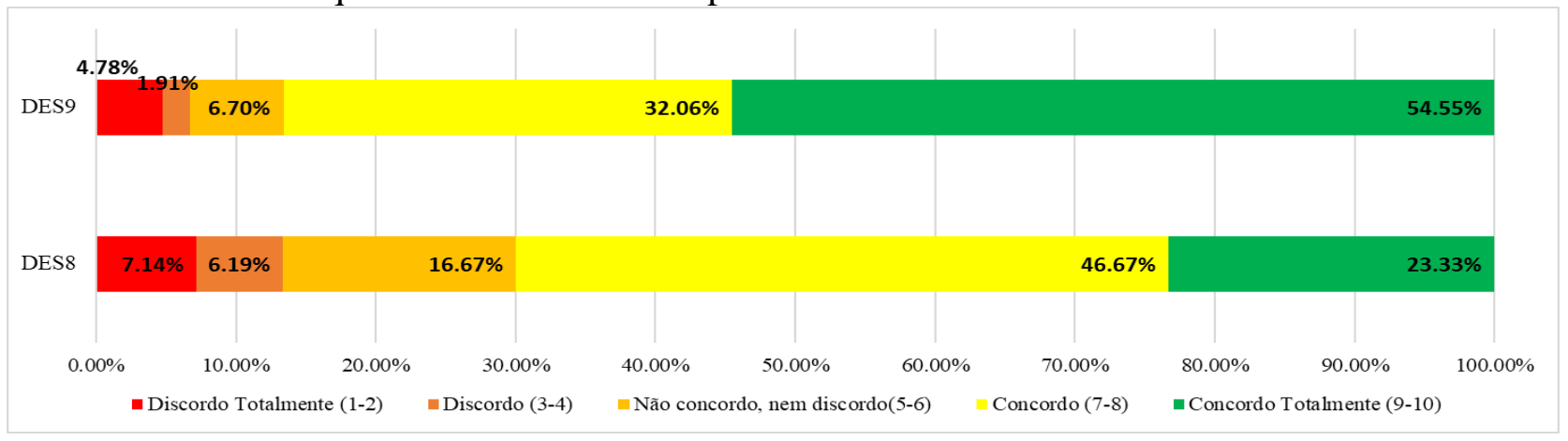

Fonte: Dados da Pesquisa (2020)

No geral, nota-se que os cooperados estão satisfeitos com a sua relação com a cooperativa (DES9 - Moda $=10$, Satisfeitos e Muito Satisfeitos $=86,61 \%$ ) e a maioria concorda totalmente $(23,33 \%)$ ou concorda $(46,67 \%)$ que a sua participação na cooperativa tem proporcionado um aumento na renda familiar. Na visão dos cooperados, portanto, a cooperativa apresenta um bom desempenho socioeconômico. Este resultado diverge daqueles encontrados por Lauermann et al. (2018) nas cooperativas paranaenses, os quais verificaram que a maioria das cooperativas com bom desempenho econômico-financeiro não apresentaram um bom desempenho socioeconômico (Lauermann et al., 2018). Lauermann et al. (2018) utilizaram medidas objetivas para mensurar o desempenho socioeconômico, enquanto que neste estudo utilizou-se uma medida subjetiva, a percepção dos cooperados. Tal fator pode justificar a diferença nas respostas, uma vez que as medidas objetivas não captam todos os benefícios percebidos pelos cooperados, como a satisfação (Benos et al., 2018).

Ao analisar os itens específicos, nota-se que aqueles que demonstram os maiores índices de satisfação referem-se aos serviços oferecidos pela cooperativa, sendo eles: assistência técnica (Moda=10; Satisfeitos e Muito Satisfeitos $=84,21 \%$ ), armazenamento do grão (Moda=9; Satisfeitos e Muito Satisfeitos $=88,10 \%$ ), eventos e programas educacionais e sociais (Moda=10; Satisfeitos e Muito Satisfeitos $=84,21 \%$ ). Os itens com menor grau de satisfação são aqueles que se referem ao preço $(M o d a=8)$ : de venda da produção agrícola (Satisfeitos e Muito Satisfeitos $=76,67 \%$ ), de compra dos insumos (Satisfeitos e Muito Satisfeitos $=58.85 \%$ ), da política de preço adotada pela cooperativa para armazenar o grão (Satisfeitos e Muito Satisfeitos $=56,83 \%$ ) e do valor das sobras (Satisfeitos e Muito Satisfeitos $=58,85 \%)$. Hernández-Espallardo et al., (2013), em cooperativas espanholas, encontraram que no quesito satisfação, o preço é o item com menor importância comparado a outros aspectos que reduzem o custo de transação do cooperado. Nesta mesma linha, os 
cooperados deste estudo estão mais satisfeitos com os serviços prestados do que com os preços oferecidos pela cooperativa, o que demonstra que o desempenho dela é melhor avaliado em relação aos serviços do que aos preços.

O constructo "Comunicação Efetiva" buscou mensurar o quanto os cooperados estão satisfeitos com a qualidade e a frequência da informação compartilhada. A moda, a mediana e a média de cada pergunta estão relacionadas na Tabela 9. Nos Gráficos 3 e 4 encontra-se a distribuição da frequência relativa de cada pergunta.

Tabela 9 - Estatística descritiva "Comunicação Efetiva"

\begin{tabular}{|c|c|c|c|c|c|c|c|c|}
\hline Item & Pergunta & 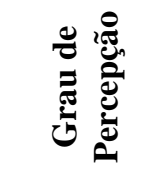 & 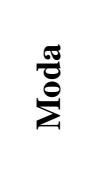 & 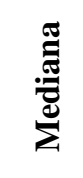 & 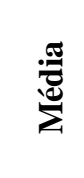 & 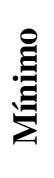 & 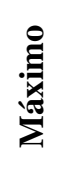 & •ำ \\
\hline COM1 & $\begin{array}{l}\text { A frequência com que a cooperativa organiza } \\
\text { eventos, nos quais fornece informações técnicas } \\
\text { (exemplo, dias de campo, palestras na unidade e dia } \\
\text { de campo de inverno). }\end{array}$ & $\begin{array}{l}\text { Muito } \\
\text { Satisfeito }\end{array}$ & 9.00 & 9.00 & 8.34 & 2 & 10 & 1.49 \\
\hline COM2 & $\begin{array}{l}\text { A frequência com que a cooperativa ouve as suas } \\
\text { expectativas, reclamações e sugestões. }\end{array}$ & $\begin{array}{l}\text { Muito } \\
\text { Satisfeito }\end{array}$ & 9.00 & 8.00 & 7.34 & 1 & 10 & 2.16 \\
\hline COM7 & A facilidade de acesso às informações da cooperativa. & Ótima & 9.00 & 9.00 & 8.23 & 1 & 10 & 1.80 \\
\hline COM3 & $\begin{array}{l}\text { A frequência com que a cooperativa realiza prestação } \\
\text { de contas. }\end{array}$ & Satisfeito & 8.00 & 8.00 & 8.11 & 1 & 10 & 1.67 \\
\hline COM4 & $\begin{array}{l}\text { A clareza e a facilidade de entendimento das } \\
\text { informações recebidas da cooperativa. }\end{array}$ & Satisfeito & 8.00 & 8.00 & 8.04 & 1 & 10 & 1.63 \\
\hline COM5 & $\begin{array}{l}\text { Qualidade da informação sobre o desempenho } \\
\text { financeiro (por exemplo, caixa e sobras) da } \\
\text { cooperativa. }\end{array}$ & Boa & 8.00 & 8.00 & 7.61 & 1 & 10 & 1.83 \\
\hline COM6 & $\begin{array}{l}\text { Qualidade da informação sobre os serviços e produtos } \\
\text { disponíveis na cooperativa. }\end{array}$ & Boa & 8.00 & 8.00 & 8.00 & 4 & 10 & 1.49 \\
\hline
\end{tabular}

Fonte: Dados da Pesquisa (2020)

\section{Gráfico 3 - Frequência relativa "Comunicação Efetiva" - Parte 1}

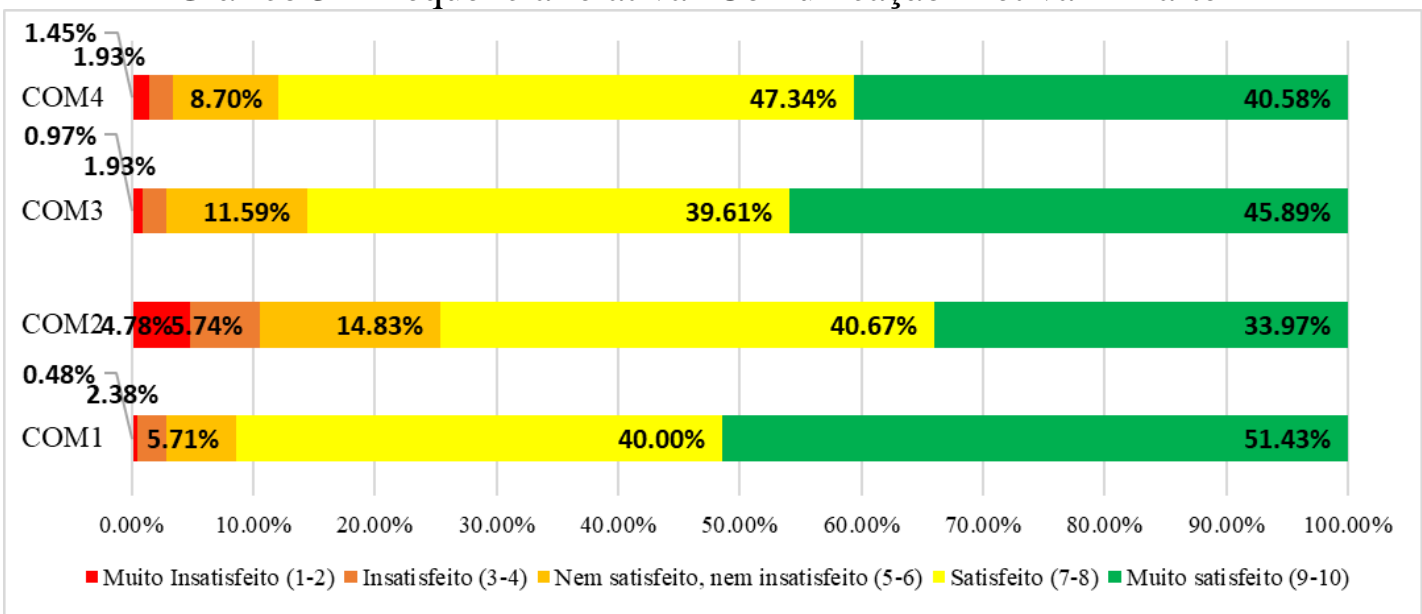

Fonte: Dados da pesquisa (2020) 
Gráfico 4 - Frequência relativa "Comunicação Efetiva" - Parte 2

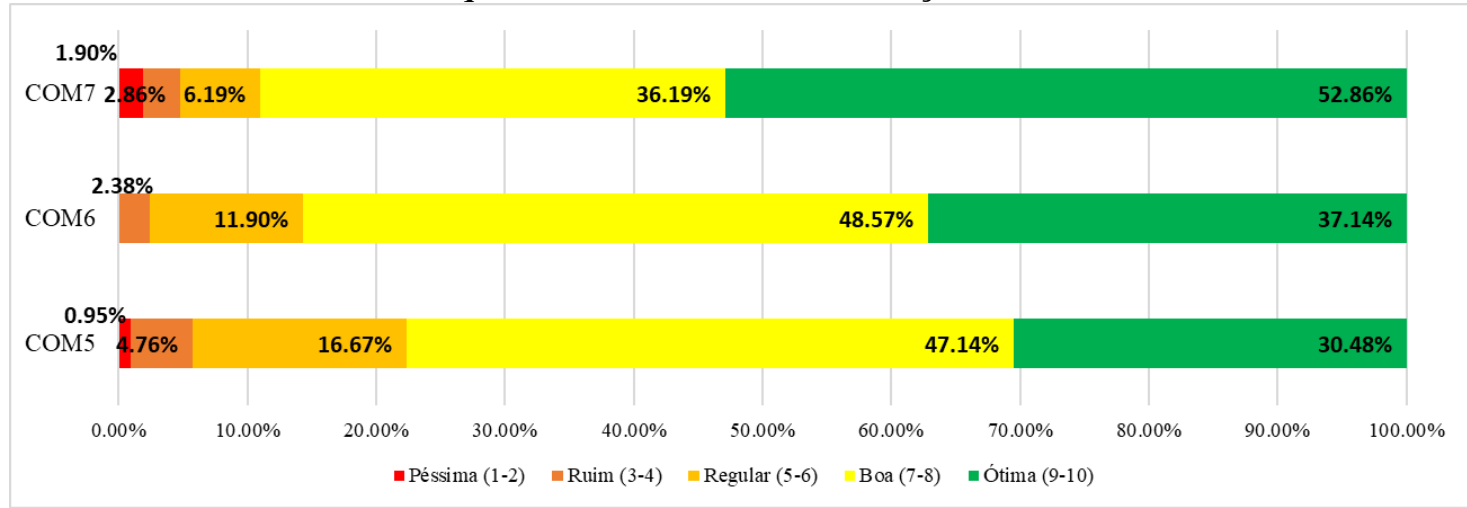

Fonte: Dados da pesquisa (2020)

No geral, os cooperados estão satisfeitos com a qualidade e a frequência da informação compartilhada entre os membros da cooperativa, pois todos os itens apresentam moda entre 8 e 9. Quanto à frequência da comunicação, os itens com maior grau de satisfação são aqueles relacionado à frequência com que a cooperativa realiza eventos de informações técnicas (Moda=9, Satisfeitos e Muito Satisfeitos $=91,43 \%$ ) e ouve as expectativas, reclamações e sugestões dos cooperados (Moda=9, Satisfeitos e Muitos Satisfeitos=74,64\%). E, quanto a qualidade da comunicação, o item com maior índice refere-se à facilidade de acesso às informações da cooperativa (COM7 - Moda=9, Ótima e Boa=89,05\%). Os resultados apontam que a cooperativa está investindo em comunicação efetiva, reforçando o argumento de que em organizações gerenciadas por contratos relacionais é importante que a gestão invista em uma boa comunicação entre as partes (Hendrikse \& Veerman, 2003).

O constructo "Confiança" buscou identificar quanto os cooperados confiam na gestão e nos demais membros da cooperativa. Na Tabela 10 é apresentado a moda, a mediana e a média de cada pergunta. No Gráfico 5 evidencia-se a frequência relativa de cada item. 
Tabela 10 - Estatística descritiva "Confiança"

\begin{tabular}{|c|c|c|c|c|c|c|c|c|}
\hline Item & Pergunta & 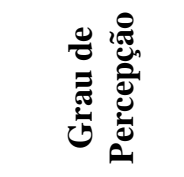 & $\stackrel{\frac{\pi}{0}}{\Sigma}$ & 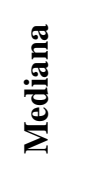 & 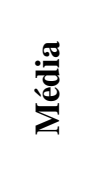 & 咅 & 竞 & 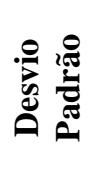 \\
\hline CF1 & $\begin{array}{l}\text { A cooperativa está sempre pronta para me } \\
\text { ajudar. }\end{array}$ & $\begin{array}{l}\text { Concordo } \\
\text { Totalmente }\end{array}$ & 10.00 & 8.00 & 7.99 & 1 & 10 & 2.16 \\
\hline CF3 & $\begin{array}{l}\text { A cooperativa sempre cumpre com aquilo que } \\
\text { foi acordado em assembleia e está no estatuto. }\end{array}$ & $\begin{array}{l}\text { Concordo } \\
\text { Totalmente }\end{array}$ & 10.00 & 8.00 & 8.20 & 1 & 10 & 1.83 \\
\hline CF2 & $\begin{array}{l}\text { As decisões tomadas pela gestão da cooperativa } \\
\text { (por exemplo, instalar novas unidades e } \\
\text { oferecer novos serviços) demonstram } \\
\text { preocupação com o meu bem-estar financeiro. }\end{array}$ & $\begin{array}{l}\text { Concordo } \\
\text { Totalmente }\end{array}$ & 9.00 & 8.00 & 7.04 & 1 & 10 & 2.43 \\
\hline CF4 & $\begin{array}{l}\text { As informações fornecidas pela cooperativa são } \\
\text { confiáveis. }\end{array}$ & $\begin{array}{l}\text { Concordo } \\
\text { Totalmente }\end{array}$ & 9.00 & 9.00 & 8.37 & 1 & 10 & 1.70 \\
\hline CF5 & Eu posso confiar nos outros cooperados. & Concordo & 8.00 & 7.00 & 6.40 & 1 & 10 & 2.22 \\
\hline
\end{tabular}

Fonte: Dados da Pesquisa (2020)

Gráfico 5 - Frequência relativa "Confiança"

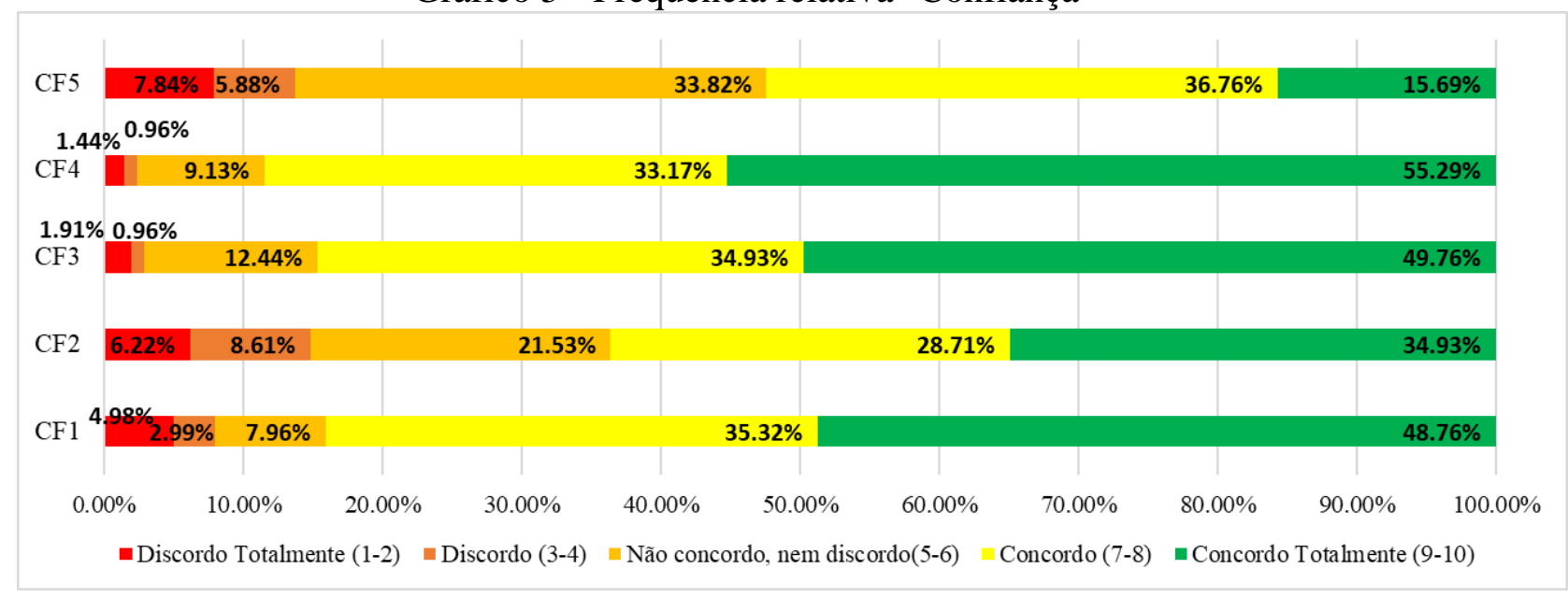

Fonte: Dados da Pesquisa (2020)

Nota-se que há um alto grau de confiança entre os cooperados e a cooperativa (CF1, $\mathrm{CF} 2, \mathrm{CF} 3$ e CF4). Os cooperados concordam que a cooperativa está sempre pronta para lhes ajudar $($ Moda $=10$, Concordam e Concordam Totalmente $=84,08 \%)$, sempre cumpre com aquilo que foi acordado na assembleia e está no estatuto (Moda =10, Concordam e Concordam Totalmente $=89,19 \%$ ), demonstra preocupação com o bem-estar financeiro dos cooperados $($ Moda $=9$, Concordam e Concordam Totalmente $=63,64 \%)$ e fornece informações confiáveis (Moda=9, Concordam e Concordam Totalmente $=88,46 \%)$. O item que mensura a confiança entre os cooperados (CF5) apresentou o menor nível de percepção (Moda=8, Concordam e Concordam Totalmente $=52,45 \%$ ). Alguns relataram que, como são muitos cooperados (cerca de 14.000), nem sempre cada um pode conhecer o outro ao ponto de 
afirmar que confia ou não nele. No entanto, as respostas demonstram que a maior parte deles concorda $(52,45 \%)$ que pode confiar nos outros cooperados.

O constructo Comprometimento buscou identificar o quanto as partes acreditam que a continuidade da relação com a cooperativa é tão importante que justifica os esforços para mantê-la. Na Tabela 11 evidencia-se a estatística descritiva de cada item do constructo. No Gráfico 6 encontra-se a frequência relativa.

Tabela 11 - Estatística descritiva "Comprometimento"

\begin{tabular}{|c|c|c|c|c|c|c|c|c|}
\hline Item & Pergunta & 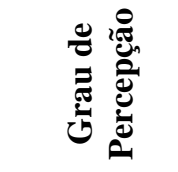 & 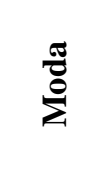 & 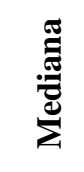 & 莺 & $\stackrel{\text { : }}{\stackrel{B}{\Xi}}$ & 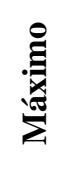 & فำ \\
\hline CPT1* & $\begin{array}{l}\text { Eu vendo a minha produção agrícola para a empresa } \\
\text { que oferecer o maior preço. }\end{array}$ & $\begin{array}{l}\text { Concordo } \\
\text { Totalmente }\end{array}$ & 10.00 & 6.00 & 5.31 & 1 & 10 & 3.32 \\
\hline СРT2* & $\begin{array}{l}\text { Eu compro insumos (fertilizantes, inseticidas, } \\
\text { sementes, etc) da empresa que oferecer o menor } \\
\text { preço. }\end{array}$ & $\begin{array}{l}\text { Concordo } \\
\text { Totalmente }\end{array}$ & 10.00 & 7.00 & 5.91 & 1 & 10 & 3.23 \\
\hline CPT4 & Eu me preocupo com o futuro da cooperativa. & $\begin{array}{l}\text { Concordo } \\
\text { Totalmente }\end{array}$ & 10.00 & 9.00 & 8.73 & 1 & 10 & 1.79 \\
\hline CPT5 & $\begin{array}{l}\text { O meu comprometimento com as ações da cooperativa } \\
\text { é importante para que a situação econômica de todos } \\
\text { os cooperados melhore ao longo do tempo. }\end{array}$ & $\begin{array}{l}\text { Concordo } \\
\text { Totalmente }\end{array}$ & 10.00 & 9.00 & 8.53 & 1 & 10 & 1.62 \\
\hline CPT3 & $\begin{array}{l}\text { No futuro, se a cooperativa precisar, eu comprarei } \\
\text { mais quotas-partes (capital integralizado) }\end{array}$ & $\begin{array}{l}\text { Discordo } \\
\text { Totalmente }\end{array}$ & 1.00 & 6.00 & 5.55 & 1 & 10 & 2.92 \\
\hline
\end{tabular}

* Itens com escala reversa. A análise da estatística descritiva foi realizada com a escala original utilizada no questionário. Na análise do modelo de mensuração e do modelo estrutural os valores foram invertidos.

Fonte: Dados da Pesquisa (2020)

\section{Gráfico 6 - Frequência relativa "Comprometimento"}

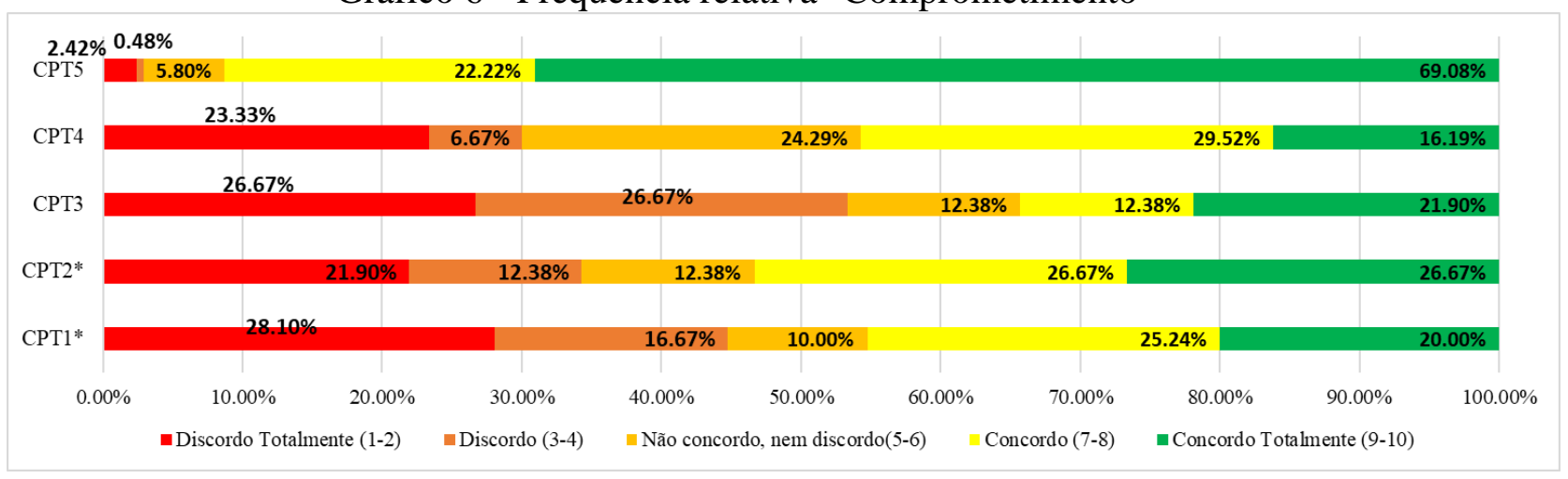

Fonte: Dados da Pesquisa (2020)

Em geral, os cooperados acreditam que o seu comprometimento com as ações da cooperativa é importante para que a situação econômica de todos os cooperados melhore ao longo do tempo (Moda=10, Concordam e Concordam Totalmente $=91,30 \%$ ), bem como se 
preocupam com o futuro da cooperativa $(M o d a=10$, Concordam e Concordam Totalmente $=$ $45,71 \%$ ). Por outro lado, no item que diz respeito a investir mais no capital social, 53,34\% dos cooperados afirmam que não integralizariam mais quotas-partes. Alguns explicaram, durante a aplicação do questionário, que a cooperativa já destina parte das sobras para reservas de investimento e, por isso, não desembolsariam mais dinheiro para investir no capital social.

Os itens CPT1 e CPT2 estão com escalas reversas, por isso é preciso analisa-los de maneira diferente. A moda evidencia que os cooperados vendem sua produção e compram seus insumos com base no preço $(M o d a=10)$. No entanto, devido ao alto desvio padrão (maior do que 3), no Gráfico 6 observa-se que há uma grande dispersão dos valores atribuídos nas respostas, uma vez que 34,28\% (Discordo e Discordo Totalmente) afirmam que não compram insumos com base no preço e 44,77\% (Discordo e Discordo Totalmente) afirmam que não vendem sua produção com base no preço. Em tese, quanto menos o cooperado considerar o preço no momento de negociar, maior é o seu nível de comprometimento, porque ele observará outros benefícios que a cooperativa oferece, como a distribuição de sobras e a segurança. Neste estudo, os cooperados apresentam comportamento diverso neste quesito. Isto pode estar relacionado ao entendimento de cada um sobre quais são os benefícios que uma cooperativa deve oferecer e quais são os esforços que ele deve realizar na relação contratual.

O constructo Volume de Transação como Usuário buscou identificar o comportamento dos cooperados como usuários (cliente e fornecedor). Foi questionado qual era o percentual de volume de negócios que o cooperado realizou com a cooperativa na última safra, considerando o total da sua atividade agrícola. Na Tabela 12 evidencia-se os resultados da estatística descritiva de cada item. 
Tabela 12 - Frequência do Volume de Transação como Usuário

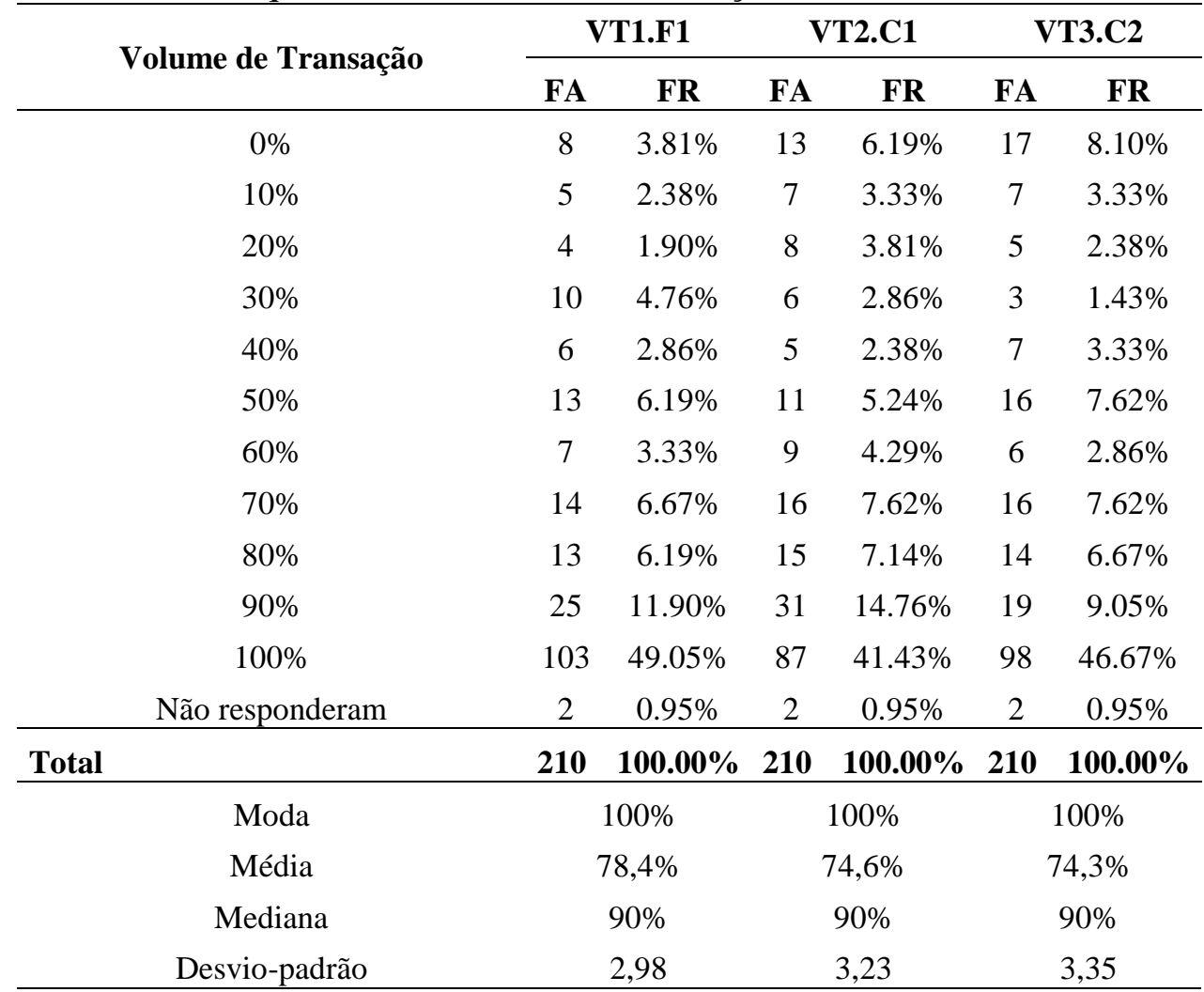

Legenda: FA: Frequência Absoluta, FR: Frequência Relativa

VT1.F1: Volume de transação como fornecedor, na entrega da produção agrícola

VT2.C1: Volume de transação como cliente, na compra de insumos agrícolas

VT3.C3: Volume de transação como cliente, no uso de serviços de assistência técnica

Fonte: Dados da Pesquisa (2020)

A maioria dos cooperados mantém uma frequência alta de transações como usuário (fornecedor e cliente). Em média, os produtores negociam $78,4 \%$ do seu produto com a cooperativa, compram 74,6\% dos insumos na cooperativa e, do total da assistência técnica utilizada nas suas lavouras, 74,3\% advém da cooperativa. Dentre os respondentes, 49,05\% entregam totalmente sua produção na cooperativa, $41,43 \%$ compram todos os seus insumos na cooperativa e $46,67 \%$ sempre que precisam de assistência técnica, utilizam a da cooperativa. O volume de entrega da produção é alto, comparado aquele encontrado por Pascucci et al. (2012) em cooperativas italianas. Os autores relataram que apenas 10\% dos produtores rurais associados a uma cooperativa entregam toda a sua produção nela. No caso da cooperativa deste estudo, muitos agricultores relataram que entregam sua produção nela por que é mais seguro. Ou seja, há um sentimento de confiança na organização. Há, também, um histórico de empresas privadas que não pagaram pelo produto recebido ou decretaram falência, ocasionando perdas aos agricultores. No caso da compra de insumos, os cooperados relatam que compram na cooperativa por que o prazo de pagamento é bom (geralmente para pagar na colheita da safra) e por que é oferecida assistência técnica. 
O constructo Intensidade da Participação como Proprietário buscou avaliar o comportamento dos cooperados como proprietários da cooperativa. Na Tabela 13 está a estatística descritiva de cada item e no Gráfico 7 a frequência relativa.

Tabela 13 - Estatística descritiva "Intensidade da Participação como Proprietário"

\begin{tabular}{|c|c|c|c|c|c|c|c|c|}
\hline Item & Pergunta & 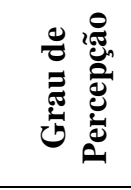 & 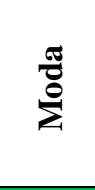 & 莺 & 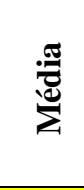 & $\stackrel{\varrho}{\stackrel{\Xi}{\Xi}}$ & 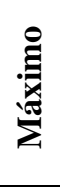 & 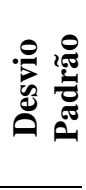 \\
\hline $\mathbf{P 2}$ & $\begin{array}{l}\text { Frequência com que o cooperado participa de reuniões } \\
\text { e assembleias de prestação de contas e } \\
\text { acompanhamento das estratégias da cooperativa. }\end{array}$ & Sempre & 10.00 & 9.00 & 7.73 & 1 & 10 & 2.70 \\
\hline P4 & $\begin{array}{l}\text { Frequência com que o cooperado procura saber } \\
\text { informações sobre o desempenho da cooperativa. }\end{array}$ & Sempre & 10.00 & 9.00 & 7.73 & 1 & 10 & 2.52 \\
\hline P3 & $\begin{array}{l}\text { Frequência com que o cooperado vota nas eleições } \\
\text { para o Conselho de Administração. }\end{array}$ & Nunca & 1.00 & 7.00 & 5.92 & 1 & 10 & 3.54 \\
\hline P5 $^{1}$ & $\begin{array}{l}\text { Quantas vezes o cooperado já assumiu cargos em } \\
\text { conselhos ou comitês. }\end{array}$ & Nunca & 1 & 1.00 & 1.25 & 1 & 5 & 0.62 \\
\hline
\end{tabular}

Gráfico 7 - Frequência relativa "Intensidade da Participação como Proprietário"

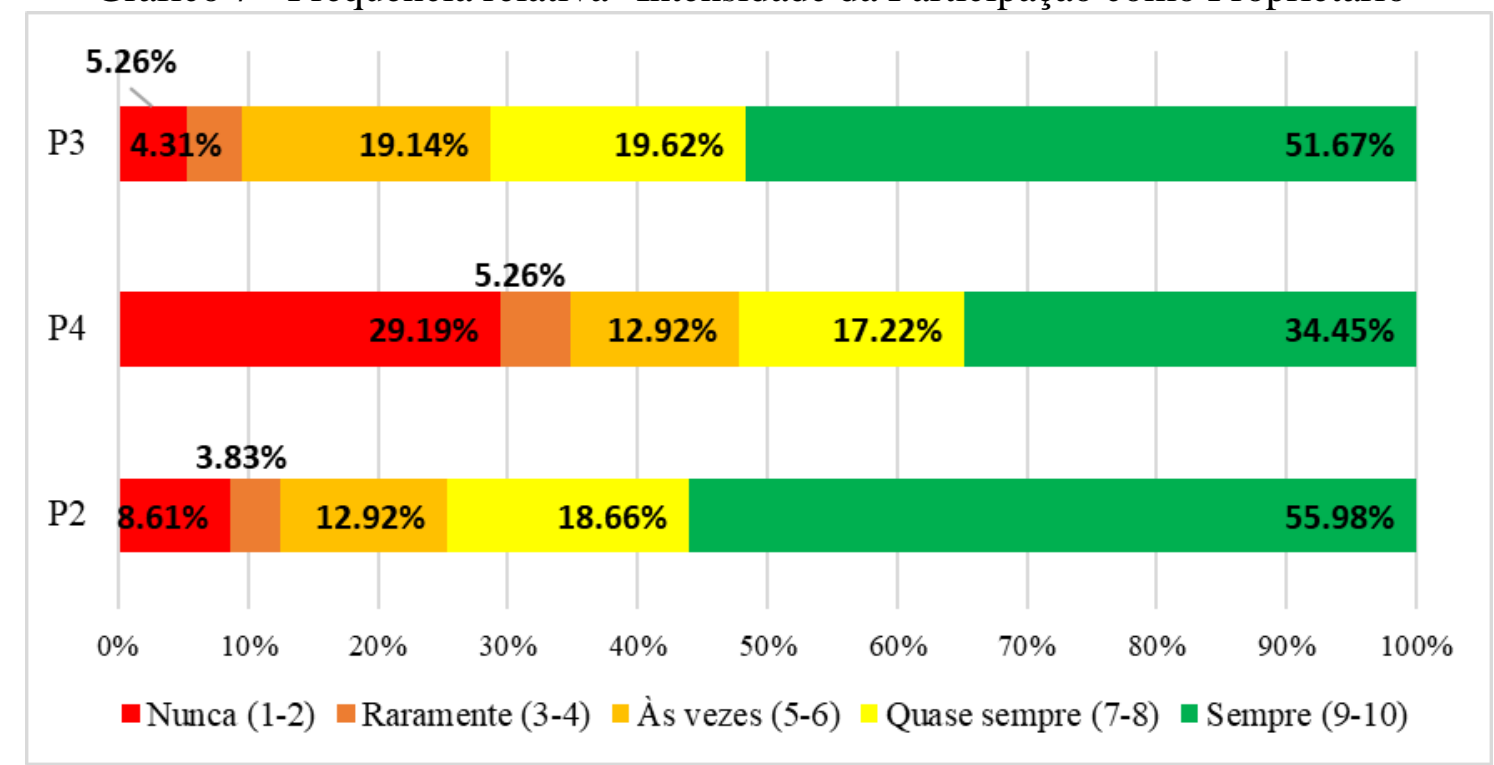

Fonte: Dados da pesquisa (2020)

Bialoskorski Neto (2005) argumenta que no Brasil é comum que o cooperado exerça mais o seu papel de usuário do que de proprietário, pois como usuário ele tem apenas benefícios e como proprietário ele tem também o custo de participação. Neste estudo, os resultados apontam que os cooperados participam das atividades como proprietário, mas a frequência é diferente em cada item do constructo. Os cooperados participam mais das 
atividades relacionadas ao acompanhamento da gestão e menos daquelas atividades que envolvem a atuação deles na gestão ou na escolha dos gestores. O comportamento mais frequente dos cooperados é participar das reuniões e assembleias de prestação de contas e acompanhamento das estratégias da cooperativa (Moda=10, Sempre=51,67\%) e procurar saber informações da cooperativa (Moda=10, Sempre $=55,98 \%$ ). E, os itens com menor frequência referem-se à participação na gestão, pois a maioria dos respondentes $(96,17 \%)$ nunca assumiram um cargo em conselhos ou comitês da cooperativa e apenas 51,67\% afirmam que quase sempre ou sempre votam nas eleições para o conselho de administração.

\subsection{Validação do modelo de mensuração}

A validação do modelo de mensuração é o primeiro passo na análise da modelagem de equações estruturais com estimação por mínimos quadrados parciais. Em vista disso, nesta etapa, analisou-se a validade convergente, validade discriminante e a confiabilidade do modelo de mensuração. Os valores faltantes foram substituídos pela média, pois os dados faltantes por indicador correspondem a menos de 5\% do total das observações (Hair Jr et al., 2016).

A Figura 3 mostra as cargas fatoriais de cada indicador e o $\mathrm{R}^{2}$ de cada constructo endógeno, na primeira análise do modelo.

Figura 3 - Modelo estrutural antes dos ajustes $(n=210)$

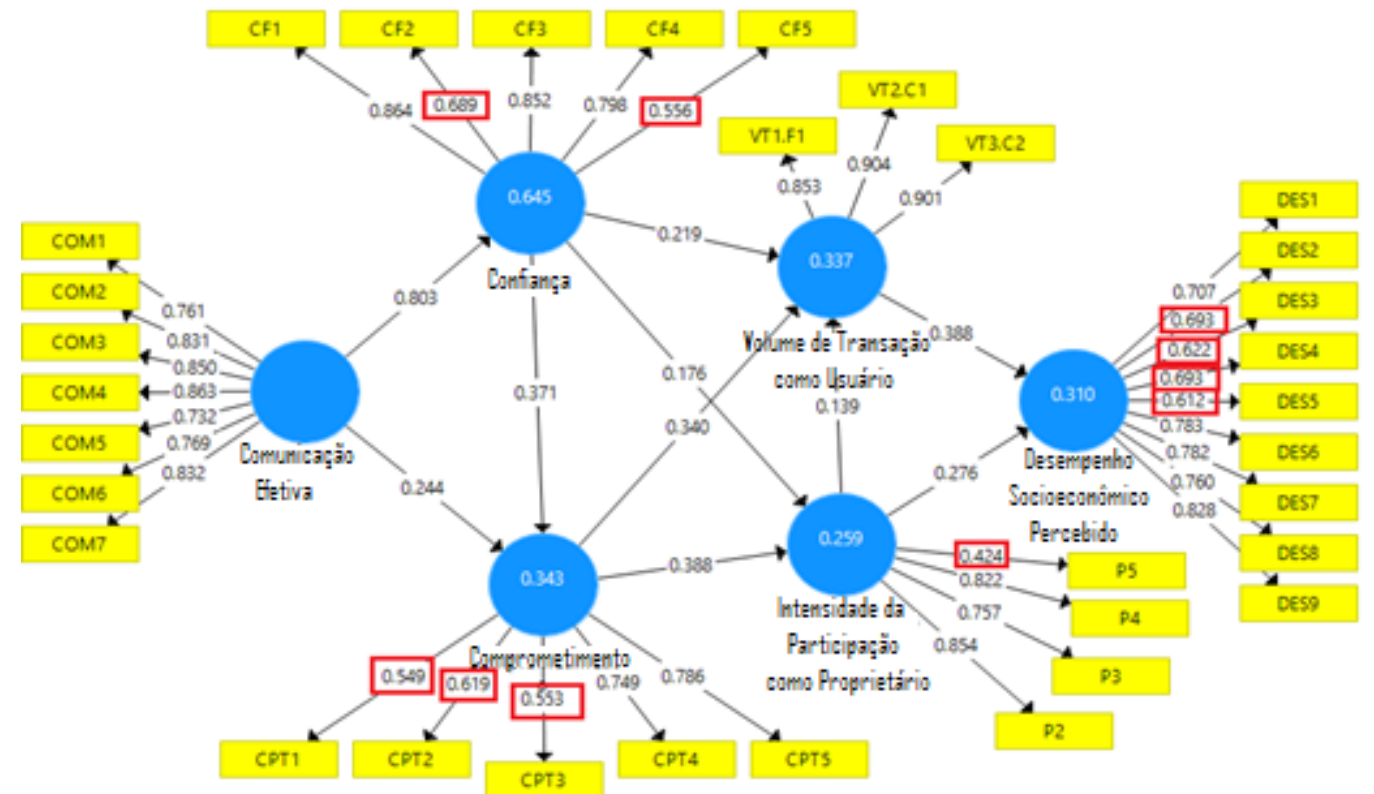

Nota 1: Os itens CPT1 e CPT2 tiveram suas escalas invertidas, ou seja, de 10 para 1, de 9 para 2 e assim sucessivamente.

Fonte: Dados da pesquisa (2020) 
As cargas fatoriais baixas (menores que 0,7) estão circuladas em vermelho. Na Tabela 14 apresenta-se a matriz de correlações entre as variáveis latentes e medidas de validade convergente, validade discriminante e confiabilidade do modelo antes dos ajustes.

Tabela 14 - Matriz de correlação entre as variáveis latentes antes dos ajustes $(n=210)$

\begin{tabular}{lcccccc}
\multicolumn{1}{c}{ Variáveis latentes } & $\mathbf{1}$ & $\mathbf{2}$ & $\mathbf{3}$ & $\mathbf{4}$ & $\mathbf{5}$ & $\mathbf{6}$ \\
\hline 1-Comprometimento & $\mathbf{0 . 6 5 8}$ & & & & & \\
2-Comunicação Efetiva & 0.542 & $\mathbf{0 . 8 0 7}$ & & & & \\
3-Confiança & 0.567 & 0.803 & $\mathbf{0 . 7 6 1}$ & & & \\
4-Desempenho Socioeconômico Percebido & 0.555 & 0.849 & 0.815 & $\mathbf{0 . 7 2 3}$ & & \\
5-Intensidade da Participação como Proprietário & 0.488 & 0.389 & 0.396 & 0.428 & $\mathbf{0 . 7 3 5}$ & \\
6-Volume de Transação como Usuário & 0.531 & 0.399 & 0.466 & 0.496 & 0.391 & $\mathbf{0 . 8 8 6}$ \\
\hline Alfa de Cronbach (>0,7) & 0.671 & 0.910 & 0.810 & 0.886 & 0.698 & 0.863 \\
Confiabilidade Composta (>0,7) & 0.789 & 0.929 & 0.870 & 0.907 & 0.816 & 0.917 \\
Variância Média Extraída (AVE) (>0,5) & 0.434 & 0.651 & 0.578 & 0.523 & 0.540 & 0.786 \\
\hline
\end{tabular}

Nota 1: Os valores na diagonal principal são a raiz quadrada da AVE.

Nota 2: Todas as correlações são significantes a 5\%

Fonte: Dados da pesquisa (2020)

$\mathrm{Na}$ primeira análise, o modelo de mensuração apresentou problemas de validade convergente, validade discriminante e confiabilidade. Os construtos "Intensidade da Participação como Proprietário" e "Comprometimento" obtiveram valores menores que 0,7 para o Alfa de Cronbach. O construto "Comprometimento" obteve um valor de AVE menor que 0,5. Os itens "Comunicação Efetiva", "Confiança" e "Desempenho Socioeconômico Percebido" exibiram problemas de validade discriminante, pois as correlações com as variáveis latentes são maiores do que a raiz quadrada da AVE (diagonal principal da Tabela 13) e as cargas fatoriais são altas entre os indicadores desses constructos, conforme demonstra-se na Tabela 15. 
Tabela 15 - Matriz das Cargas Fatoriais antes dos ajustes $(n=210)$

\begin{tabular}{|c|c|c|c|c|c|c|}
\hline Indicadores & Confiança & $\begin{array}{c}\text { Comunicação } \\
\text { Efetiva }\end{array}$ & Comprometimento & $\begin{array}{c}\text { Desempenho } \\
\text { Socioeconômico } \\
\text { Percebido }\end{array}$ & $\begin{array}{c}\text { Intensidade da } \\
\text { Participação } \\
\text { como } \\
\text { Proprietário }\end{array}$ & $\begin{array}{c}\text { Volume de } \\
\text { Transação } \\
\text { como } \\
\text { Usuário }\end{array}$ \\
\hline CF1 & 0.864 & 0.763 & 0.569 & 0.758 & 0.355 & 0.441 \\
\hline $\mathrm{CF} 2$ & 0.689 & 0.471 & 0.447 & 0.517 & 0.298 & 0.302 \\
\hline CF3 & 0.852 & 0.696 & 0.397 & 0.671 & 0.281 & 0.341 \\
\hline CF4 & 0.798 & 0.639 & 0.371 & 0.650 & 0.246 & 0.362 \\
\hline CF5 & 0.556 & 0.415 & 0.342 & 0.447 & 0.332 & 0.306 \\
\hline COM1 & 0.564 & 0.761 & 0.439 & 0.578 & 0.241 & 0.234 \\
\hline COM2 & 0.748 & 0.831 & 0.517 & 0.721 & 0.359 & 0.333 \\
\hline COM3 & 0.714 & 0.85 & 0.476 & 0.763 & 0.373 & 0.405 \\
\hline COM4 & 0.692 & 0.863 & 0.408 & 0.732 & 0.322 & 0.319 \\
\hline COM5 & 0.544 & 0.732 & 0.334 & 0.624 & 0.342 & 0.261 \\
\hline COM6 & 0.608 & 0.769 & 0.432 & 0.648 & 0.283 & 0.328 \\
\hline COM7 & 0.629 & 0.832 & 0.432 & 0.705 & 0.267 & 0.352 \\
\hline CPT1 & 0.197 & 0.221 & 0.549 & 0.202 & 0.205 & 0.376 \\
\hline CPT2 & 0.248 & 0.222 & 0.619 & 0.254 & 0.224 & 0.534 \\
\hline CPT3 & 0.411 & 0.335 & 0.553 & 0.363 & 0.330 & 0.218 \\
\hline CPT4 & 0.408 & 0.416 & 0.749 & 0.400 & 0.316 & 0.35 \\
\hline CPT5 & 0.522 & 0.511 & 0.786 & 0.526 & 0.468 & 0.327 \\
\hline DES1 & 0.541 & 0.571 & 0.276 & 0.707 & 0.266 & 0.206 \\
\hline DES2 & 0.512 & 0.544 & 0.296 & 0.693 & 0.251 & 0.292 \\
\hline DES3 & 0.431 & 0.463 & 0.292 & 0.622 & 0.285 & 0.371 \\
\hline DES4 & 0.539 & 0.607 & 0.359 & 0.693 & 0.201 & 0.293 \\
\hline DES5 & 0.445 & 0.43 & 0.320 & 0.612 & 0.208 & 0.281 \\
\hline DES6 & 0.599 & 0.659 & 0.406 & 0.783 & 0.303 & 0.332 \\
\hline DES7 & 0.628 & 0.734 & 0.435 & 0.782 & 0.348 & 0.431 \\
\hline DES8 & 0.676 & 0.609 & 0.498 & 0.76 & 0.445 & 0.423 \\
\hline DES9 & 0.815 & 0.814 & 0.594 & 0.828 & 0.366 & 0.472 \\
\hline $\mathrm{P} 2$ & 0.364 & 0.419 & 0.486 & 0.413 & 0.854 & 0.336 \\
\hline P3 & 0.267 & 0.246 & 0.302 & 0.266 & 0.757 & 0.284 \\
\hline P4 & 0.325 & 0.277 & 0.384 & 0.351 & 0.822 & 0.310 \\
\hline P5 & 0.164 & 0.129 & 0.190 & 0.167 & 0.424 & 0.202 \\
\hline VT1.F1 & 0.417 & 0.413 & 0.515 & 0.431 & 0.403 & 0.853 \\
\hline VT2.C1 & 0.388 & 0.284 & 0.458 & 0.415 & 0.293 & 0.904 \\
\hline VT3.C2 & 0.432 & 0.354 & 0.435 & 0.469 & 0.336 & 0.901 \\
\hline
\end{tabular}

Nota 1: Todas as cargas fatoriais são significantes a 1\%. Nota 2: As cargas fatoriais altas estão destacadas em vermelho.

Fonte: Dados da pesquisa (2020)

Em consequência dos valores obtidos na primeira análise, alguns ajustes foram realizados. Para tal, primeiro eliminou-se alguns itens com cargas fatoriais menores que 0,7 (P5 e CPT3) (Hair Jr et al., 2016). Alguns itens com carga fatorial menor do que 0,7 não foram eliminados para não prejudicar a validade de conteúdo dos constructos (Bido \& Silva, 2019). Após, como não havia validade discriminante analisou-se as cargas fatoriais dos construtos e eliminou-se aqueles com pequenas diferenças (CF5, COM3, COM7, DES4, DES6, DES7 e DES9). O modelo estrutural após os ajustes pode ser observado na Figura 4. 
Figura 4 - Modelo estrutural após os ajustes $(\mathrm{n}=210)$

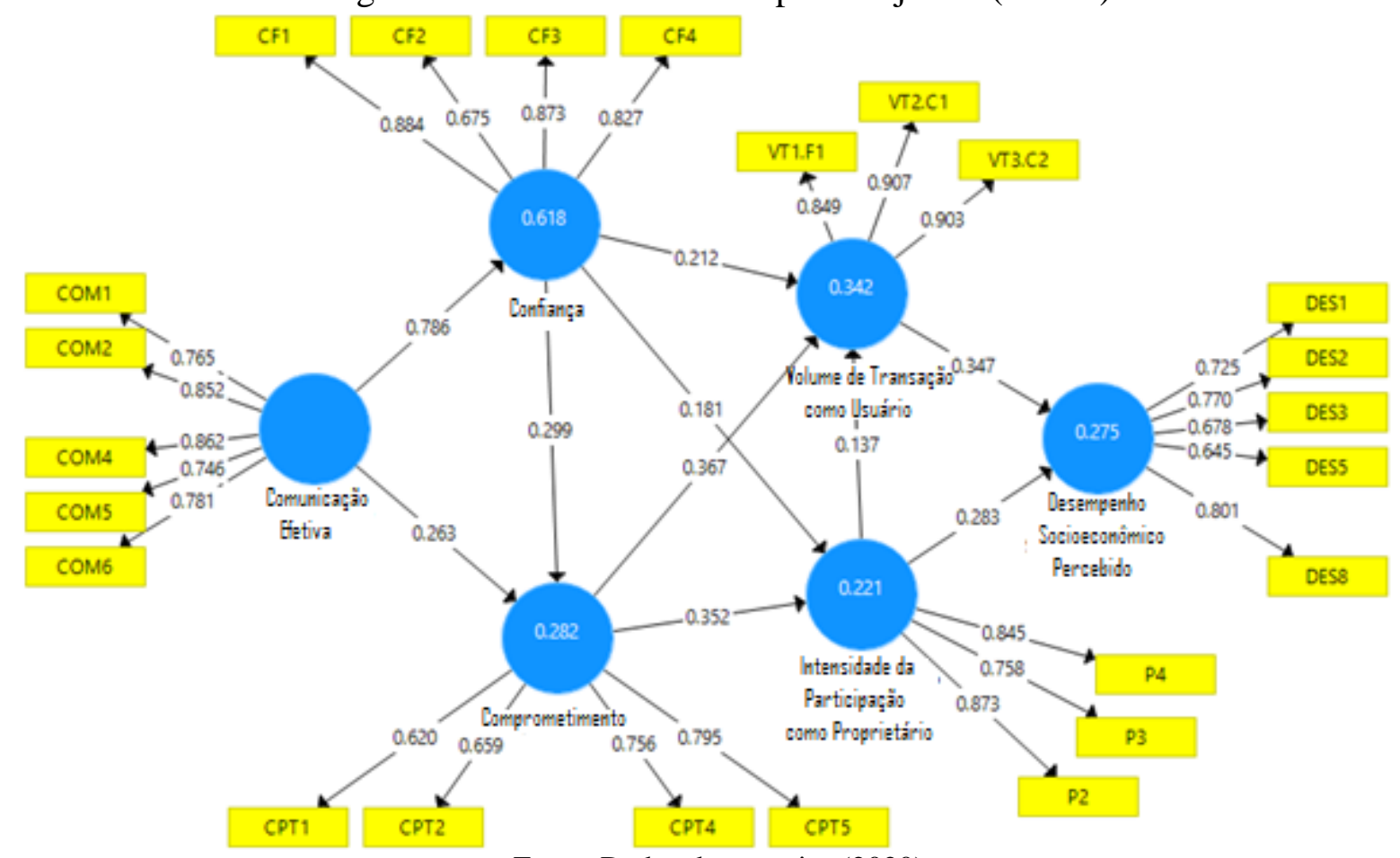

Fonte: Dados da pesquisa (2020)

Nas Tabelas 16 e 17 são apresentados os indicadores de validade convergente, validade discriminante e confiabilidade após os ajustes.

Tabela 16 - Matriz de correlação entre as variáveis latentes depois dos ajustes do modelo $(\mathrm{n}=210)$

\begin{tabular}{lcccccc}
\hline \multicolumn{1}{c}{ Variáveis latentes } & $\mathbf{1}$ & $\mathbf{2}$ & $\mathbf{3}$ & $\mathbf{4}$ & $\mathbf{5}$ & $\mathbf{6}$ \\
\hline 1-Comprometimento & $\mathbf{0 . 7 1 1}$ & & & & & \\
2-Comunicação Efetiva & 0.497 & $\mathbf{0 . 8 0 3}$ & & & & \\
3-Confiança & 0.505 & 0.786 & $\mathbf{0 . 8 1 9}$ & & & \\
4-Desempenho Socioeconômico Percebido & 0.441 & 0.715 & 0.708 & $\mathbf{0 . 7 2 6}$ & & \\
5-Intensidade da Participação como Proprietário & 0.443 & 0.386 & 0.358 & 0.414 & $\mathbf{0 . 8 2 7}$ & \\
6-Volume de Transação como Usuário & 0.534 & 0.368 & 0.446 & 0.453 & 0.375 & $\mathbf{0 . 8 8 7}$ \\
\hline Alfa de Cronbach (>0,7) & 0.685 & 0.862 & 0.833 & 0.780 & 0.770 & 0.863 \\
Confiabilidade Composta (>0,7) & 0.802 & 0.9 & 0.89 & 0.847 & 0.866 & 0.917 \\
Variância Média Extraída (AVE) $(>0,5)$ & 0.506 & 0.644 & 0.671 & 0.527 & 0.684 & 0.786 \\
\hline
\end{tabular}

Nota 1: Os valores na diagonal principal são a raiz quadrada da AVE. Nota 2: Todas as correlações são significantes a $1 \%$. Nota 3: As correlações altas entre as variáveis latentes estão destacadas em vermelho. Fonte: Dados da pesquisa (2020) 
Tabela 17 - Matriz das Cargas Fatoriais depois dos ajustes $(\mathrm{n}=210)$

\begin{tabular}{|c|c|c|c|c|c|c|}
\hline Indicadores & Confiança & $\begin{array}{c}\text { Comunicação } \\
\text { Efetiva }\end{array}$ & Comprometimento & $\begin{array}{c}\text { Desempenho } \\
\text { Socioeconômico } \\
\text { Percebido }\end{array}$ & $\begin{array}{c}\text { Intensidade } \\
\text { da } \\
\text { Participação } \\
\text { como } \\
\text { Proprietário }\end{array}$ & $\begin{array}{c}\begin{array}{c}\text { Volume } \\
\text { de }\end{array} \\
\text { Transação } \\
\text { como } \\
\text { Usuário } \\
\end{array}$ \\
\hline $\mathrm{CF} 1$ & 0.884 & 0.749 & 0.539 & 0.653 & 0.351 & 0.440 \\
\hline CF2 & 0.675 & 0.480 & 0.374 & 0.500 & 0.298 & 0.302 \\
\hline CF3 & 0.873 & 0.696 & 0.363 & 0.587 & 0.279 & 0.341 \\
\hline $\mathrm{CF} 4$ & 0.827 & 0.614 & 0.353 & 0.564 & 0.239 & 0.362 \\
\hline COM1 & 0.592 & 0.765 & 0.441 & 0.466 & 0.252 & 0.234 \\
\hline COM2 & 0.735 & 0.852 & 0.462 & 0.618 & 0.363 & 0.332 \\
\hline COM4 & 0.685 & 0.862 & 0.371 & 0.640 & 0.315 & 0.318 \\
\hline COM5 & 0.519 & 0.746 & 0.296 & 0.556 & 0.335 & 0.259 \\
\hline COM6 & 0.595 & 0.781 & 0.406 & 0.585 & 0.286 & 0.327 \\
\hline CPT1 & 0.198 & 0.202 & 0.620 & 0.142 & 0.181 & 0.374 \\
\hline СРT2 & 0.235 & 0.206 & 0.659 & 0.207 & 0.192 & 0.534 \\
\hline CPT4 & 0.385 & 0.408 & 0.756 & 0.352 & 0.325 & 0.350 \\
\hline CPT5 & 0.525 & 0.506 & 0.795 & 0.460 & 0.476 & 0.326 \\
\hline DES1 & 0.535 & 0.579 & 0.235 & 0.725 & 0.261 & 0.205 \\
\hline DES2 & 0.473 & 0.542 & 0.266 & 0.770 & 0.245 & 0.293 \\
\hline DES3 & 0.433 & 0.451 & 0.272 & 0.678 & 0.282 & 0.372 \\
\hline DES5 & 0.432 & 0.415 & 0.300 & 0.645 & 0.192 & 0.281 \\
\hline DES8 & 0.650 & 0.596 & 0.456 & 0.801 & 0.439 & 0.422 \\
\hline P2 & 0.339 & 0.408 & 0.465 & 0.363 & 0.873 & 0.334 \\
\hline P3 & 0.246 & 0.249 & 0.254 & 0.266 & 0.758 & 0.284 \\
\hline P4 & 0.293 & 0.281 & 0.350 & 0.384 & 0.845 & 0.309 \\
\hline VT1.F1 & 0.403 & 0.394 & 0.513 & 0.346 & 0.394 & 0.849 \\
\hline VT2.C1 & 0.363 & 0.259 & 0.470 & 0.411 & 0.275 & 0.907 \\
\hline VT3.C2 & 0.417 & 0.319 & 0.436 & 0.450 & 0.323 & 0.903 \\
\hline
\end{tabular}

Nota 1: Todas as cargas fatoriais são significantes a $1 \%$.

Nota 2: As cargas fatoriais altas estão destacadas em vermelho.

Fonte: Dados da pesquisa (2020)

Em todos os constructos o Alfa de Cronbach é maior ou muito próximo à 0,7 , a confiabilidade composta é maior do que 0,7 e a variância média explicada é maior que 0,5 (Hair Jr et al., 2016). Nota-se que a correlação entre os constructos confiança e comunicação efetiva possuem um valor muito próximo a raiz quadrada da AVE (diagonal principal), indicando um potencial problema de validade discriminante. Optou-se por não excluir mais indicadores do modelo para não prejudicar a validade de conteúdo (Hair Jr et al., 2016). Desta forma, o modelo foi validado após os ajustes e prosseguiu-se com a análise do modelo estrutural (seção 4.3). 


\subsection{Análise do modelo estrutural}

\subsubsection{Análise dos efeitos diretos}

No modelo estrutural foram estabelecidas as hipóteses de pesquisa e algumas variáveis de controle. Por isso, adotou-se o procedimento recomendado por Bido e Silva (2019) para a análise dos dados. Primeiro, analisou-se um modelo apenas com as variáveis de controle e a variável endógena "Desempenho Socioeconômico Percebido". A Figura 5 exibe para cada relação estrutural, os coeficientes e o nível de significância estatística (valor-p).

Figura 5 - Modelo estrutural com as variáveis de controle e a variável endógena

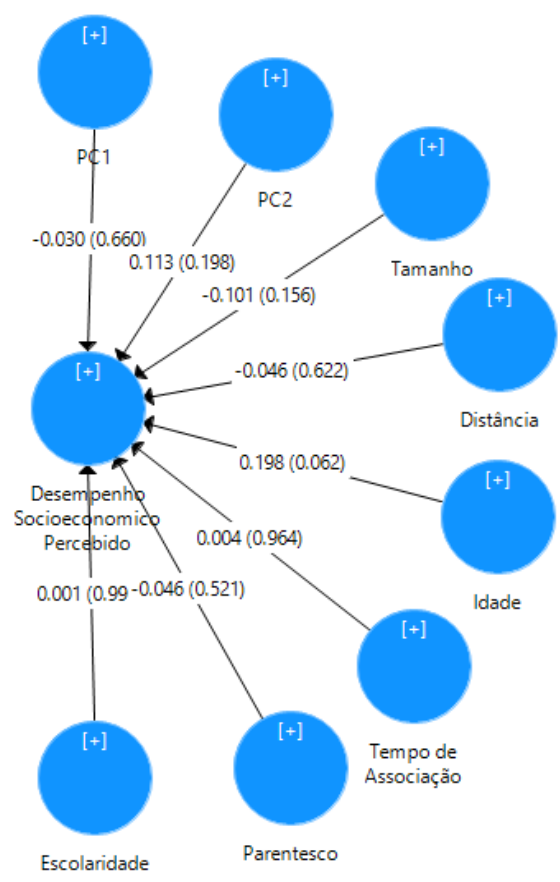

Fonte: Dados da pesquisa (2020)

Todas as variáveis de controle foram retiradas do modelo, visto que nenhuma apresentou relação estatisticamente significativa $(\mathrm{p}<0,05)$. Caso alguma variável apresentasse relação significativa, seria necessário analisar o modelo completo com as variáveis de controle significantes. Ao observarmos as características da amostra (seção 4.1.1), nota-se que ela é homogênea, o que seria uma explicação para o resultado não significativo de todas as variáveis de controle.

Por fim, analisou-se o modelo estrutural completo, sem as variáveis de controle, utilizando a técnica de bootstrapping com 5000 repetições (Hair Jr et al., 2016). A Tabela 18 demonstra o coeficiente estrutural, $\mathrm{f}^{2}$, erro padrão, valor-p e o $\mathrm{R}^{2}$ ajustado para cada relação 
estrutural. E, na Figura 6 verifica-se o coeficiente estrutural de cada relação e o respectivo valor-p (entre parênteses).

Tabela 18 - Análise do modelo estrutural $(n=210)$

\begin{tabular}{|c|c|c|c|c|c|c|}
\hline Relação Estrutural & 总 & $\Sigma$ & 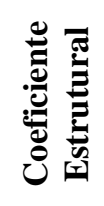 & 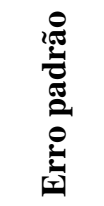 & 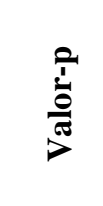 & 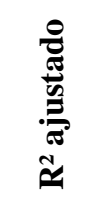 \\
\hline Comunicação Efetiva -> Confiança & $\mathrm{H} 5_{\mathrm{a}}$ & 1.616 & 0.786 & 0.028 & 0.000 & 0.616 \\
\hline Comunicação Efetiva -> Comprometimento & $\mathrm{H} 5_{\mathrm{b}}$ & 0.037 & 0.263 & 0.110 & 0.017 & \\
\hline Confiança -> Comprometimento & $\mathrm{H} 3_{\mathrm{a}}$ & 0.047 & 0.299 & 0.106 & 0.005 & 0.275 \\
\hline Confiança -> Intensidade da Participação como Proprietário & $\mathrm{H} 3_{\mathrm{b}}$ & 0.031 & 0.181 & 0.075 & 0.016 & \\
\hline $\begin{array}{l}\text { Comprometimento -> Intensidade da Participação como } \\
\text { Proprietário }\end{array}$ & $\mathrm{H} 4_{b}$ & 0.118 & 0.352 & 0.080 & 0.000 & 0.213 \\
\hline Confiança -> Volume de Transação como Usuário & $\mathrm{H} 3_{\mathrm{c}}$ & 0.049 & 0.212 & 0.083 & 0.010 & \\
\hline $\begin{array}{l}\text { Intensidade da Participação como Proprietário -> Volume de } \\
\text { Transação como Usuário }\end{array}$ & $\mathrm{H} 1_{\mathrm{a}}$ & 0.022 & 0.137 & 0.069 & 0.049 & \\
\hline Comprometimento -> Volume de Transação como Usuário & $\mathrm{H} 4_{\mathrm{a}}$ & 0.136 & 0.367 & 0.073 & 0.000 & 0.332 \\
\hline $\begin{array}{l}\text { Intensidade da Participação como Proprietário -> Desempenho } \\
\text { Socioeconômico Percebido }\end{array}$ & $\mathrm{H} 1_{\mathrm{b}}$ & 0.095 & 0.283 & 0.076 & 0.000 & \\
\hline $\begin{array}{l}\text { Volume de Transação como Usuário -> Desempenho } \\
\text { Socioeconômico Percebido }\end{array}$ & $\mathrm{H} 2_{\mathrm{a}}$ & 0.143 & 0.347 & 0.072 & 0.000 & 0.268 \\
\hline
\end{tabular}

Nota 1: Valores-p estimados por bootstrapping com 5000 repetições

Nota 2: O maior valor de VIF é 2,942

Nota 3: $\mathrm{f}^{2}=\mathrm{R}^{2} /\left(1-\mathrm{R}^{2}\right)$. Por isso, $\mathrm{f}^{2}$ de H5a: Comunicação Efetiva $\rightarrow$ Confiança é maior do que 1.

Fonte: Dados da Pesquisa (2020)

Figura 6 - Análise do modelo estrutural $(n=210)$

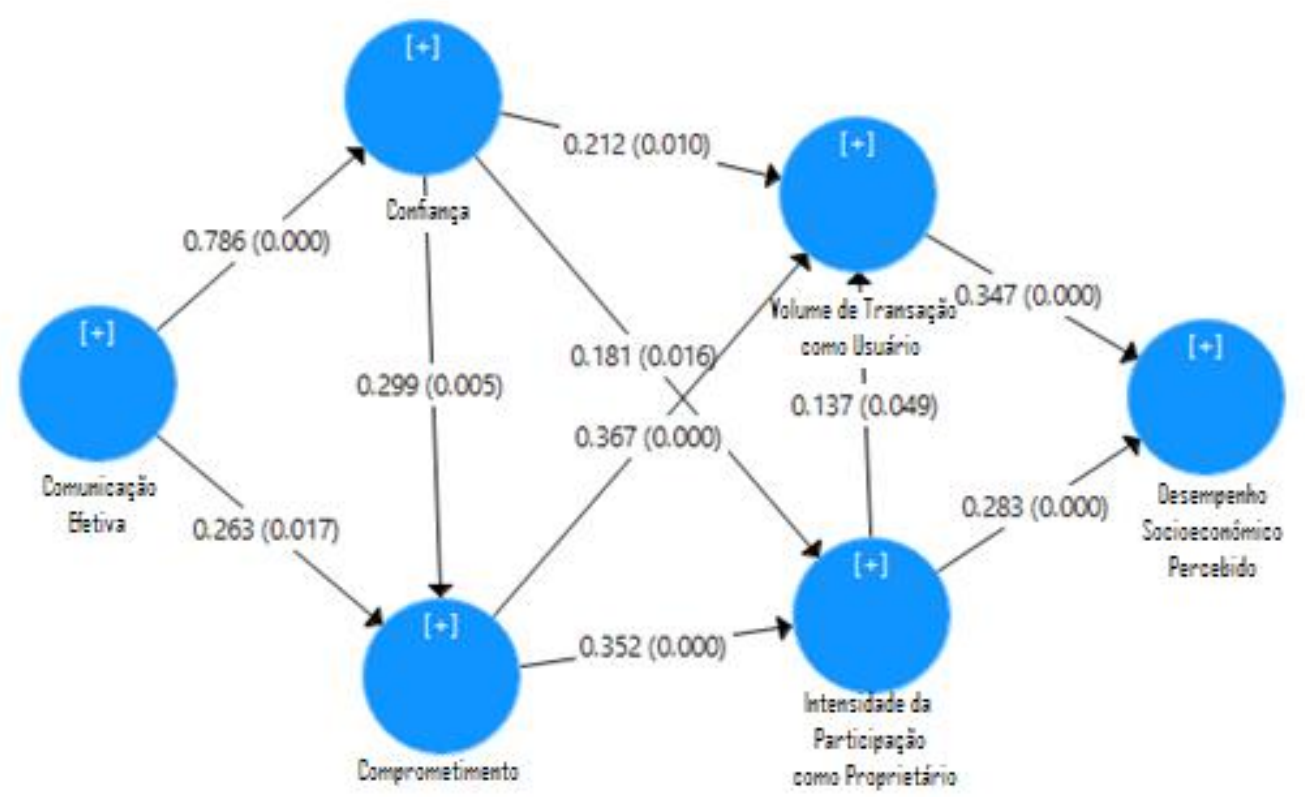

Fonte: Dados da pesquisa (2020) 
Todas as hipóteses foram confirmadas, de forma que as variáveis do modelo explicam $26,8 \%$ da variância do desempenho socioeconômico percebido $\left(R^{2}\right.$ ajustado $\left.=0,268\right)$. No contexto das ciências comportamentais, se o valor do $\mathrm{R}^{2}$ ajustado é maior do que 0,26 , o poder explicativo do modelo é considerado grande (Cohen, 1988). Ao comparar com outros estudos que mensuraram o desempenho das cooperativas por meio da percepção dos gestores $\left(\mathrm{R}^{2}=0,09\right.$ (Yang \& Chaddad, 2014)) e dos cooperados $\left(\mathrm{R}^{2}=0,155\right.$ (Guzmán, Santos, \& Barroso, 2019), $\mathrm{R}^{2}=0,285$ (Susanty et al., 2017), observa-se que o poder explicativo do modelo está dentro dos níveis mais altos apontados pelos resultados das pesquisas até agora. Para as outras variáveis endógenas, o modelo explica 33,2\% da variância do volume de transação como usuário, 21,3\% da variância da intensidade da participação como proprietário, $27,5 \%$ da variância do comprometimento e $61,6 \%$ da variância da confiança.

$\mathrm{Na}$ análise das hipóteses de pesquisa, verifica-se que a comunicação efetiva tem uma relação positiva com a confiança $(\beta=0,786, p=0,000)$ e com o comprometimento $(\beta=0,263$, $\mathrm{p}=0,017)$. Argumenta-se que em organizações gerenciadas por contratos relacionais, a comunicação é capaz de influenciar a confiança e o comprometimento (Hendrikse \& Veerman, 2003). Neste estudo, nota-se que a influência direta da comunicação efetiva é maior sob a confiança $(\beta=0,786)$ do que sob o comprometimento $(\beta=0,263)$. Tais resultados confirmam as hipóteses de pesquisa $\left(\mathrm{H} 5_{\mathrm{a}}\right.$ e $\left.\mathrm{H} 5_{\mathrm{b}}\right)$ e corroboram com os achados de Fischer (2013) e Susanty et al. (2013) de que a comunicação efetiva influencia positivamente a confiança.

As hipóteses $\mathrm{H} 3_{\mathrm{a}}, \mathrm{H} 3_{\mathrm{b}}, \mathrm{H} 3_{\mathrm{c}}, \mathrm{H} 4_{\mathrm{a}}$ e $\mathrm{H} 4_{\mathrm{b}}$ analisam as relações entre confiança, comprometimento, intensidade da participação como proprietário e volume de transação como usuário. As duas últimas variáveis mensuram o comportamento oportunista do cooperado. Quanto maior o índice da intensidade da participação como proprietário e do volume de transação como usuário, menor é o comportamento oportunista. Os resultados apontam que a confiança exerce influência positiva sobre o comprometimento $(\beta=0,299, p=0,005)$, a intensidade da participação como proprietário $(\beta=0,151, p=0,016)$ e o volume de transação como usuário $(\beta=0,212, \mathrm{p}=0,010) \mathrm{e}, \mathrm{o}$ comprometimento influencia positivamente a intensidade da participação como proprietário $(\beta=0,352, p=0,000)$ e o volume de transação como usuário $(\beta=0,367, p=0,000)$. Portanto, os resultados confirmam o argumento de que num contexto de risco de comportamento oportunista, o comprometimento e a confiança reduzem tais riscos (Hakelius \& Hansson, 2016a) ao aumentar o nível do volume de transação como usuário e intensidade da participação como proprietário. 
A confiança, intensidade da participação como proprietário e o comprometimento explicam 33,2\% da variância do volume de transação como usuário. O comprometimento tem uma relação positiva mais forte $(\beta=0,367, p=0,000)$, seguida pela confiança $(\beta=0,212$, $\mathrm{p}=0,010)$ e pela intensidade da participação como proprietário $(\beta=0,137, \mathrm{p}=0,049)$. O volume de transação como usuário é um indicativo do quanto o cooperado mantém relações como usuário com a cooperativa, negociando sua produção, comprando insumos e utilizando assistência técnica. Segundo Bialoskorki Neto (2005) a confiança não é uma garantia de que o cooperado irá comprar e vender com a cooperativa. Nos resultados da pesquisa, observa-se que, embora haja uma influência positiva da confiança sob o volume de transação, ela é menor do que aquela exercida pelo comprometimento. Conforme Morgan \& Hunt (1984), o indivíduo comprometido realiza o máximo de esforço para manter a relação porque julga ela importante. Portanto, tal fato, justificaria a influência do comprometimento no volume de transação.

Por fim, quanto ao desempenho socioeconômico percebido pelos membros, os resultados mostram que a intensidade da participação como proprietário e o volume de transação como usuário explicam $26,8 \%$ da sua variância. O resultado confirmam as hipóteses $\mathrm{H} 1_{b}$ e $\mathrm{H} 2_{\mathrm{a}}$ e o pressuposto teórico de que, a frequência das transações influencia positivamente o desempenho da relação contratual (Williamson, 2010b). Como no caso das cooperativas é possível que haja dois tipos de relações (usuário e proprietário), verificamos que tanto o volume de transação como usuário $(\beta=0,347, \mathrm{p}=0,000)$ quanto a intensidade da participação como proprietário $(\beta=0,283, \quad \mathrm{p}=0,000)$ influenciam positivamente o desempenho socioeconômico percebido.

\subsubsection{Análise dos efeitos indiretos e totais}

$\mathrm{Na}$ análise dos efeitos diretos observou-se que todas as variáveis têm uma relação positiva, confirmando as hipóteses de pesquisa. Como o modelo é complexo, isto é, há relações em que uma variável tem mais do que uma variável relacionada, optou-se por avançar na análise para melhor compreender o processo de relação entre essas variáveis do modelo. Esta complexidade é comum nos estudos que envolvem o comportamento dos indivíduos nas cooperativas (Grashuis \& Cook, 2019). Assim, optou-se por verificar os efeitos indiretos e totais, por meio das variáveis mediadoras. A análise da mediação assume uma sequência de relações, na qual uma variável antecedente afeta uma variável mediadora que afeta uma variável dependente (Nitzl, Roldan, \& Cepeda, 2016). Os resultados da Tabela 19 
apontam que das cinco relações analisadas, três apresentam mediação parcial. Isto significa que a variável mediadora contribui para o efeito da variável independente sob a dependente.

Tabela 19 - Efeitos indiretos específicos

\begin{tabular}{|c|c|c|c|c|c|}
\hline & Efeitos & نْ & & $\frac{a}{\frac{0}{n}}$ & 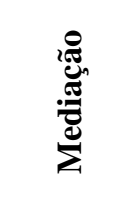 \\
\hline Direto & Comunicação Efetiva -> Comprometimento & 0.263 & 0.110 & 0.017 & \\
\hline Indireto & Comunicação Efetiva $->$ Confiança $->$ Comprometimento & 0.235 & 0.085 & 0.006 & Parcial \\
\hline Total & Comunicação Efetiva -> Comprometimento & 0.497 & 0.070 & 0.000 & \\
\hline Direto & Confiança -> Intensidade da Participação como Proprietário & 0.181 & 0.075 & 0.016 & \\
\hline Indireto & $\begin{array}{l}\text { Confiança -> Comprometimento -> Intensidade da Participação como } \\
\text { Proprietário }\end{array}$ & 0.105 & 0.041 & 0.010 & Parcial \\
\hline Total & Confiança -> Intensidade da Participação como Proprietário & 0.286 & 0.077 & 0.000 & \\
\hline Direto & Confiança -> Volume de Transação como Usuário & 0.212 & 0.083 & 0.010 & \\
\hline Indireto & $\begin{array}{l}\text { Confiança -> Comprometimento -> Volume de Transação como } \\
\text { Usuário }\end{array}$ & 0.110 & 0.049 & 0.024 & Parcial \\
\hline Indireto & $\begin{array}{l}\text { Confiança -> Intensidade da Participação como Proprietário -> } \\
\text { Volume de Transação como Usuário }\end{array}$ & 0.025 & 0.017 & 0.146 & Não \\
\hline Indireto & $\begin{array}{l}\text { Confiança -> Comprometimento -> Intensidade da Participação como } \\
\text { Proprietário -> Volume de Transação como Usuário }\end{array}$ & 0.014 & 0.01 & 0.139 & Não \\
\hline Total & Confiança -> Volume de Transação como Usuário & 0.361 & 0.077 & 0.000 & \\
\hline Direto & Comprometimento -> Volume de Transação como Usuário & 0.367 & 0.073 & 0.000 & \\
\hline Indireto & $\begin{array}{l}\text { Comprometimento -> Intensidade da Participação como Proprietário } \\
\text {-> Volume de Transação como Usuário }\end{array}$ & 0.048 & 0.027 & 0.076 & Não \\
\hline Total & Comprometimento -> Volume de Transação como Usuário & 0.415 & 0.064 & 0.000 & \\
\hline Direto & $\begin{array}{l}\text { Intensidade da Participação como Proprietário -> Desempenho } \\
\text { Socioeconômico Percebido }\end{array}$ & 0.283 & 0.076 & 0.000 & \\
\hline Indireto & $\begin{array}{l}\text { Intensidade da Participação como Proprietário -> Volume de } \\
\text { Transação como Usuário -> Desempenho Socioeconômico Percebido }\end{array}$ & 0.047 & 0.026 & 0.073 & Não \\
\hline Total & $\begin{array}{l}\text { Intensidade da Participação como Proprietário -> Desempenho } \\
\text { Socioeconômico Percebido }\end{array}$ & 0.331 & 0.069 & 0.000 & \\
\hline
\end{tabular}

Fonte: Dados da pesquisa (2020)

A relação entre comunicação efetiva e comprometimento é mediada parcialmente pela confiança. É uma mediação complementar, pois todos os coeficientes são positivos. Em termos práticos, isto significa que a confiança aumenta o poder da comunicação efetiva no comprometimento. A comunicação efetiva influencia positivamente o nível de confiança do cooperado, o que influencia positivamente o seu nível de comprometimento. Nota-se que o efeito total $(0,497)$ é maior do que o efeito direto da comunicação efetiva sob o comprometimento $(0,263)$, evidenciando a importância da confiança na relação entre a comunicação efetiva e o comprometimento. Para fins gerenciais, a análise demonstra que a 
cooperativa deve investir em comunicação efetiva quando deseja aumentar o nível de comprometimento, pois esta o influencia diretamente e por intermédio da confiança (mediação).

A segunda mediação analisada refere-se à relação entre confiança e intensidade da participação como proprietário. Na análise dos efeitos diretos, a intensidade da participação como proprietário é influenciada positivamente pela confiança. Quando analisado os efeitos indiretos, os resultados mostram que a relação entre confiança e a intensidade da participação como proprietário é mediada parcialmente pelo comprometimento. É uma mediação complementar, pois a confiança influencia positivamente o nível de comprometimento do cooperado, o qual influencia positivamente a intensidade da participação como proprietário. Por isso, o efeito total da confiança sob a intensidade da participação como proprietário é de 0,286 , o qual é maior do que o efeito direto $(\beta=0,181)$. Além de contribuir com o efeito total da confiança, o comprometimento influencia diretamente a intensidade da participação como proprietário $(\beta=0,352)$. Portanto, em termos práticos, se a gestão da cooperativa investir em ações que aumentem a confiança e o comprometimento dos cooperados aumentará o nível de intensidade da participação como proprietário.

$\mathrm{Na}$ terceira mediação analisou-se a relação entre confiança e volume de transação como usuário mediada pelo comprometimento e intensidade participação como proprietário. Os resultados confirmam que o comprometimento media parcialmente a relação entre confiança e volume de transação como usuário. Já a intensidade da participação como proprietário, embora tenha efeito direto significativo sobre o volume de transação como usuário, na análise de mediação (Confiança X Intensidade da Participação como Proprietário X Volume de Transação como Usuário e Confiança X Comprometimento X Intensidade da Participação como Proprietário X Volume de Transação como Usuário) não apresentou efeito indireto significativo. Em termos práticos, o resultado indica que, primeiro, a confiança influencia o comprometimento, e este influencia o volume de transação como usuário. No total, o efeito da confiança sobre o volume de transação como usuário é de 0,361 , o qual é maior do que o efeito direto $(\beta=0,212)$. Em vista disto, para aumentar o nível do volume de transação como usuário, a gestão deve investir em ações que estimulem o comprometimento e a confiança.

$\mathrm{Na}$ análise dos efeitos diretos é possível observar que o comprometimento exerce maior influência direta do que a confiança sob a intensidade da participação como proprietário e o sob o volume de transação como usuário. Adicionalmente, ao analisar os resultados da segunda e da terceira mediação verificou-se que a confiança complementa o efeito do 
comprometimento sob o volume de transação como usuário e a intensidade da participação como proprietário. A confiança tem esse efeito positivo sobre o comportamento dos cooperados porque faz com que o indivíduo acredite que a outra parte cumprirá com o seu compromisso na relação contratual (Fischer, 2013), o que estimula ele a cooperar (Tadesse \& Kassie, 2017). Estes resultados corroboram com estudos que já encontraram uma relação positiva entre a confiança e o comprometimento (Pesämaa et al., 2013) e entre a confiança e a fidelidade (Graca \& Arnaldo, 2016; Susanty et al., 2017). Indo além, os resultados apresentados aqui mostram que estas variáveis também são capazes de influenciar positivamente o comportamento dos cooperados como usuários e proprietários.

$\mathrm{Na}$ quarta mediação analisou-se a relação entre comprometimento, intensidade da participação como proprietário e volume de transação como usuário. Na análise dos efeitos diretos (Seção 4.3.1), o comprometimento e a intensidade da participação como proprietário apresentaram influência positiva e significativa sob o volume de transação como usuário. No entanto, na análise dos efeitos indiretos, a intensidade da participação como proprietário não media a relação entre comprometimento e volume de transação como usuário. Da mesma forma, na quinta mediação analisada, o volume de transação como usuário não media a relação entre a intensidade da participação como proprietário e o desempenho socioeconômico percebido. Enquanto que, na análise dos efeitos diretos tanto a intensidade da participação como proprietário quanto o volume de transação como usuário influenciam positivamente o desempenho socioeconômico percebido. Isto significa que a frequência com que o cooperado mantém relações de usuário e proprietário influencia positivamente a percepção deles acerca do desempenho socioeconômico, mas não é possível afirmar, na análise do modelo, que há uma relação entre esses comportamentos no processo de avaliação do desempenho da cooperativa.

Por fim, pela análise do mapa importância-desempenho (IPMA - ImportancePerformance Map Analysis) (Gráfico 8) buscou-se verificar qual a importância e o desempenho de cada constructo em relação ao constructo-objetivo "Desempenho Socioeconômico Percebido". A importância identifica os efeitos totais de cada constructo do modelo, ou seja, a soma dos efeitos diretos e indiretos de cada construto predecessor no construto-objetivo (Ringle \& Sarstedt, 2016). O desempenho identifica o escore médio das variáveis latentes do modelo, padronizado entre notas de 0 a 100 (Ringle \& Sarstedt, 2016). Na prática, a análise do IPMA fornece orientações para a priorização de atividades gerenciais de alta importância para o constructo em análise, mas que requerem melhorias no desempenho (Ringle \& Sarstedt, 2016). 


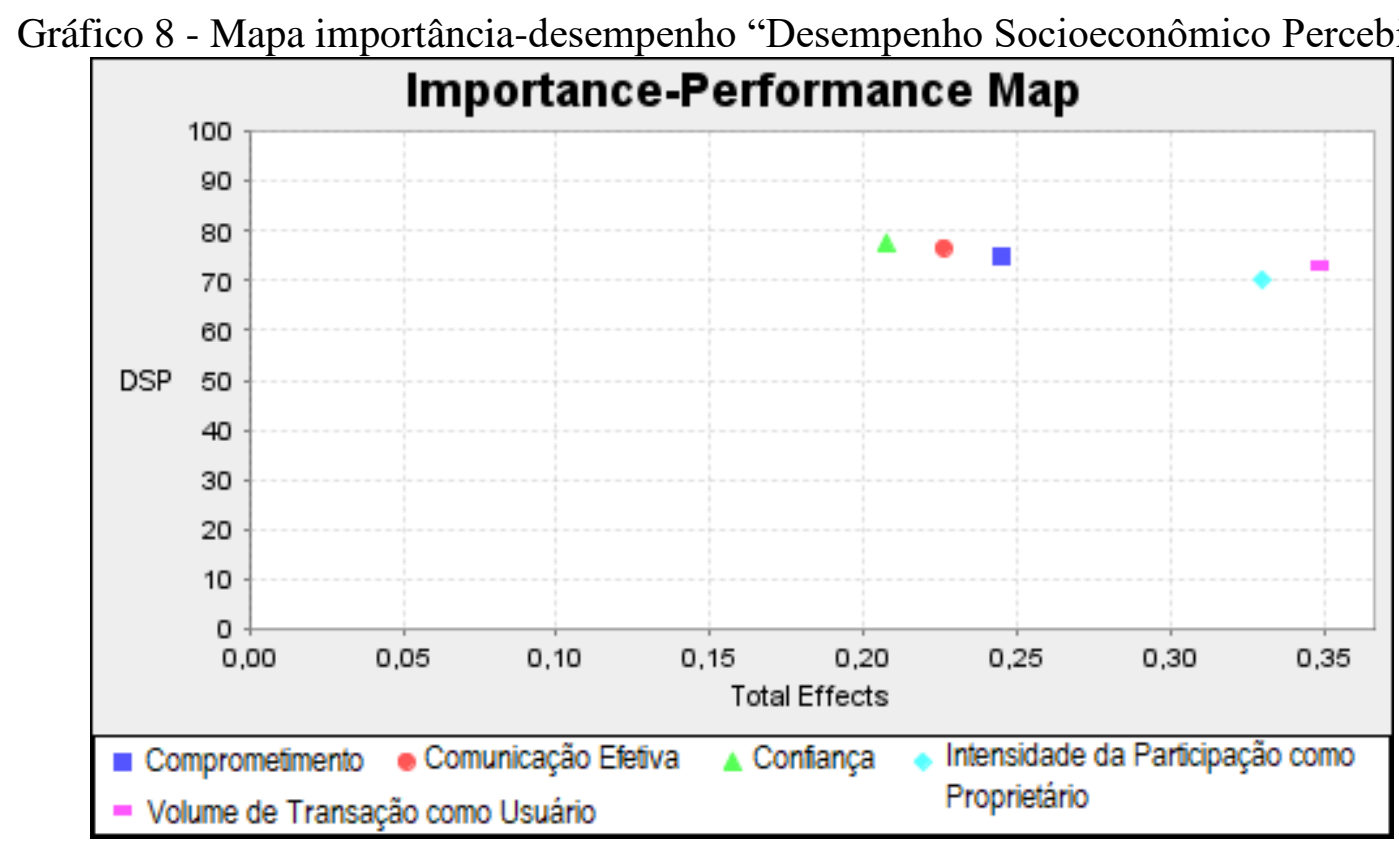

Legenda: DSP=Desempenho Socioeconômico Percebido Fonte: Dados da Pesquisa (2020)

No modelo em análise, os construtos com maior importância são, nesta ordem, volume de transação como usuário $(0,349)$, intensidade da participação como proprietário $(0,333)$, comprometimento $(0,245)$, comunicação efetiva $(0,226)$ e confiança $(0,207)$. Com este resultado fica explícito a importância da manutenção das relações dos cooperados como usuário e proprietário para melhorar o desempenho socioeconômico percebido. Dada esta importância, estes aspectos devem ter seu desempenho melhorado pela gestão da cooperativa: o volume de transação como usuário de 73,15 para 100 e a intensidade da participação como proprietário de 70,43 para 100. Este resultado corrobora com aquele relatado por Limnios et al. (2018), os quais encontraram que na percepção dos gestores de cooperativas, o papel de usuário e investidor/proprietário deve ser incentivado para fortalecer a fidelidade e o engajamento dos membros com a cooperativa. Indo além dos aspectos analisado por Limnios et al. (2018), os resultados deste estudo mostram que estes papéis também são importantes para o desempenho socioeconômico percebido.

\subsection{Análise entre o papel do cooperado e o desempenho socioeconômico percebido}

$\mathrm{Na}$ análise das relações entre volume de transação como usuário, intensidade da participação como proprietário e desempenho socioeconômico percebido verificou-se que as duas primeiras variáveis exercem influência direta e positiva sob a última, assim como que o 
volume de transação como usuário tem efeito total maior sob o desempenho socioeconômico percebido do que a intensidade da participação como proprietário. Este resultado considera a média geral dos respondentes. Ao saber que os cooperados podem escolher assumir um ou mais papéis na sua relação com a cooperativa, buscou-se ir além desse resultado e verificar, a nível do indivíduo, se existe e qual é a diferença na percepção do cooperado acerca do desempenho socioeconômico conforme o(s) papel(is) que ele assume.

Nesse sentido, primeiro, classificou-se os cooperados de acordo com os seguintes critérios:

- se a variável VT1.F1 maior ou igual à $8(80 \%)$, o cooperado foi classificado como fornecedor $(\mathrm{F})$;

- se a média entre as variáveis VT2.C1 e VT3.C2 maior ou igual à 8 (80\%), o cooperado foi classificado como cliente (C);

- $\quad$ se a média entre as variáveis P2, P3 e P4 maior ou igual à 8 (80\%), o cooperado foi classificado como proprietário $(\mathrm{P})$.

Após identificar os papéis que cada cooperado assume na sua relação com a cooperativa, agrupou-se os indivíduos da seguinte maneira:

- grupo $1=\in \mathrm{F} \in \mathrm{C} \in \mathrm{P}(\mathrm{n}=72)$, cooperados que assumem os papéis de fornecedor, cliente e proprietário;

- grupo 2 = $\in \mathrm{F} \in \mathrm{C} \notin \mathrm{P}(\mathrm{n}=49)$ = cooperados que assumem os papéis de fornecedor e cliente e não assumem o papel de proprietário;

- grupo $3=\in \mathrm{F} \notin \mathrm{C} \notin \mathrm{P}(\mathrm{n}=12)$ = cooperados que assumem o papel de fornecedor e não assumem os papéis de cliente e proprietário;

- grupo $4=\notin F \notin C \in P(n=15)=$ cooperados que não assumem os papéis de cliente e fornecedor, mas assumem o papel de proprietário;

- grupo $5=\notin \mathrm{F} \notin \mathrm{C} \notin \mathrm{P}(\mathrm{n}=46)=$ cooperados que não assumem os papéis de fornecedor, cliente e proprietário; e,

- grupo $6=$ Outros $=\in F \notin C \in P(n=8), \notin F \in C \in P \quad(n=3), \notin F \in C \notin P \quad(n=5)=$ demais cooperados que, no grupo $\in \mathrm{F} \notin \mathrm{C} \in \mathrm{P}$ assumem os papéis de fornecedor e proprietário, no grupo $\notin F \in C \in P$ assumem os papéis de cliente e proprietário e no grupo $\notin F \in C \notin P$ assumem apenas o papel de cliente.

Para verificar se há diferença nas respostas entre os seis grupos utilizou-se o teste nãoparamétrico Kruskal-Wallis, no software SPSS. A Tabela 20 apresenta os resultados do teste estatístico: 
Tabela 20 - Teste de diferenças Kruskal-Wallis para 6 grupos

\begin{tabular}{lccccccccc}
\hline & DES1 & DES2 & DES3 & DES4 & DES5 & DES6 & DES7 & DES8 & DES9 \\
\hline Chi-square & 13.432 & 18.635 & 21.487 & 20.464 & 17.753 & 24.576 & 35.005 & 41.966 & 27.726 \\
Graus de liberdade & 5 & 5 & 5 & 5 & 5 & 5 & 5 & 5 & 5 \\
Valor-p $(\mathrm{p}<0,0033)$ & .020 & .002 & .001 & .001 & .003 & .000 & .000 & .000 & .000 \\
\hline Nota 1: Como a comparação é entre 6 grupos, há 15 combinações, logo é preciso fazer a correção de \\
Bonferroni, na qual $<<0,05 / 15=\mathrm{p}<0,0033$. \\
Fonte: Dados da pesquisa $(2020)$
\end{tabular}

Os resultados apontam que há uma diferença significativa entre as respostas dos seis grupos em 8 indicadores do constructo de Desempenho Socioeconômico Percebido. Para saber em quais grupos está a diferença, especificamente, utilizou-se a comparação par-a-par no software SPSS. A comparação par-a-par compara as diferenças de resposta de cada item (questão do questionário) entre todos os grupos, fazendo combinações de dois grupos por vez. Desta forma, verificou-se que as diferenças estão entre os grupos 5 e 1,5 e 2 , e 5 e 6 (o resultado completo está no Anexo B).

A partir destes resultados, realizou-se o teste não-paramétrico Mann-Whitney para cada par com diferença estatisticamente significativa: grupo 1 versus grupo 5, grupo 2 versus grupo 5 e grupo 5 versus grupo 6. A Tabela 21 apresenta os resultados da comparação entre os grupos 1 e 5 .

Tabela 21 - Teste de diferença entre Grupo 1 e 5 (continua)

\begin{tabular}{lrrrrrrrrr}
\hline GRUPO 1 = $\in \mathbf{F} \in \mathbf{C} \in \mathbf{P}$ & DES1 & DES2 & DES3 & DES4 & DES5 & DES6 & DES7 & DES8 & DES9 \\
\hline Média & 7.67 & 7.24 & 8.68 & 7.90 & 7.21 & 8.83 & 8.80 & 7.96 & 8.90 \\
Moda & 8 & 8 & 10 & 8 & 8 & 10 & 9 & 8 & 10 \\
Mediana & 8 & 8 & 9 & 8 & 8 & 9 & 9 & 8 & 9 \\
Desvio-Padrão & 1.59 & 1.72 & 1.40 & 1.89 & 2.33 & 1.29 & 1.33 & 1.69 & 1.04 \\
$\mathrm{~N}$ & 72 & 71 & 71 & 72 & 71 & 72 & 71 & 72 & 72 \\
Mean Rank & 66.44 & 67.25 & 68.42 & 69.15 & 67.65 & 46 & 71.76 & 74.06 & 71.56 \\
\hline GRUPO 5 = $\notin \mathbf{F} \notin \mathbf{C} \notin \mathbf{P}$ & & & & & & & & & \\
Média & 6.67 & 5.83 & 7.35 & 6.39 & 5.83 & 7.48 & 6.98 & 5.48 & 6.54 \\
Moda & 7 & 8 & 8 & 7 & 8 & 9 & 8 & 7 & 9 \\
Mediana & 7 & 6 & 8 & 7 & 6 & 8 & 8 & 6 & 7 \\
Desvio-Padrão & 2.16 & 2.26 & 1.97 & 2.24 & 2.19 & 1.79 & 2.29 & 2.37 & 2.88 \\
$\mathrm{~N}$ & 46 & 46 & 46 & 46 & 46 & 46 & 46 & 46 & 46 \\
Mean Rank & 48.63 & 46.26 & 44.47 & 44.40 & 45.65 & 43 & 39.30 & 36.72 & 40.63 \\
\hline Diferença de média & 0.99 & 1.41 & 1.33 & 1.51 & 1.39 & 1.36 & 1.82 & 2.48 & 2.36 \\
\hline Diferença de moda & 1 & 0 & 2 & 1 & 0 & 1 & 1 & 1 & 1 \\
\hline Diferença de medianas & 1 & 2 & 1 & 1 & 2 & 1 & 1 & 2 & 2
\end{tabular}


Tabela 21 - Teste de diferença entre Grupo 1 e 5

(conclusão)

\begin{tabular}{lrrrrrrrrr}
\hline & DES1 & \multirow{2}{*}{ DES2 } & DES3 & DES4 & \multirow{2}{*}{ DES5 } & DES6 & \multirow{2}{*}{ DES7 } & \multirow{2}{*}{ DES8 } & \multirow{2}{*}{ DES9 } \\
\hline Mann-Whitney U & 1156.0 & 1047.0 & 964.5 & 961.5 & 1019.0 & 892.0 & 727.0 & 608.0 & 788.0 \\
Wilcoxon W & 2237.0 & 2128.0 & 2045.5 & 2042.5 & 2100.0 & 1973.0 & 1808.0 & 1689.0 & 1869.0 \\
Z & -2.8 & -3.3 & -3.8 & -3.9 & -3.5 & -4.3 & -5.2 & -5.9 & -4.9 \\
Valor-p (p<0,0033) & .005 & .001 & .000 & .000 & .001 & .000 & .000 & .000 & .000 \\
\hline
\end{tabular}

Nota 1: Como a comparação é entre 6 grupos, há 15 combinações, logo é preciso fazer a correção de Bonferroni, na qual $\mathrm{p}<0,05 / 15=\mathrm{p}<0,0033$

Fonte: Dados da Pesquisa (2020)

No grupo 1 estão aqueles que assumem os 3 papéis na cooperativa (proprietário, fornecedor e cliente), no grupo 5 estão aqueles que não assumem nenhum dos papéis. Pela Tabela 21, nota-se que há uma diferença significativa na percepção do desempenho socioeconômico entre os dois grupos em 8 itens. Os cooperados que assumem os três papéis na cooperativa demostram maior satisfação com o desempenho da cooperativa do que aqueles que não assumem nenhum papel. O único item que não apresenta diferença na percepção entre esses dois grupos refere-se ao preço pago pela cooperativa pela produção agrícola do cooperado (DES 1).

Na Tabela 22 evidencia-se os resultados da comparação entre os grupos 5 e 2. No grupo 2 estão aqueles cooperados que desempenham o papel de usuário (fornecedor e cliente) e no grupo 5 aqueles que não assumem nenhum dos papéis. Os cooperados que assumem o papel de cliente e fornecedor apresentam satisfação maior em todos os itens, mas as diferenças estatisticamente significativas estão em 6 itens. Estes itens referem-se aos serviços (assistência técnica-DES3, qualidade de armazenamento do grão-DES6, eventos sociais e educacionais-DES7), às sobras distribuídas (DES4) e à satisfação geral (DES8 e DES9). Não há diferença entre aqueles itens relacionados ao preço (produção-DES1, insumos-DES2 e de armazenagem do grão-DES5). Embora o preço seja um aspecto relacionado aos atributos do cooperado como usuário, ele não diferencia a satisfação entre os cooperados do grupo 2 (usuário) e do grupo 5 (nenhum papel). Isto pode indicar que os cooperados do grupo 2 compram e vendem com a cooperativa por que consideram outros atributos no momento da negociação. 
Tabela 22 - Teste de diferença entre Grupo 2 e 5

\begin{tabular}{lrrrrrrrrr}
\hline GRUPO 2 $=\in \mathbf{F} \in \mathbf{C} \notin \mathbf{P}$ & DES1 & DES2 & DES3 & DES4 & DES5 & DES6 & DES7 & DES8 & DES9 \\
\hline Média & 7.33 & 6.76 & 8.51 & 7.94 & 7.20 & 8.80 & 8.67 & 7.20 & 8.67 \\
Moda & 8 & 8 & 10 & 9 & 8 & 9 & 10 & 8 & 9 \\
Mediana & 8 & 7 & 9 & 8 & 7 & 9 & 9 & 8 & 9 \\
Desvio-Padrão & 1.36 & 1.56 & 1.54 & 1.61 & 1.87 & 1.12 & 1.43 & 1.86 & 1.20 \\
$\mathrm{~N}$ & 49 & 49 & 49 & 49 & 49 & 58 & 49 & 49 & 49 \\
Mean Rank & 52.13 & 53.17 & 56.35 & 57.53 & 55.85 & 37 & 59.24 & 58.79 & 58.50 \\
\hline GRUPO 5 = $\notin \mathbf{F} \notin \mathbf{C} \notin \mathbf{P}$ & & & & & & & & & \\
Média & 6.67 & 5.83 & 7.35 & 6.39 & 5.83 & 7.48 & 6.98 & 5.48 & 6.54 \\
Moda & 7 & 8 & 8 & 7 & 8 & 9 & 8 & 7 & 9 \\
Mediana & 7 & 6 & 8 & 7 & 6 & 8 & 8 & 6 & 7 \\
Desvio-Padrão & 2.16 & 2.26 & 1.97 & 2.24 & 2.19 & 1.79 & 2.29 & 2.37 & 2.88 \\
N & 46 & 46 & 46 & 46 & 46 & 46 & 46 & 46 & 46 \\
Mean Rank & 43.60 & 42.49 & 39.11 & 37.85 & 39.64 & 36.85 & 36.02 & 36.51 & 36.82 \\
\hline Diferença de média & 0.65 & 0.93 & 1.16 & 1.55 & 1.38 & 1.32 & 1.70 & 1.73 & 2.13 \\
\hline Diferença de moda & 1 & 0 & 2 & 2 & 0 & 0 & 2 & 1 & 0 \\
\hline Diferença de medianas & 1 & 1 & 1 & 1 & 1 & 1 & 1 & 2 & 2 \\
\hline Mann-Whitney U & 924.5 & 873.5 & 718.0 & 660.0 & 742.5 & 614.0 & 576.0 & 598.5 & 612.5 \\
Wilcoxon W & 2005.5 & 1954.5 & 1799.0 & 1741.0 & 1823.5 & 1695.0 & 1657.0 & 1679.5 & 1693.5 \\
Z & -1.6 & -1.9 & -3.1 & -3.5 & -2.9 & -3.9 & -4.2 & -4.0 & -3.9 \\
Valor-p (p<0,0033) & .118 & .054 & .002 & .000 & .004 & .000 & .000 & .000 & .000 \\
\hline
\end{tabular}

Nota 1: Como a comparação é entre 6 grupos, há 15 combinações, logo é preciso fazer a correção de Bonferroni, na qual $\mathrm{p}<0,05 / 15=\mathrm{p}<0,0033$

Fonte: Dados da pesquisa (2020)

Por fim, a Tabela 23 mostra os resultados para a comparação entre os grupos 5 e 6 . Observa-se que aqueles cooperados que estão no Grupo 6 (desempenham pelo menos um papel na cooperativa) apresentam um grau maior de satisfação em relação ao desempenho socioeconômico percebido do que aqueles que estão no Grupo 5 (não assumem nenhum papel). Essa diferença é estatisticamente significativa nos itens DES7 e DES8. O item DES7 refere-se aos eventos e programas educacionais e sociais e o DES8 refere-se ao quanto o cooperado concorda que a cooperativa contribui com o aumento da sua renda familiar. Portanto, o índice de satisfação é maior entre aqueles cooperados que mantém pelo menos um tipo de relação com a cooperativa do que aqueles que não mantém nenhuma relação. 
Tabela 23 - Teste de diferença entre Grupo 5 e 6

\begin{tabular}{|c|c|c|c|c|c|c|c|c|c|}
\hline GRUPO 6 = outros & DES1 & DES2 & DES3 & DES4 & DES5 & DES6 & DES7 & DES8 & DES9 \\
\hline Média & 7.06 & 6.44 & 8.44 & 7.56 & 6.50 & 8.75 & 8.88 & 7.88 & 8.69 \\
\hline Moda & 7 & 6 & 9 & 10 & 5 & 9 & 10 & 10 & 10 \\
\hline Mediana & 7 & 6.5 & 9 & 7 & 6.5 & 9 & 9.5 & 8 & 9 \\
\hline Desvio-Padrão & 1.69 & 2.25 & 1.59 & 1.93 & 2.56 & 1.24 & 1.54 & 2.00 & 1.40 \\
\hline $\mathrm{N}$ & 16 & 16 & 16 & 16 & 16 & 16 & 16 & 16 & 16 \\
\hline Mean Rank & 32.41 & 34.81 & 39.69 & 37.75 & 34.44 & 41.72 & 44.47 & 44.91 & 42.13 \\
\hline \multicolumn{10}{|l|}{ GRUPO $5=\notin F \notin C \notin P$} \\
\hline Média & 6.67 & 5.83 & 7.35 & 6.39 & 5.83 & 7.48 & 6.98 & 5.48 & 6.54 \\
\hline Moda & 7 & 8 & 8 & 7 & 8 & 9 & 8 & 7 & 9 \\
\hline Mediana & 7 & 6 & 8 & 7 & 6 & 8 & 8 & 6 & 7 \\
\hline Desvio-Padrão & 2.16 & 2.26 & 1.97 & 2.24 & 2.19 & 1.79 & 2.29 & 2.37 & 2.88 \\
\hline $\mathrm{N}$ & 46 & 46 & 46 & 46 & 46 & 46 & 46 & 46 & 46 \\
\hline Mean Rank & 31.18 & 30.35 & 28.65 & 29.33 & 30.48 & 27.95 & 26.99 & 26.84 & 27.80 \\
\hline Diferença de média & 0.39 & 0.61 & 1.09 & 1.17 & 0.67 & 1.27 & 1.90 & 2.40 & 2.14 \\
\hline Diferença de moda & 0.00 & -2.00 & 1.00 & 3.00 & -3.00 & 0.00 & 2.00 & 3.00 & 1.00 \\
\hline Difere & 0 & 0.5 & 1 & 0 & 0.5 & 1 & 1.5 & 2 & 2 \\
\hline Mann-Whitney U & 353.5 & 315.0 & 237.0 & 268.0 & 321.0 & 204.5 & 160.5 & 153.5 & 198.0 \\
\hline Wilcoxon W & 1434.5 & 1396.0 & 1318.0 & 1349.0 & 1402.0 & 1285.5 & 1241.5 & 1234.5 & 1279.0 \\
\hline $\mathrm{Z}$ & -.2 & -.9 & -2.2 & -1.6 & -.8 & -2.7 & -3.4 & -3.5 & -2.8 \\
\hline Valor-p $(\mathrm{p}<0,0033)$ & .811 & .388 & .031 & .104 & .444 & .007 & .001 & .000 & .006 \\
\hline
\end{tabular}

Nota 1: Como a comparação é entre 6 grupos, há 15 combinações, logo é preciso fazer a correção de Bonferroni, na qual $\mathrm{p}<0,05 / 15=\mathrm{p}<0,0033$.

Fonte: Dados da pesquisa (2020)

Em síntese, os resultados do teste de comparação mostram que há diferença na percepção dos indivíduos a depender do papel que ele assume na relação contratual. Desta forma, o teste confirma dois achados da análise do modelo estrutural. Primeiro, as principais diferenças nas respostas ocorreram entre aquele grupo que não mantém nenhuma relação com a cooperativa (Grupo 5) e aqueles que mantém, pelo menos, um tipo de relação (Grupos 1, 2 e 6). A maioria das diferenças estatisticamente significativas ( 8 dos 9 itens) está entre o grupo que mantém as duas relações (Grupo 1 = usuário e proprietário) e o grupo daqueles que não mantém nenhuma relação com a cooperativa (Grupo 5). Esse resultado corrobora com o achado de que quanto maior a frequência com que o cooperado mantém relações com a cooperativa, seja de usuário ou proprietário, melhor é a sua satisfação com o desempenho socioeconômico dela.

Segundo, na comparação entre o grupo que mantém relação de usuário (Grupo 2 = fornecedor e cliente) e o grupo que não mantém nenhum tipo de relação (Grupo 5), 6 dos 9 itens do constructo de desempenho socioeconômico percebido apresentam diferença 
estatisticamente significativa. E, na comparação entre o grupo que mantém relação de proprietário (Grupo 4) e o Grupo 5 nenhum dos itens apresenta diferença estatisticamente significativa. Tais resultados confirmam que se o cooperado mantém relações como usuário (maior volume de transação como usuário) o efeito total sob o desempenho socioeconômico percebido é maior do que se ele mantém relações como proprietário (intensidade da participação como proprietário). 


\section{CONSIDERAÇÕES FINAIS}

A teoria dos custos de transação pressupõe que quanto mais frequente são as transações, melhor é o desempenho da relação contratual. No caso das cooperativas agropecuárias, estas transações ocorrem conforme os papéis que os cooperados assumem na relação contratual: proprietário e/ou usuário. Neste sentido, este estudo teve como objetivo explicar como os papéis assumidos pelo cooperado (usuário e proprietário) relacionam-se com a comunicação efetiva, confiança, comprometimento e a percepção sobre o desempenho socioeconômico da cooperativa agropecuária. Para atingir o objetivo foi proposto um modelo de equações estruturais relacionando o comportamento do cooperado como usuário (volume de transação como usuário) e proprietário (intensidade da participação como proprietário), com a comunicação efetiva, confiança, comprometimento e desempenho socioeconômico percebido. Os dados foram coletados a partir de um questionário aplicado à 210 cooperados de uma cooperativa agropecuária brasileira.

Os principais resultados contribuem com a literatura ao trazer evidências empíricas sobre a relação entre os papéis assumidos pelo cooperado, seu comportamento e o desempenho socioeconômico percebido por ele. Primeiro, encontrou-se que a comunicação efetiva influencia positivamente a confiança e o comprometimento, os quais influenciam positivamente o comportamento dos cooperados como usuário e proprietário, e este influencia positivamente a percepção deles acerca do desempenho socioeconômico. Este resultado confirma todas as hipóteses de pesquisa ( $\left.\mathrm{H} 1_{\mathrm{a}}, \mathrm{H} 1_{\mathrm{b}}, \mathrm{H} 2_{\mathrm{a}}, \mathrm{H} 3_{\mathrm{a}}, \mathrm{H} 3_{\mathrm{b}}, \mathrm{H} 3_{\mathrm{c}}, \mathrm{H} 4_{\mathrm{a}}, \mathrm{H} 4_{\mathrm{b}}, \mathrm{H} 5_{\mathrm{a}}, \mathrm{H} 5_{\mathrm{b}}\right)$.

Estudos anteriores como os de Hansen et al. (2002), Graca e Arnaldo (2016) e Susanty et al. (2017) já traziam evidências empíricas de que a confiança e o comprometimento estavam relacionados positivamente com o desempenho da cooperativa, pois reduzem o comportamento oportunista. Indo além, os resultados deste estudo ampliam as evidências empíricas sobre esse processo, ao incluir as variáveis referente ao comportamento dos cooperados como usuário e proprietário, a qual é considerada uma proxy para o comportamento oportunista. Argumenta-se que quanto mais o cooperado manter relações como usuário e proprietário menor é o seu comportamento oportunista. Desta forma, os resultados deste estudo demonstram que a confiança e o comprometimento reduzem o comportamento oportunista, por que estimulam os cooperados a assumirem os seus papéis como usuários e proprietários da cooperativa e, este comportamento contribui para a avaliação positiva do desempenho socioeconômico. 
Segundo, os resultados da análise do mapa importância-desempenho (IPMA) indicam que o comportamento do cooperado como usuário apresenta uma influência positiva maior sob o desempenho socioeconômico percebido do que o comportamento dele como proprietário. Quando estudaram gestores de cooperativas australianas, Limnios et al. (2018) concluíram que eles consideram tanto o papel de usuário quanto de proprietário nas estratégias para melhorar o engajamento e o comprometimento dos cooperados. Já os resultados do presente estudo apontam que, quando se trata da percepção do desempenho socioeconômico, a dimensão de usuário é mais relevante do que a de proprietário.

Para a prática o estudo contribui ao informar para a gestão como os cooperados se comportam na sua relação com a cooperativa. O entendimento de como a pluralidade de papéis do cooperado influencia o seu comportamento e o desempenho percebido por ele auxiliam a gestão a atuar de maneira mais efetiva nas ações que envolvem o cooperado. Por exemplo, ao considerar que a dimensão de usuário é mais relevante na percepção do desempenho socioeconômico, ações que visem a melhoria da assistência técnica e preço dos insumos e da produção devem ser priorizadas pela gestão. No entanto, salienta-se que estes aspectos podem mudar ao longo do tempo, uma vez que o comportamento dos indivíduos é mutável.

Embora esta pesquisa traga evidências sobre o comportamento dos cooperados como usuário e proprietário da cooperativa, há algumas limitações que podem ser melhoradas por pesquisas futuras. Primeiro, os resultados não são generalizáveis para todas as cooperativas, pois analisou-se apenas uma num período do tempo. No entanto, o somatório com outros estudos já realizados contribui para o avanço das relações analisadas. Além disso, utilizou-se o questionário e a modelagem de equações estruturais para mensurar e identificar o comportamento dos cooperados. Apesar de ser considerada uma técnica adequada para modelos complexos, ela não permite um estudo aprofundado do fenômeno. Por isso, sugere-se que pesquisas futuras utilizem técnicas e análises qualitativas, como a entrevista e análise do discurso, para investigar com mais detalhes a dinâmica dos papéis do cooperado na cooperativa. 


\section{REFERÊNCIAS}

Alho, E. (2015). Farmers' self-reported value of cooperative membership: evidence from heterogeneous business and organization structures. Agricultural and Food Economics, 3(1). https://doi.org/10.1186/s40100-015-0041-6

Arcas-Lario, N., Martín-Ugedo, J. F., \& Mínguez-Verac, A. (2014). Farmers' satisfaction with fresh fruit and vegetable marketing spanish cooperatives: An explanation from agency theory. International Food and Agribusiness Management Review, 17(1), 127146.

Bachmann, R., \& Inkpen, A. C. (2011). Understanding institutional-based trust building processes in inter-organizational relationships. Organization Studies, 32(2), 281-301. https://doi.org/10.1177/0170840610397477

Baker, G., Gibbons, R., \& Murphy, K. J. (2002). Relational Contracts and the Theory of the Firm. The Quarterly Journal of Economic, 117(1), 39-84.

Benos, T., Kalogeras, N., Verhees, F. J. H. M., Sergaki, P., \& Pennings, J. M. E. (2016). Cooperatives' Organizational Restructuring, Strategic Attributes, and Performance: The Case of Agribusiness Cooperatives in Greece. Agribusiness, 32(1), 127-150. https://doi.org/10.1002/agr

Benos, T., Kalogeras, N., Wetzels, M., Ruyter, K. De, \& Pennings, J. M. E. (2018). Harnessing a ' Currency Matrix ' for Performance Measurement in Cooperatives: A Multi-Phased Study. Sustainability (Switzerland), 10(12), 1-40. https://doi.org/10.3390/su10124536

Bhuyan, S. (2007). The "people" factor in cooperatives: An analysis of members' attitudes and behavior. Canadian Journal of Agricultural Economics, 55(3), 275-298. https://doi.org/10.1111/j.1744-7976.2007.00092.x

Bialoskorski Neto, S. (2005). Culture and relational contracts in Brazil's agribusiness cooperatives. XXI International Co-operatives Research Conference on The Contribution of Co-operatives to Community Culture (Vol. 10). Ireland.

Bialoskorski Neto, S. (2006). Member participation and Relational Contracts in Agribusiness Co-operatives in Brazil. International Journal of Co-Operative Management, 3(1), 20 33.

Bialoskorski Neto, S. (2012). Economia e Gestão de Organizações Cooperativas (2a). São Paulo: Atlas.

Bido, D. D. S., \& Silva, D. da. (2019). SmartPLS 3: especificação, estimação, avaliação e relato. Administração: Ensino e Pesquisa, 20(2), 488-536. https://doi.org/10.13058/raep.2019.v20n2.1545

Bijman, J. (2018). Exploring the sustainability of the cooperative model in dairy: The case of the Netherlands. Sustainability (Switzerland), 10(7). https://doi.org/10.3390/su10072498

Bijman, J., Muradian, R., \& Cechin, A. (2011). Agricultural Cooperatives and Value Chain Coordination. In A. H. J. (Bert) Helmsing \& S. Vellema (Eds.), Value chains, inclusion and endogenous development: Contrasting theories and realities (1st ed., pp. 82-101). London: Routledge Studies in Development Economics. https://doi.org/10.4324/9780203816806

Boniface, B., Gyau, A., Stringer, R., \& Umberger, W. (2010). Building producer loyalty in Malaysia's fresh milk supply chain. Australasian Agribusiness Review, 18(5), 66-84.

Borgström, M. (2013). Effective co-operative governance: A practitioner's perspective. Journal of Co-Operative Organization and Management, 1(1), 49-50. https://doi.org/10.1016/j.jcom.2013.05.001

Brown, J. R., Crosno, J. L., \& Tong, P. Y. (2018). Is the theory of trust and commitment in marketing relationships incomplete? Industrial Marketing Management, (October), 1-15. 
https://doi.org/10.1016/j.indmarman.2018.10.005

Cechin, A., Bijman, J., Pascucci, S., \& Omta, O. (2013). Decomposing the Member Relationship in Agricultural Cooperatives: Implications for Commitment. Agribusiness, 29(1), 39-61. https://doi.org/10.1002/agr.21321

Cechin, A., Bijman, J., Pascucci, S., Zylbersztajn, D., \& Omta, O. (2013a). Drivers of proactives member participation in agricultural cooperatives: Evidence from Brazil. Annals of Public and Cooperative Economics, 84(4), 443-468. https://doi.org/10.1111/apce.12023

Cechin, A., Bijman, J., Pascucci, S., Zylbersztajn, D., \& Omta, O. (2013b). Quality in Cooperatives versus Investor- owned Firms: Evidence from Broiler Production in Paraná, Brazil. Managerial and Decision Economics, 34, 230-243. https://doi.org/10.1002/mde

Chaddad, F. R., \& Cook, M. L. (2004). Understanding new cooperative models: An ownership-control rights typology. Review of Agricultural Economics, 26(3), 348-360. https://doi.org/10.1111/j.1467-9353.2004.00184.x

Chaddad, F. R., \& Iliopoulos, C. (2013). Control Rights, Governance, and the Costs of Ownership in Agricultural Cooperatives. Agribusiness, 29(1), 3-22. https://doi.org/10.1002/agr.21328

Chen, P. Y., Chen, K. Y., \& Wu, L. Y. (2017). The impact of trust and commitment on value creation in asymmetric buyer-seller relationships: the mediation effect of specific asset investments. Journal of Business and Industrial Marketing, 32(3), 457-471. https://doi.org/10.1108/JBIM-09-2014-0171

Chin, W. W. (2010). How to Write Up and Report PLS Analyses. In V. E. Vinzi, W. W. Chin, J. Hensele, \& H. Wang (Eds.), Handbook of Partial Least Squares: Concepts, Methods and Applications (1 ${ }^{\mathrm{a}}$, p. 813). Berlim, Germany.: Springer. https://doi.org/10.1007/9783-540-32827-8

Coase, R. H. (1937). The Nature of the Firm. Economica, 4(16), 386-405. https://doi.org/10.1016/S0039-6109(16)37642-3

Cohen, J. (1988). Statistical Power Analysis for the Behavioral Sciences. (2nd ed.). New York: Psychology Press.

Cook, M. L. (2018). A life cycle explanation of cooperative longevity. Sustainability (Switzerland), 10(5). https://doi.org/10.3390/su10051586

Deng, W., \& Hendrikse, G. W. J. (2015). Managerial vision bias and cooperative governance. European Review of Agricultural Economics, 42(5), 797-828. https://doi.org/10.1093/erae/jbv017

DeVellis, R. F. (2016). Scale development: Theory and applications (4th ed.). Los Angeles: Sage publications.

EXAME. (2018). Melhores \& Maiores 2018. Retrieved from https://exame.abril.com.br/edicoes/melhores-maiores-2018/

Faul, F., Erdfelder, E., Lang, A.-G., \& Buchner, A. (2007). G*Power 3: A flexible statistical power analysis program for the social, behavioral, and biomedical sciences FRANZ. Behavior Research Methods, 39(2), 175-191. https://doi.org/10.1109/ISIT.2013.6620417

Feng, L., Friis, A., \& Nilsson, J. (2016). Social Capital among Members in Grain Marketing Cooperatives of Different Sizes. Agribusiness, 32(1), 113-126. https://doi.org/10.1002/agr

Ferraz, L. Z. T., Rezende, A. J., Lima, J. P. R. de, \& Todeva, E. (2018). Perception of Value Co-Creation Actions in Agricultural Cooperatives. Brazilian Administration Review, 15(3), 1-18.

Figueiredo, V., \& Franco, M. (2018). Factors influencing cooperator satisfaction: A study applied to wine cooperatives in Portugal. Journal of Cleaner Production, 191, 15-25. 
https://doi.org/10.1016/j.jclepro.2018.04.177

Fischer, C. (2013). Trust and communication in European agri-food chains. Supply Chain Management, 18(2), 208-218. https://doi.org/10.1108/13598541311318836

Fornell, C., \& Larcker, D. F. (1981). Evaluating Structural Equation Models with Unobservable Variables and Measurement Error. Journal of Marketing Research, 18(1), 39-50. https://doi.org/10.2307/3151312

Franken, J. R. V., \& Cook, M. L. (2013). Impact of Board structure and process on cooperative performance. In Proceedings of the 2013 Agricultural and Applied Economics Association (AAEA) \& Canadian Agricultural Economics Society (CAES) Joint Annual Meeting. Washington, DC, USA.

Franken, J. R. V., \& Cook, M. L. (2015). Informing Measurement of Cooperative Performance. In J. Windsperger, G. Cliquet, T. Ehrmann, \& G. Hendrike (Eds.), Interfirm Networks: Franchising, Cooperatives and Strategic Alliances (1st ed., pp. 209226). Springer.

Franken, J. R. V., \& Cook, M. L. (2017). A Descriptive Summary of Cooperative Governance and Performance. Journal of Cooperatives, 32, 23-45. https://doi.org/10.1111/00029092.00276

Fulton, M. (1999). Cooperatives and member commitment. Finnish Journal of Business Economics, 4(48), 418-437.

Giagnocavo, C., Galdeano-Gómez, E., \& Pérez-Mesa, J. (2018). Cooperative Longevity and Sustainable Development in a Family Farming System. Sustainability, 10(7), 2198. https://doi.org/10.3390/su10072198

Graca, C. A. M., \& Arnaldo, C. (2016). The role of corporate reputation on co-operants behavior and organizational performance. Journal of Management Development, 35(1), 17-37. https://doi.org/10.1108/JMD-08-2014-0079

Grashuis, J., \& Cook, M. L. (2019). A structural equation model of cooperative member satisfaction and long-term commitment. International Food and Agribusiness Management Review, 1-18. https://doi.org/10.22434/IFAMR2018.0101

Grashuis, J., \& Su, Y. (2018). A Review of the Empirical Literature on Farmer Cooperatives: Performance, Ownership and Governance, Finance, and Member Attitude. Annals of Public and Cooperative Economics, 1-26. https://doi.org/10.1111/apce.12205

Guzmán, C., Santos, F. J., \& Barroso, M. de la O. (2019). Analysing the links between cooperative principles, entrepreneurial orientation and performance. Small Business Economics. https://doi.org/10.1007/s11187-019-00174-5

Hair Jr, J. F., Hult, G. T. M., Ringle, C. M., \& Sarstedt, M. (2014). A primer on partial least squares structural equation modeling (1st ed.). Los Angeles: SAGE Publications.

Hair Jr, J. F., Hult, G. T. M., Ringle, C. M., \& Sarstedt, M. (2016). A primer on Partial Least Squares Structural Equation Model (PLS-SEM) (2nd ed.). Los Angeles: Sage publications.

Hakelius, K., \& Hansson, H. (2016a). Measuring Changes in Farmers' Attitudes to Agricultural Cooperatives: Evidence from Swedish Agriculture 1993-2013. Agribusiness, 32(4), 531-546. https://doi.org/10.1002/agr

Hakelius, K., \& Hansson, H. (2016b). Members' attitudes towards cooperatives and their perception of agency problems. International Food and Agribusiness Management Review, 19(4), 23-36. https://doi.org/10.22434/IFAMR2015.0219

Hansen, M. H., Morrow Jr., J. L., \& Batista, J. C. (2002). The impact of trust on cooperative membership retention, performance, and satisfaction: an exploratory study. International Food and Agribusiness Management Review, 5(1), 41-59. https://doi.org/10.1016/S1096-7508(02)00069-1

Hansmann, H. (1996). The ownership of enterprise. London: Harvard University Press. 
Hendrikse, G. W. J., \& Veerman, C. P. (2003). On The Future of Co-operatives: Talking Stock, Looking Ahead. In G. W. J. HENDRIKSE (Ed.), ERIM REPORT SERIES RESEARCH IN MANAGEMENT (p. 16). Amsterdam. https://doi.org/No. ERS-2004-034ORG

Hernández-Espallardo, M., Arcas-Lario, N., \& Marcos-Matas, G. (2013). Farmers' satisfaction and intention to continue membership in agricultural marketing cooperatives: Neoclassical versus transaction cost considerations. European Review of Agricultural Economics, 40(2), 239-260. https://doi.org/10.1093/erae/jbs024

Höhler, J., \& Kühl, R. (2017). Dimensions of member heterogeneity in cooperatives and their impact on organization - a literature review. Annals of Public and Cooperative Economics, 1-16. https://doi.org/10.1111/apce.12177

Jensen-Auvermann, T., Adams, I., \& Doluschitz, R. (2018). Trust-Factors that have an impact on the interrelations between members and employees in rural cooperatives. Journal of Co-Operative Organization and Management, 6(2), 100-110. https://doi.org/10.1016/j.jcom.2018.09.001

Jia, X., \& Huang, J. (2011). Contractual arrangements between farmer cooperatives and buyers in China. Food Policy, 36(5), 656-666. https://doi.org/10.1016/j.foodpol.2011.06.007

Kalogeras, N., Pennings, J. M. E., van der Lans, I. A., Garcia, P., \& Van Dijk, G. (2009). Understanding Heterogeneous Preferences of Cooperative Members. Agribusiness, 25(1), 90-111. https://doi.org/10.1002/agr

Lauermann, G. J., Moreira, V. R., Souza, A., \& Piccoli, P. G. R. (2018). Do Cooperatives with Better Economic-Financial Indicators also have Better Socioeconomic Performance? VOLUNTAS: International Journal of Voluntary and Nonprofit Organizations, 1-12. https://doi.org/10.1007/s11266-018-0036-5

Liang, Q., Huang, Z., Lu, H., \& Wang, X. (2015). Social Capital,Member Participation, and Cooperative Performance: Evidence from China's Zhejiang. International Food and Agribusiness Management Review, 18(I), 49-77.

Limnios, E. M., Mazzarol, T., Soutar, G. N., \& Siddique, K. H. (2018). The member wears Four Hats: A member identification framework for co-operative enterprises. Journal of Co-Operative Organization and Management, 6(1), 20-33. https://doi.org/10.1016/j.jcom.2018.03.003

Lui, S. S., Wong, Y. yee, \& Liu, W. (2009). Asset specificity roles in interfirm cooperation: Reducing opportunistic behavior or increasing cooperative behavior? Journal of Business Research, 62(11), 1214-1219. https://doi.org/10.1016/j.jbusres.2008.08.003

Martins, G. de A., \& Theóphilo, C. R. (2016). Metodologia da Investigação Científica Para Ciências Sociais Aplicadas (3rd ed.). São Paulo: Atlas.

Mazzarol, T., Simmons, R., \& Limnios, E. M. (2014). A conceptual framework for research into co-operative enterprise. In Research handbook on sustainable co-operative enterprise: Case studies of organisational resilience in the co-operative business model (pp. 22-50). Cheltenham: Edward Elgas.

Ménard, C. (2004). The Economics of Hybrid Organizations. Journal of Institutional and Theoretical Economics JITE, 160(3), 345-376. https://doi.org/10.1628/0932456041960605

Ménard, C. (2018). Organization and governance in the agrifood sector: How can we capture their variety? Agribusiness, 34(1), 142-160. https://doi.org/10.1002/agr.21539

Milgrom, P., \& Roberts, J. (1992). Economics, Organization \& Management. (Prentice-Hall, Ed.). New Jersey: Englewood Cliffs.

Mooi, E., Sarstedt, M., \& Mooi-Reci, I. (2018). Market Research The Process, Data, and Methods Using Stata (1st ed.). Singapore: Springer Texts in Business and Economics. 
https://doi.org/10.1007/978-981-10-5218-7

Morfi, C., Ollila, P., Nilsson, J., Feng, L., \& Karantininis, K. (2014). Motivation Behind Members' Loyalty to Agricultural Cooperatives. In W. Josef, T. Ehrmann, G. Cliquet, \& G. Hendrikse (Eds.), Interfirm Networks: Franchising, Cooperatives and Strategic Alliances (pp. 173-190). London: Spring. https://doi.org/10.1007/978-3-319-10184-2

Morgan, R. M., \& Hunt, S. D. (1984). The Commitment-Trust Theory of Relationship Marketing. Journal of Marketing, 58(3), 20-38. https://doi.org/10.2307/1252308

Munoz, L., \& Mallin, M. (2019). Unethical sales behavior neutralization: the impact of salesperson role variables and moderating effects of role relationship orientation. Journal of Business and Industrial Marketing, 34(1), 62-79. https://doi.org/10.1108/JBIM-102017-0243

Nilsson, J. (1996). The nature of cooperative values and principles: Transaction cost theoretical explanations. Annals of Public and Cooperative Economics, 67(4), 633-653. https://doi.org/10.1111/j.1467-8292.1996.tb01411.x

Nilsson, J. (2001). Organisational principles for co-operative firms. Scandinavian Journal of Management, 17(3), 329-356. https://doi.org/10.1016/S0956-5221(01)00010-0

Nitzl, C., Roldan, J. L., \& Cepeda, G. (2016). Mediation analysis in partial least squares path modeling: helping researchers discuss more sophisticated models. Industrial Management and Data Systems, 116(9), 1849-1864. https://doi.org/10.1108/IMDS-072015-0302

Nunnally, J. C., \& Bernstein, I. H. (1994). Psychometric Theory (3rd ed.). New York: McGraw-Hill.

Östeberg, P., \& Nilsson, J. (2009). Members' perception of their participation in the governance of cooperatives: the key to trust and commitment in Agricultural Cooperatives. Agribusiness, 25(2), 181-197. https://doi.org/10.1002/agr.20200

Pascucci, S., Gardebroek, C., \& Dries, L. (2012). Some like to join, others to deliver: an econometric analysis of farmers relationships with agricultural co-operatives. European Review of Agricultural Economics, 39(1), 51-74. https://doi.org/10.1093/erae/jbr027

Peng, X., Hendrikse, G. W. J., \& Deng, W. (2016). Communication and Innovation in Cooperatives. Journal of the Knowledge Economy, (November 2015). https://doi.org/10.1007/s13132-016-0401-9

Pesämaa, O., Pieper, T., Vinhas da Silva, R., Black, W. C., \& Hair Jr, J. F. (2013). Trust and reciprocity in building inter-personal and inter-organizational commitment in small business co-operatives. Journal of Co-Operative Organization and Management, 1(2), 81-92. https://doi.org/10.1016/j.jcom.2013.10.003

Richard, P. J., Devinney, T. M., Yip, G. S., \& Johnson, G. (2009). Measuring organizational performance: Towards methodological best practice. Journal of Management, 35(3), 718-804. https://doi.org/10.1177/0149206308330560

Ringle, C. M., \& Sarstedt, M. (2016). Gain more insight from your PLS-SEM results: : the importance-performance map analysis. Industrial Management \& Data Systems, 116(9), 1865-1886. https://doi.org/10.1108/imds-10-2015-0449

Ringle, C. M., Silva, D. da, \& Bido, D. D. S. (2014). Structural Equation Modeling with the Smartpls. Revista Brasileira de Marketing, 13(02), 56-73. https://doi.org/10.5585/remark.v13i2.2717

Sisay, D. T., Verhees, F. J. H. M., \& van Trijp, H. C. M. (2017). The influence of market orientation on firm performance and members' livelihood in Ethiopian seed producer cooperatives. Agrekon, 56(4), 366-382. https://doi.org/10.1080/03031853.2017.1409126

Soboh, R., Lansink, A. O., Giesen, G., \& van Dijk, G. (2009). Performance Measurement of the Agricultural Marketing Cooperatives: The Gap between Theory and Practice. Review of Agricultural Economics, 31(3), 446-469. https://doi.org/10.1111/j.1467- 
9353.2009.01448.x

Staatz, J. M. (1987). Recent Developments in the Theory of Agricultural Cooperation. Journal of Agricultural Cooperation, 75-95.

Susanty, A., Bakhtiar, A., Jie, F., \& Muthi, M. (2017). The empirical model of trust, loyalty, and business performance of the dairy milk supply chain: A comparative study. British Food Journal, 119(12), 2765-2787. https://doi.org/10.1108/BFJ-10-2016-0462

Sykuta, M. E., \& Cook, M. L. (2001). A New Institutional Economics Approach to Contracts and Cooperatives. American Journal of Agricultural Economics, 83(5), 1273-1279.

Tadesse, G., \& Kassie, G. T. (2017). Measuring trust and commitment in collective actions Evidence from farmers' marketing organizations in rural Ethiopia. International Journal of Social Economics, 44(7), 980-996. https://doi.org/10.1108/IJSE-09-2015-0253

Tana, W., Mesquita, J. M. C., Gonçalves, C. A., \& Martins, H. C. (2017). Social Networks, Social Capital and Performance: A Study with Brazilian Dairy Cooperatives. Revista de Ciências Da Administração, 19(48), 38-53. https://doi.org/10.5007/21758077.2017v19n48p38

Trechter, D. D., King, R. P., \& Walsh, L. (2002). Using Communications to influence member commitment in cooperatives. Journal of Cooperatives, 0, 1-19.

Valentinov, V., \& Iliopoulos, C. (2013). Economic Theories of Nonprofits and Agricultural Cooperatives Compared: New Perspectives for Nonprofit Scholars. Nonprofit and Voluntary Sector Quarterly, 42(1), 109-126. https://doi.org/10.1177/0899764012436399

Williamson, O. E. (1979). Transaction-Cost Economics: The Governance of Contractual Relations. The Journal of Law and Economics, 22(2), 233-261. https://doi.org/10.1086/466942

Williamson, O. E. (2010a). The New Institutional Economics: Taking Stock, Looking Ahead. Journal of Economic Literature, 38(3), 595-613. https://doi.org/10.1257/jel.38.3.595

Williamson, O. E. (2010b). Transaction Cost Economics: the Natural Progression. American Economic Review, 100(June), 673-690.

Williamson, O. E. (2010c). Transaction Cost Economics: The Origins. Journal of Retailing, 86(3), 227-231. https://doi.org/10.1016/j.jretai.2010.07.006

Wollni, M., \& Fischer, E. (2015). Member deliveries in collective marketing relationships: Evidence from coffee cooperatives in Costa Rica. European Review of Agricultural Economics, 42(2), 287-314. https://doi.org/10.1093/erae/jbu023

Yang, S., \& Chaddad, F. R. (2014). The relationship between Performance and Governance in Agricultural Co-operaties. A structural equation modeling approach. International Journal of Co-Operative Management2, 7(1), 43-57.

Zheng, S., Wang, Z., \& Awokuse, T. O. (2012). Determinants of producers' participation in agricultural cooperatives: Evidence from Northern china. Applied Economic Perspectives and Policy, 34(1), 167-186. https://doi.org/10.1093/aepp/ppr044

Zylbersztajn, D. (2005). Papel dos contratos na coordenação agro-industrial: um olhar além dos mercados. Revista de Economia e Sociologia Rural, 43(3), 385-420. https://doi.org/10.1590/S0103-20032005000300001 


\section{ANEXOS}

\section{ANEXO A - Tabelas com descrição do perfil do cooperado - população}

Tabela - Dez principais culturas cultivadas pelos cooperados

\begin{tabular}{cc}
\hline Cultura & Quantidade de produtores \\
\hline SOJA & 10.258 \\
MILHO SAFRINHA & 8.881 \\
PASTAGEM & 4.031 \\
TRIGO & 1.834 \\
CAFÉ & 1.204 \\
AVEIA & 696 \\
MANDIOCA & 665 \\
MILHO EM GRAOS & 663 \\
LARANJA A GRANEL & 572 \\
CANA DE ACUCAR & 541
\end{tabular}

Fonte: Dados enviados pela cooperativa (2020).

Tabela - Distribuição Latifundiária - por hectares

\begin{tabular}{ccccc}
\hline Classificação & Faixa Inicial & Faixa Final & Quantidade de cooperados & $\%$ \\
\hline Familiar & 0 & 10 & 2.239 & $15,89 \%$ \\
Pequeno & 11 & 50 & 5.799 & $41,17 \%$ \\
Médio & 51 & 100 & 2.272 & $16,13 \%$ \\
Grande & Acima de 100 & 3.777 & $26,81 \%$ \\
& \multicolumn{2}{c}{ Total } & 14.087 & $100,00 \%$ \\
\hline
\end{tabular}

Fonte: Dados enviados pela cooperativa (2020).

Tabela - Cooperados por faixa de Idade

\begin{tabular}{|c|c|c|c|}
\hline Idade Inicial & Idade Final & Quantidade & $\%$ \\
\hline 18 & 25 & 238 & $1,63 \%$ \\
\hline 26 & 35 & 1.120 & $7,67 \%$ \\
\hline 36 & 45 & 1.809 & $12,39 \%$ \\
\hline 46 & 55 & 2.822 & $19,33 \%$ \\
\hline 56 & 65 & 3.646 & $24,98 \%$ \\
\hline 66 & 70 & 1.564 & $10,72 \%$ \\
\hline 71 & 75 & 1.267 & $8,68 \%$ \\
\hline 76 & 129 & 2.130 & $14,59 \%$ \\
\hline \multicolumn{2}{|c|}{ Total } & 14.596 & $100,00 \%$ \\
\hline
\end{tabular}

Fonte: Dados enviados pela cooperativa (2020). 


\section{ANEXO B - Resultado da comparação par-a-par do teste Kruskal-Wallis no SPSS}

\section{DES 2}

\section{Pairwise Comparisons of} Agrupamento 1. \&gt;=8)

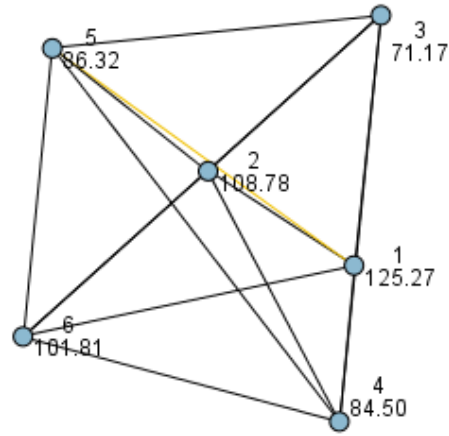

Each node shows the sample average rank of Agrupamento 1. \&gt; $=8$ ).

\begin{tabular}{|l|ccccc|}
\hline $\begin{array}{l}\text { Sample } \\
\text { 1-Sam... }\end{array}$ & $\begin{array}{c}\text { Test } \\
\text { Statistic }\end{array}$ & $\begin{array}{c}\text { Std. } \\
\text { Error }\end{array}$ & $\begin{array}{c}\text { Std. Test } \\
\text { Statistic }\end{array}$ & Sig. & Adj.Sig. \\
\hline $\mathbf{3 4}$ & -13.333 & 23.071 & -.578 & .563 & 1.000 \\
\hline $\mathbf{3 - 5}$ & -15.149 & 19.309 & -.785 & .433 & 1.000 \\
\hline $\mathbf{3 - 6}$ & -30.646 & 22.749 & -1.347 & .178 & 1.000 \\
\hline $\mathbf{3 - 2}$ & 37.609 & 19.187 & 1.960 & .050 & .750 \\
\hline $\mathbf{3 - 1}$ & 54.101 & 18.593 & 2.910 & .004 & .054 \\
\hline $\mathbf{4 - 5}$ & -1.815 & 17.712 & -.102 & .918 & 1.000 \\
\hline $\mathbf{4 - 6}$ & -17.312 & 21.409 & -.809 & .419 & 1.000 \\
\hline $\mathbf{4 - 2}$ & 24.276 & 17.578 & 1.381 & .167 & 1.000 \\
\hline $\mathbf{4 - 1}$ & 40.768 & 16.928 & 2.408 & .016 & .240 \\
\hline $\mathbf{5 - 6}$ & -15.497 & 17.289 & -.896 & .370 & 1.000 \\
\hline $\mathbf{5 - 2}$ & 22.460 & 12.230 & 1.837 & .066 & .994 \\
\hline $\mathbf{5 - 1}$ & 38.952 & 11.275 & 3.455 & .001 & .008 \\
\hline $\mathbf{6 - 2}$ & 6.963 & 17.152 & .406 & .685 & 1.000 \\
\hline $\mathbf{6 - 1}$ & 23.455 & 16.485 & 1.423 & .155 & 1.000 \\
\hline $\mathbf{2 - 1}$ & 16.492 & 11.063 & 1.491 & .136 & 1.000 \\
\hline
\end{tabular}

Each row tests the null hypothesis that the Sample 1 and Sample 2 distributions are the same.

Asymptotic significances (2-sided tests) are displayed. The significance level is .05 .

\section{DES 3}

Pairwise Comparisons of Agrupamento 1. \&gt;=8)

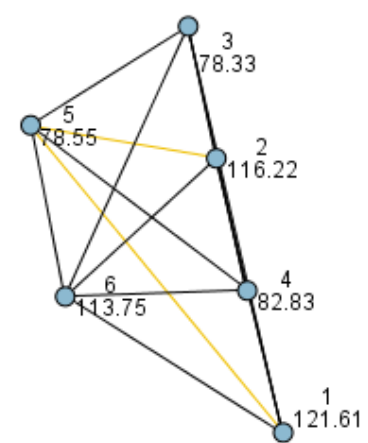

Each node shows the sample average rank of Agrupamento 1. \&gt; $=8$ ).

\begin{tabular}{|l|rrrrr|}
\hline $\begin{array}{l}\text { Sample } \\
\text {-Sam... }\end{array}$ & $\begin{array}{c}\text { Test } \\
\text { Statistic }\end{array}$ & $\begin{array}{c}\text { Std. } \\
\text { Error }\end{array}$ & $\begin{array}{c}\text { Std. Test } \\
\text { Statistic }\end{array}$ & Sig. & Adj.Sig. \\
\hline $\mathbf{3 - 5}$ & -.221 & 19.157 & -.012 & .991 & 1.000 \\
\hline $\mathbf{3 4}$ & -4.500 & 22.889 & -.197 & .844 & 1.000 \\
\hline $\mathbf{3 - 6}$ & -35.417 & 22.569 & -1.569 & .117 & 1.000 \\
\hline $\mathbf{3 - 2}$ & 37.891 & 19.036 & 1.991 & .047 & .698 \\
\hline $\mathbf{3 - 1}$ & 43.272 & 18.446 & 2.346 & .019 & .285 \\
\hline $\mathbf{5 4}$ & 4.279 & 17.572 & .244 & .808 & 1.000 \\
\hline $\mathbf{5 - 6}$ & -35.196 & 17.153 & -2.052 & .040 & .603 \\
\hline $\mathbf{5 - 2}$ & 37.670 & 12.133 & 3.105 & .002 & .029 \\
\hline $\mathbf{5 - 1}$ & 43.051 & 11.186 & 3.849 & .000 & .002 \\
\hline $\mathbf{4 - 6}$ & -30.917 & 21.241 & -1.456 & .146 & 1.000 \\
\hline $\mathbf{4 - 2}$ & 33.391 & 17.440 & 1.915 & .056 & .833 \\
\hline $\mathbf{4 - 1}$ & 38.772 & 16.794 & 2.309 & .021 & .314 \\
\hline $\mathbf{6 - 2}$ & 2.474 & 17.017 & .145 & .884 & 1.000 \\
\hline $\mathbf{6 - 1}$ & 7.856 & 16.355 & .480 & .631 & 1.000 \\
\hline $\mathbf{2 - 1}$ & 5.381 & 10.976 & .490 & .624 & 1.000 \\
\hline
\end{tabular}

Each row tests the null hypothesis that the Sample 1 and Sample 2 distributions are the same.

Asymptotic significances (2-sided tests) are displayed. The significance level is .05 . 


\section{DES 4}

\section{Pairwise Comparisons of} Agrupamento 1. \&gt;=8)

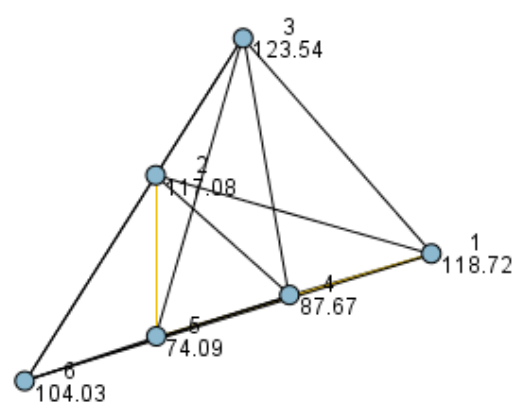

Each node shows the sample average rank of Agrupamento 1. \&gt;=8)

\begin{tabular}{|l|ccccc|}
\hline $\begin{array}{l}\text { Sample } \\
\text { 1-Sam... }\end{array}$ & $\begin{array}{c}\text { Test } \\
\text { Statistic }\end{array}$ & $\begin{array}{c}\text { Std. } \\
\text { Error }\end{array}$ & $\begin{array}{c}\text { Std. Test } \\
\text { Statistic }\end{array}$ & Sig. & Adj.Sig. \\
\hline $\mathbf{5 - 4}$ & 13.580 & 17.791 & .763 & .445 & 1.000 \\
\hline $\mathbf{5 - 6}$ & -29.944 & 17.366 & -1.724 & .085 & 1.000 \\
\hline $\mathbf{5 - 2}$ & 42.995 & 12.284 & 3.500 & .000 & .007 \\
\hline $\mathbf{5 - 1}$ & 44.635 & 11.294 & 3.952 & .000 & .001 \\
\hline $\mathbf{5 - 3}$ & 49.455 & 19.395 & 2.550 & .011 & .162 \\
\hline $\mathbf{4 - 6}$ & -16.365 & 21.504 & -.761 & .447 & 1.000 \\
\hline $\mathbf{4 - 2}$ & 29.415 & 17.656 & 1.666 & .096 & 1.000 \\
\hline $\mathbf{4 - 1}$ & 31.056 & 16.982 & 1.829 & .067 & 1.000 \\
\hline $\mathbf{4 - 3}$ & 35.875 & 23.174 & 1.548 & .122 & 1.000 \\
\hline $\mathbf{6 - 2}$ & 13.050 & 17.229 & .757 & .449 & 1.000 \\
\hline $\mathbf{6 - 1}$ & 14.691 & 16.537 & .888 & .374 & 1.000 \\
\hline $\mathbf{6 - 3}$ & 19.510 & 22.850 & .854 & .393 & 1.000 \\
\hline $\mathbf{2 - 1}$ & 1.641 & 11.081 & .148 & .882 & 1.000 \\
\hline $\mathbf{2 - 3}$ & -6.460 & 19.272 & -.335 & .737 & 1.000 \\
\hline $\mathbf{1 - 3}$ & -4.819 & 18.657 & -.258 & .796 & 1.000 \\
\hline
\end{tabular}

Each row tests the null hypothesis that the Sample 1 and Sample 2 distributions are the same.

Asymptotic significances (2-sided tests) are displayed. The significance level is .05 .

\section{DES 5}

\section{Pairwise Comparisons of Agrupamento 1. \&gt;=8)}

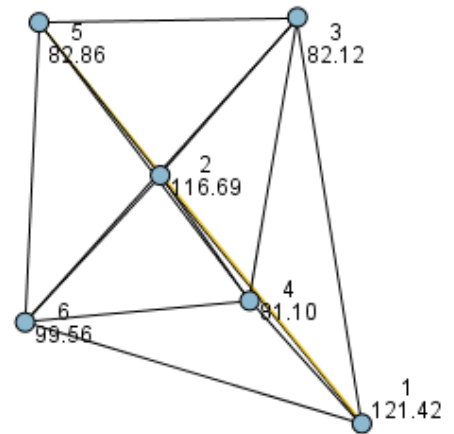

Each node shows the sample average rank of Agrupamento 1. \&gt;=8)

\begin{tabular}{|c|c|c|c|c|c|}
\hline $\begin{array}{l}\text { Sample } \\
\text { 1-Sam.... }\end{array}$ & $\begin{array}{c}\text { Test } \\
\text { Statistic }\end{array}$ & $\begin{array}{l}\text { Std. } \\
\text { Error }\end{array}$ & $\begin{array}{l}\text { Std. Test } \\
\text { Statistic }\end{array}$ & Sig. & Adj.Sig. \\
\hline 4-3 & 1.025 & 23.200 & .044 & .965 & 1.000 \\
\hline $4-5$ & -1.759 & 17.811 & -.099 & .921 & 1.000 \\
\hline $4-6$ & -18.462 & 21.529 & -.858 & .391 & 1.000 \\
\hline $4-2$ & 35.594 & 17.677 & 2.014 & .044 & .661 \\
\hline 4-1 & 40.315 & 17.023 & 2.368 & .018 & .268 \\
\hline $3-5$ & -.734 & 19.418 & -.038 & .970 & 1.000 \\
\hline $3-6$ & -17.438 & 22.876 & -.762 & .446 & 1.000 \\
\hline 3-2 & 34.569 & 19.294 & 1.792 & .073 & 1.000 \\
\hline $3-1$ & 39.290 & 18.697 & 2.101 & .036 & .534 \\
\hline $5-6$ & -16.704 & 17.386 & -.961 & .337 & 1.000 \\
\hline $5-2$ & 33.835 & 12.298 & 2.751 & .006 & .089 \\
\hline $5-1$ & 38.557 & 11.338 & 3.401 & .001 & .010 \\
\hline $6-2$ & 17.131 & 17.248 & .993 & .321 & 1.000 \\
\hline $6-1$ & 21.853 & 16.578 & 1.318 & .187 & 1.000 \\
\hline $2-1$ & 4.722 & 11.125 & .424 & .671 & 1.000 \\
\hline
\end{tabular}

Each row tests the null hypothesis that the Sample 1 and Sample 2 distributions are the same.

Asymptotic significances (2-sided tests) are displayed. The significance level is .05 . 


\section{DES 6}

Pairwise Comparisons of Agrupamento 1. \&gt;=8)

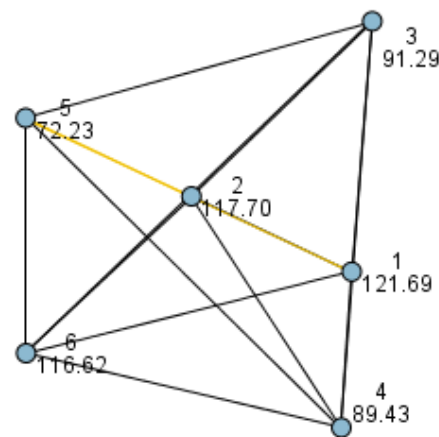

Each node shows the sample average rank of Agrupamento 1. \&gt:=8).

\begin{tabular}{|c|c|c|c|c|c|}
\hline $\begin{array}{l}\text { Sample } \\
\text { 1-Sam... }\end{array}$ & $\begin{array}{c}\text { Test } \\
\text { Statistic }\end{array}$ & $\begin{array}{l}\text { Std. } \\
\text { Error }\end{array}$ & $\begin{array}{l}\text { Std. Test } \\
\text { Statistic }\end{array}$ & Sig. & Adj.Sig. \\
\hline 54 & 17.205 & 17.525 & .982 & .326 & 1.000 \\
\hline $5-3$ & 19.063 & 19.106 & .998 & .318 & 1.000 \\
\hline $5-6$ & -44.397 & 17.107 & -2.595 & .009 & .142 \\
\hline $5-2$ & 45.476 & 12.100 & 3.758 & .000 & .003 \\
\hline $5-1$ & 49.466 & 11.125 & 4.446 & .000 & .000 \\
\hline $4-3$ & 1.858 & 22.828 & .081 & .935 & 1.000 \\
\hline $4-6$ & -27.192 & 21.183 & -1.284 & .199 & 1.000 \\
\hline $4-2$ & 28.271 & 17.392 & 1.625 & .104 & 1.000 \\
\hline $4-1$ & 32.261 & 16.729 & 1.928 & .054 & .807 \\
\hline $3-6$ & -25.333 & 22.508 & -1.126 & .260 & 1.000 \\
\hline $3-2$ & 26.412 & 18.984 & 1.391 & .164 & 1.000 \\
\hline $3-1$ & 30.403 & 18.378 & 1.654 & .098 & 1.000 \\
\hline $6-2$ & 1.079 & 16.971 & .064 & .949 & 1.000 \\
\hline $6-1$ & 5.069 & 16.290 & .311 & .756 & 1.000 \\
\hline $2-1$ & 3.990 & 10.915 & .366 & .715 & 1.000 \\
\hline
\end{tabular}

Each row tests the null hypothesis that the Sample 1 and Sample 2 distributions are the same.

Asymptotic significances (2-sided tests) are displayed. The significance level is .05 .

\section{DES 7}

\section{Pairwise Comparisons of \\ Agrupamento 1. \&gt;=8)}

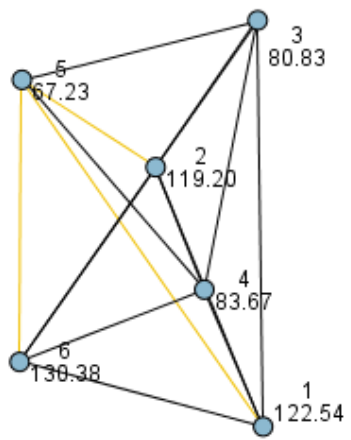

Each node shows the sample average rank of Agrupamento 1. \&gt;=8)

\begin{tabular}{|c|c|c|c|c|c|}
\hline $\begin{array}{l}\text { Sample } \\
\text { 1-Sam... }\end{array}$ & $\begin{array}{c}\text { Test } \\
\text { Statistic }\end{array}$ & $\begin{array}{c}\text { Std. } \\
\text { Error }\end{array}$ & $\begin{array}{l}\text { Std. Test } \\
\text { Statistic }\end{array}$ & Sig. & Adj.Sig. \\
\hline $5-3$ & 13.605 & 19.097 & .712 & .476 & 1.000 \\
\hline 54 & 16.438 & 17.517 & .938 & .348 & 1.000 \\
\hline $5-2$ & 51.976 & 12.095 & 4.297 & .000 & .000 \\
\hline $5-1$ & 55.314 & 11.151 & 4.961 & .000 & .000 \\
\hline $5-6$ & -63.147 & 17.099 & -3.693 & .000 & .003 \\
\hline 34 & -2.833 & 22.818 & -.124 & .901 & 1.000 \\
\hline $3-2$ & 38.371 & 18.976 & 2.022 & .043 & .648 \\
\hline $3-1$ & 41.709 & 18.388 & 2.268 & .023 & .350 \\
\hline $3-6$ & -49.542 & 22.498 & -2.202 & .028 & .415 \\
\hline $4-2$ & 35.537 & 17.385 & 2.044 & .041 & .614 \\
\hline 4-1 & 38.876 & 16.742 & 2.322 & .020 & .303 \\
\hline $4-6$ & -46.708 & 21.174 & -2.206 & .027 & .411 \\
\hline $2-1$ & 3.338 & 10.942 & .305 & .760 & 1.000 \\
\hline $2-6$ & -11.171 & 16.964 & -.659 & .510 & 1.000 \\
\hline $1-6$ & -7.833 & 16.304 & -.480 & .631 & 1.000 \\
\hline
\end{tabular}

Each row tests the null hypothesis that the Sample 1 and Sample 2 distributions are the same.

Asymptotic significances (2-sided tests) are displayed. The significance level is .05 . 
DES 8

Pairwise Comparisons of Agrupamento 1. \&gt;=8)

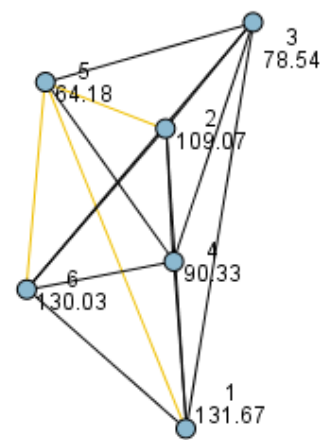

Each node shows the sample average rank of Agrupamento 1. \&gt:=8)

\begin{tabular}{|l|rrrrr|}
\hline $\begin{array}{l}\text { Sample } \\
\text { 1-Sam... }\end{array}$ & $\begin{array}{c}\text { Test } \\
\text { Statistic }\end{array}$ & $\begin{array}{c}\text { Std. } \\
\text { Error }\end{array}$ & $\begin{array}{c}\text { Std. Test } \\
\text { Statistic }\end{array}$ & Sig. & Adj.Sig. \\
\hline $\mathbf{5 - 3}$ & 14.357 & 19.395 & .740 & .459 & 1.000 \\
\hline $\mathbf{5 - 4}$ & 26.149 & 17.790 & 1.470 & .142 & 1.000 \\
\hline $\mathbf{5 - 2}$ & 44.887 & 12.284 & 3.654 & .000 & .004 \\
\hline $\mathbf{5 - 6}$ & -65.846 & 17.366 & -3.792 & .000 & .002 \\
\hline $\mathbf{5 - 1}$ & 67.482 & 11.294 & 5.975 & .000 & .000 \\
\hline $\mathbf{3 - 4}$ & -11.792 & 23.173 & -.509 & .611 & 1.000 \\
\hline $\mathbf{3 - 2}$ & 30.530 & 19.272 & 1.584 & .113 & 1.000 \\
\hline $\mathbf{3 - 6}$ & -51.490 & 22.849 & -2.253 & .024 & .363 \\
\hline $\mathbf{3 - 1}$ & 53.125 & 18.656 & 2.848 & .004 & .066 \\
\hline $\mathbf{4 - 2}$ & 18.738 & 17.656 & 1.061 & .289 & 1.000 \\
\hline $\mathbf{4 - 6}$ & -39.698 & 21.504 & -1.846 & .065 & .973 \\
\hline $\mathbf{4 - 1}$ & 41.333 & 16.982 & 2.434 & .015 & .224 \\
\hline $\mathbf{2 - 6}$ & -20.960 & 17.228 & -1.217 & .224 & 1.000 \\
\hline $\mathbf{2 - 1}$ & 22.595 & 11.081 & 2.039 & .041 & .622 \\
\hline $\mathbf{6 - 1}$ & 1.635 & 16.537 & .099 & .921 & 1.000 \\
\hline & & & & .000 \\
\hline
\end{tabular}

Each row tests the null hypothesis that the Sample 1 and Sample 2 distributions are the same.

Asymptotic significances (2-sided tests) are displayed. The significance level is .05 .

\section{DES 9}

\section{Pairwise Comparisons of} Agrupamento 1. \&gt;=8)

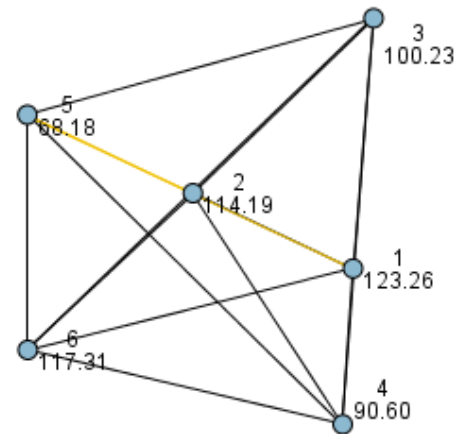

Each node shows the sample average rank of Agrupamento 1. \&gt;=8)

\begin{tabular}{|c|c|c|c|c|c|}
\hline $\begin{array}{l}\text { Sample } \\
\text { 1-Sam... }\end{array}$ & $\begin{array}{c}\text { Test } \\
\text { Statistic }\end{array}$ & $\begin{array}{l}\text { Std. } \\
\text { Error }\end{array}$ & $\begin{array}{l}\text { Std. Test } \\
\text { Statistic }\end{array}$ & Sig. & Adj.Sig. \\
\hline 54 & 22.415 & 17.521 & 1.279 & .201 & 1.000 \\
\hline $5-3$ & 32.042 & 19.777 & 1.620 & .105 & 1.000 \\
\hline $5-2$ & 46.009 & 12.097 & 3.803 & .000 & .002 \\
\hline $5-6$ & -49.128 & 17.103 & -2.873 & .004 & .061 \\
\hline $5-1$ & 55.072 & 11.123 & 4.951 & .000 & .000 \\
\hline $4 \cdot 3$ & 9.627 & 23.391 & .412 & .681 & 1.000 \\
\hline 4-2 & 23.594 & 17.388 & 1.357 & .175 & 1.000 \\
\hline $4-6$ & -26.712 & 21.178 & -1.261 & .207 & 1.000 \\
\hline 4-1 & 32.657 & 16.725 & 1.953 & .051 & .763 \\
\hline $3-2$ & 13.967 & 19.660 & .710 & .477 & 1.000 \\
\hline $3-6$ & -17.085 & 23.080 & -.740 & .459 & 1.000 \\
\hline $3-1$ & 23.030 & 19.076 & 1.207 & .227 & 1.000 \\
\hline $2-6$ & -3.119 & 16.967 & -.184 & .854 & 1.000 \\
\hline $2-1$ & 9.063 & 10.913 & .830 & .406 & 1.000 \\
\hline $6-1$ & 5.944 & 16.286 & .365 & .715 & 1.000 \\
\hline
\end{tabular}

Each row tests the null hypothesis that the Sample 1 and Sample 2 distributions are the same.

Asymptotic significances (2-sided tests) are displayed. The significance level is .05 


\begin{abstract}
APÊNDICES
APÊNDICE A - Protocolo da entrevista realizada com os cooperados

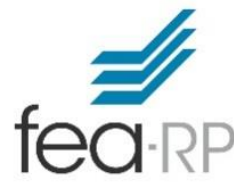

Programa de Pós-Graduação em Controladoria e Contabilidade

UNIVERSIDADE DE SÃO PAULO

\section{PROTOCOLO DE ENTREVISTA}

\section{BLOCO I:}

a. Conte um pouco sobre você, seu nome, idade, cidade onde você nasceu, formação...

b. Fale sobre a sua atual função profissional: Você é produtor rural? De quais culturas?
\end{abstract}

\title{
2. BLOCO II
}

a. Por que você decidiu ser um associado da cooperativa?

b. Atualmente, quais são os principais serviços da cooperativa que você utiliza?

\section{BLOCO III}

a. De que forma você recebe informações (sobre lavoura, safra, desempenho, atualizações tecnológicas, previsão do tempo, etc.) da cooperativa?

b. Quais meios você utiliza para comunicar suas necessidades e desejos para a cooperativa?

\section{BLOCO IV}

a. Na sua opinião, o que significa uma cooperativa com bom desempenho?

b. Para você, quais são as principais vantagens em fazer parte de uma cooperativa?

\section{BLOCO V}

a. Você gostaria de acrescentar mais alguma coisa, que eu possa ter deixado de perguntar, a respeito do seu relacionamento com a cooperativa? 


\section{APÊNDICE B - Quadro com a base teórica do questionário}

\begin{tabular}{|c|c|c|}
\hline Constructo & Definição & Indicadores \\
\hline $\begin{array}{c}\text { Comunicação } \\
\text { efetiva }\end{array}$ & $\begin{array}{l}\text { - Provê informação relevante e de } \\
\text { qualidade (Fischer, 2013; Susanty et al., } \\
\text { 2017) } \\
\text { - Frequência da comunicação é adequada } \\
\text { (Fischer, 2013; Susanty et al., 2017) } \\
\text { - Provê informações da gestão, } \\
\text { assistência técnica e assuntos diversos } \\
\text { (Peng et al., 2016) }\end{array}$ & $\begin{array}{l}\text { COM1. Satisfação com a frequência com que a cooperativa organiza eventos que fornecem } \\
\text { informações técnicas sobre a sua produção agrícola (com base em Fischer (2013) e Susanty et al. } \\
(2017) \text { ). ( } 1 \text { a } 10=\text { muito insatisfeito a muito satisfeito) } \\
\text { COM2. Satisfação com a frequência em que a cooperativa ouve as suas expectativas, reclamações e } \\
\text { sugestões (Fischer, 2013; Susanty et al., 2017). ( } 1 \text { a } 10=\text { muito insatisfeito a muito satisfeito) } \\
\text { COM3. Satisfação com a frequência da prestação de contas (Fischer, 2013; Susanty et al., 2017). (1 a } \\
10=\text { muito insatisfeito a muito satisfeito) } \\
\text { COM4. Clareza e entendimento das informações recebidas (com base em Fischer (2013)). (1 a } 10= \\
\text { muito insatisfeito a muito satisfeito) } \\
\text { COM5. Qualidade das informações sobre o desempenho da cooperativa. (com base em Fischer (2013)). } \\
\text { (1 a } 10=\text { péssima a ótima) } \\
\text { COM6. Qualidade das informações dos serviços e produtos disponíveis na cooperativa (com base em } \\
\text { Fischer (2013) e Susanty et al. (2017)). ( } 1 \text { a } 10=\text { péssima a ótima) } \\
\text { COM7. A facilidade de acesso às informações (com base em Fischer (2013) e Susanty et al. (2017)). (1 } \\
\text { a } 10=\text { péssima a ótima) }\end{array}$ \\
\hline Confiança & $\begin{array}{l}\text { - Evidencia o quanto uma parte acredita } \\
\text { que a outra parte é confiável e íntegra } \\
\text { (Morgan \& Hunt, 1984) } \\
\text { - Quanto os cooperados confiam na } \\
\text { gestão (Hakelius \& Hansson, 2016b; } \\
\text { Östeberg \& Nilsson, 2009) } \\
\text { - Quantos os cooperados confiam nos } \\
\text { demais membros da cooperativa } \\
\text { (Hakelius \& Hansson, 2016b) }\end{array}$ & $\begin{array}{l}\text { CF1. A cooperativa está sempre pronta para me ajudar (com base em Pesämaa et al. (2013) e Susanty } \\
\text { et al. (2017)). ( } 1 \text { a } 10=\text { discordo totalmente a concordo totalmente) } \\
\text { CF2. As decisões tomadas pela gestão da cooperativa (por exemplo, instalar novas unidades e oferecer } \\
\text { novos serviços) demonstram preocupação com o meu bem-estar financeiro. (Hakelius \& Hansson, } \\
2016 \text { b; Östeberg \& Nilsson, 2009; Susanty et al., 2017). (1 a } 10=\text { discordo totalmente a concordo } \\
\text { totalmente) } \\
\text { CF3. A cooperativa sempre cumpre com aquilo que foi acordado em assembleia e está no estatuto. } \\
\text { (Susanty et al., 2017). ( } 1 \text { a } 10=\text { discordo totalmente a concordo totalmente) } \\
\text { CF4. As informações fornecidas pela cooperativa são confiáveis. (Susanty et al., 2017). (1 a } 10= \\
\text { discordo totalmente a concordo totalmente) } \\
\text { CF5. Eu posso confiar nos outros cooperados (Pesämaa et al., 2013). (1 a } 10=\text { discordo totalmente a } \\
\text { concordo totalmente) }\end{array}$ \\
\hline
\end{tabular}




\begin{tabular}{|c|c|c|}
\hline Constructo & Definição & Indicadores \\
\hline Comprometimento & $\begin{array}{l}\text { - Sentimento que existe quando a parte } \\
\text { acredita que a continuidade da relação é } \\
\text { tão importante que justifica o esforço } \\
\text { máximo para mantê-la (Morgan \& Hunt, } \\
\text { 1984) } \\
\text { - Comprometimento com a estratégia de } \\
\text { mercado: atitude positiva em relação a } \\
\text { uma estratégia orientada para o cliente, } \\
\text { com maior coordenação vertical da } \\
\text { transação entre cooperados. } \\
\text { Comprometimento com a ação coletiva: } \\
\text { vontade de fazer um esforço e sacrificar } \\
\text { ganhos econômicos de curto prazo em } \\
\text { prol do sucesso de longo prazo da } \\
\text { cooperativa (Cechin, Bijman, Pascucci, } \\
\& \text { Omta, 2013) }\end{array}$ & $\begin{array}{l}\text { CPT1*. Eu vendo minha produção agrícola para a empresa que oferecer o maior preço.(Cechin, } \\
\text { Bijman, Pascucci, \& Omta, 2013). (1 a } 10=\text { discordo totalmente a concordo totalmente) } \\
\text { CPT2*. Eu compro insumos (fertilizantes, inseticidas, sementes, etc) da empresa que oferecer o menor } \\
\text { preço (Cechin, Bijman, Pascucci, \& Omta, 2013). ( } 1 \text { a } 10=\text { discordo totalmente a concordo totalmente) } \\
\text { CPT3. No futuro, se a Cooperativa precisar, eu comprarei mais quotas-partes (capital integralizado) } \\
\text { (Cechin, Bijman, Pascucci, \& Omta, 2013). ( } 1 \text { a } 10=\text { discordo totalmente a concordo totalmente) } \\
\text { CPT4. Eu me preocupo com o futuro da cooperativa (Cechin, Bijman, Pascucci, \& Omta, 2013). (1 a } \\
10=\text { discordo totalmente a concordo totalmente) } \\
\text { CPT5. O meu comprometimento com as ações da cooperativa é importante para que situação } \\
\text { econômica de todos os cooperados melhore ao longo do tempo. (Cechin, Bijman, Pascucci, \& Omta, } \\
\text { 2013; Östeberg \& Nilsson, 2009). ( } 1 \text { a } 10=\text { discordo totalmente a concordo totalmente) }\end{array}$ \\
\hline $\begin{array}{c}\text { Volume de } \\
\text { transação como } \\
\text { usuário }\end{array}$ & $\begin{array}{l}\text { Usuário (Relação de Mercado) } \\
\text { - Refere-se ao relacionamento de cadeia } \\
\text { de suprimentos que existe entre a } \\
\text { cooperativa e o cooperado. (Limnios et } \\
\text { al., 2018; Nilsson, 2001) }\end{array}$ & $\begin{array}{l}\text { VT1.F1 (Relação de fornecedor) Percentual da produção agrícola do cooperado entregue na } \\
\text { cooperativa, na safra. (0\% a 100\%) } \\
\text { VT2.C1 (Relação de cliente) Percentual de compra de insumos do cooperado na cooperativa, na safra. } \\
\text { (0\% a } 100 \%) \\
\text { VT3.C2 (Relação de cliente) Percentual de assistência técnica utilizada pelo cooperado da cooperativa, } \\
\text { na safra. (0\% a } 100 \%)\end{array}$ \\
\hline $\begin{array}{c}\text { Intensidade da } \\
\text { participação como } \\
\text { proprietário }\end{array}$ & $\begin{array}{l}\text { Proprietário (Relação de Propriedade e } \\
\text { controle): } \\
\text { - Refere-se ao direito de controle do } \\
\text { membro (Limnios et al., 2018; Mazzarol } \\
\text { et al., 2014). } \\
\text { - Surge a partir do momento em que o } \\
\text { membro adquire quotas-partes da } \\
\text { cooperativa (Limnios et al., 2018; } \\
\text { Nilsson, 2001). }\end{array}$ & $\begin{array}{l}\text { P2. Frequência com que o cooperado participa de reuniões e assembleias de prestação de contas e } \\
\text { acompanhamento das estratégias da cooperativa. ( } 1 \text { a } 10=\text { nunca a sempre }) \\
\text { P3 Frequência com que o cooperado vota nas eleições para o Conselho de Administração. (1 a } 10= \\
\text { nunca a sempre) } \\
\text { P4 Frequência com que o cooperado procura saber informações sobre o desempenho da cooperativa. (1 } \\
\text { a } 10=\text { nunca a sempre) } \\
\text { P5 Quantas vezes o cooperado já assumiu cargos em conselhos ou comitês. }(0 \text { a } 10)\end{array}$ \\
\hline
\end{tabular}




\begin{tabular}{|c|c|c|}
\hline Constructo & Definição & Indicadores \\
\hline $\begin{array}{c}\text { Desempenho } \\
\text { socioeconômico } \\
\text { percebido }\end{array}$ & $\begin{array}{l}\text { - Desempenho referente a execução das } \\
\text { relações econômicas e sociais com os } \\
\text { cooperados, considerando crescimento, } \\
\text { desenvolvimento, assistência e satisfação } \\
\text { com os resultados financeiros obtidos } \\
\text { (Lauermann et al., 2018) } \\
\text { - Produtos e serviços recebidos pelos } \\
\text { membros (Cook, 2018; Franken \& Cook, } \\
\text { 2017) } \\
\text { - Satisfazer os objetivos dos membros } \\
\text { (Benos et al., 2016; Hakelius \& } \\
\text { Hansson, 2016b; Yang \& Chaddad, } \\
\text { 2014) }\end{array}$ & $\begin{array}{l}\text { DES1. O preço pago pela cooperativa por sua produção agrícola. (Alho, 2015; Arcas-Lario et al., } \\
\text { 2014). ( } 1 \text { a } 10=\text { muito insatisfeito a muito satisfeito) } \\
\text { DES2. O preço pago por você pelos insumos agrícolas adquiridos na cooperativa. ( } 1 \text { a } 10 \text { = muito } \\
\text { insatisfeito a muito satisfeito) } \\
\text { DES3. Os serviços de assistência técnica oferecidos pela cooperativa (Alho, 2015; Arcas-Lario et al., } \\
\text { 2014). ( } 1 \text { a } 10=\text { muito insatisfeito a muito satisfeito) } \\
\text { DES4. O valor das sobras distribuídas com base nas operações pela cooperativa. (1 a } 10=\text { muito } \\
\text { insatisfeito a muito satisfeito) } \\
\text { DES5. Política de preço para armazenagem do grão da cooperativa. ( } 1 \text { a } 10=\text { muito insatisfeito a muito } \\
\text { satisfeito) } \\
\text { DES6. Qualidade do serviço de armazenamento dos grãos. ( } 1 \text { a } 10=\text { muito insatisfeito a muito } \\
\text { satisfeito) } \\
\text { DES7. Eventos e programas educacionais e sociais oferecidos pela cooperativa. (Feng et al., 2016) (1 a } \\
10=\text { muito insatisfeito a muito satisfeito) } \\
\text { DES8. A minha participação na cooperativa tem proporcionado um aumento na minha renda familiar } \\
\text { (Hansen et al., 2002). ( } 1 \text { a } 10=\text { discordo totalmente a concordo totalmente) } \\
\text { DES9. No geral, eu estou satisfeito com a minha relação com a cooperativa (Arcas-Lario et al., 2014; } \\
\text { Hansen et al., 2002). ( } 1 \text { a } 10=\text { discordo totalmente a concordo totalmente) }\end{array}$ \\
\hline
\end{tabular}

* Itens com escala reversa.

Fonte: Elaborado pelos autores (2020) 


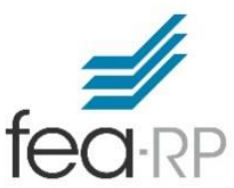

\section{APÊNDICE C - Questionário aplicado aos cooperados}

Programa de Pós-Graduação em Controladoria e Contabilidade

UNIVERSIDADE DE SÃO PAULO

\section{DESEMPENHO SOCIOECONÔMICO DA COOPERATIVA AGROPECUÁRIA}

Prezado(a) cooperado(a),

Para responder as questões a seguir, PENSE NA SUA RELAÇÃO COM A COOPERATIVA, considerando a sua participação ao longo dos anos.

Sua opinião é muito importante para o sucesso da pesquisa, por isso contamos com sua sinceridade nas respostas. Não há resposta certas ou erradas. O tempo estimado de resposta é entre 10 e 15 minutos.

Desde já, agradecemos sua colaboração.

Vanessa Schaefer

vanessaschaefer@usp.br

(51) 99622-9856

Aluna do mestrado em Controladoria e Contabilidade

- FEA-USP/RP
Prof. Dr. Amaury José Rezende

Orientador do projeto de pesquisa

Professor e Coordenador do Programa de Pós-

Graduação em Controladoria e Contabilidade - FEA$\mathrm{USP} / \mathrm{RP}$

MARQUE COM "X" o número (de 1 a 10) que melhor corresponde à sua percepção:

1) Avalie seu GRAU DE SATISFAÇÃO, de 1 a 10, em relação aos seguintes produtos e serviços oferecidos pela Cooperativa:

a) O preço pago pela cooperativa por sua produção agrícola.

b) O preço pago por você pelos insumos agrícolas adquiridos na cooperativa.

c) Os serviços de assistência técnica oferecidos pela cooperativa.

d) $\mathrm{O}$ valor das sobras distribuídas anualmente pela cooperativa.

e) A política de preço adotada pela cooperativa para armazenagem do grão.

f) $\mathrm{O}$ rendimento pago pela cooperativa sobre o valor de seu capital integralizado.

g) A qualidade do serviço para o armazenamento de grãos.

h) Os eventos e programas educacionais e sociais oferecidos pela cooperativa.

\begin{tabular}{|c|c|c|c|c|c|c|c|c|c|}
\hline \multicolumn{2}{|c|}{$\begin{array}{c}\text { Muito } \\
\text { insatisfeito }\end{array}$} & \multicolumn{2}{|c|}{ Insatisfeito } & \multicolumn{2}{|c|}{$\begin{array}{c}\text { Nem } \\
\text { satisfeito, } \\
\text { nem } \\
\text { insatisfeito }\end{array}$} & \multicolumn{2}{|c|}{ Satisfeito } & \multicolumn{3}{|c|}{$\begin{array}{c}\text { Muito } \\
\text { satisfeito }\end{array}$} \\
\hline 1 & 2 & 3 & 4 & 5 & 6 & 7 & 8 & 9 & 10 \\
\hline
\end{tabular}

\begin{tabular}{|l|l|l|l|l|l|l|l|l|l|}
\hline 1 & 2 & 3 & 4 & 5 & 6 & 7 & 8 & 9 & 10 \\
\hline
\end{tabular}

\begin{tabular}{|l|l|l|l|l|l|l|l|l|l|}
1 & 2 & 3 & 4 & 5 & 6 & 7 & 8 & 9 & 10 \\
\hline
\end{tabular}

\begin{tabular}{|l|l|l|l|l|l|l|l|l|l|}
\hline 1 & 2 & 3 & 4 & 5 & 6 & 7 & 8 & 9 & 10 \\
\hline
\end{tabular}

\begin{tabular}{|l|l|l|l|l|l|l|l|l|l|}
\hline 1 & 2 & 3 & 4 & 5 & 6 & 7 & 8 & 9 & 10 \\
\hline
\end{tabular}

\begin{tabular}{|l|l|l|l|l|l|l|l|l|l|}
\hline 1 & 2 & 3 & 4 & 5 & 6 & 7 & 8 & 9 & 10 \\
\hline
\end{tabular}

\begin{tabular}{|l|l|l|l|l|l|l|l|l|l|}
\hline 1 & 2 & 3 & 4 & 5 & 6 & 7 & 8 & 9 & 10 \\
\hline 1 & 2 & 3 & 4 & 5 & 6 & 7 & 8 & 9 & 10 \\
\hline
\end{tabular}

2) Qual (quais) meio (os) de comunicação da Cooperativa você utiliza mensalmente? Mais de uma opção pode ser assinalada.
( ) Site
( ) Whatsapp
( ) Facebook ou Instagram
( ) Outros. Quais?..
( ) TV
( )Aplicativo
( ) Jornal de serviços 


\begin{tabular}{|c|c|c|c|c|c|c|c|c|c|c|}
\hline \multicolumn{11}{|l|}{$\begin{array}{l}\text { 3) De } 1 \text { a 10, avalie a QUALIDADE da informação } \\
\text { fornecida pela cooperativa nos seguintes itens: }\end{array}$} \\
\hline $\begin{array}{l}\text { a) Sobre o desempenho financeiro (por exemplo, } \\
\text { caixa e sobras) da cooperativa. }\end{array}$ & 1 & 2 & 3 & 4 & 5 & 6 & 7 & 8 & 9 & 10 \\
\hline $\begin{array}{l}\text { b) Sobre os serviços e produtos disponíveis na } \\
\text { cooperativa. }\end{array}$ & 1 & 2 & 3 & 4 & 5 & 6 & 7 & 8 & 9 & 10 \\
\hline $\begin{array}{l}\text { c) A facilidade de acesso às informações da } \\
\text { cooperativa. }\end{array}$ & 1 & 2 & 3 & 4 & 5 & 6 & 7 & 8 & 9 & 10 \\
\hline $\begin{array}{l}\text { 4) Avalie seu GRAU DE SATISFAÇÃO, de } 1 \text { a } 10 \text {, } \\
\text { nos seguintes itens: }\end{array}$ & & $\begin{array}{l}\text { ito } \\
\text { feito }\end{array}$ & & eito & & & & & & \\
\hline $\begin{array}{l}\text { a) A frequência com que a cooperativa } \\
\text { organiza eventos, nos quais fornece } \\
\text { informações técnicas (exemplo, dias de campo, } \\
\text { palestras na unidade e Safratec). }\end{array}$ & 1 & 2 & 3 & 4 & 5 & 6 & 7 & 8 & 9 & 10 \\
\hline $\begin{array}{l}\text { b) A frequência com que a cooperativa ouve as } \\
\text { suas expectativas, reclamações e sugestões. }\end{array}$ & 1 & 2 & 3 & 4 & 5 & 6 & 7 & 8 & 9 & 10 \\
\hline $\begin{array}{l}\text { c) A frequência com que a cooperativa realiza } \\
\text { prestação de contas. }\end{array}$ & 1 & 2 & 3 & 4 & 5 & 6 & 7 & 8 & 9 & 10 \\
\hline $\begin{array}{l}\text { d) A clareza e a facilidade de entendimento das } \\
\text { informações recebidas da cooperativa. }\end{array}$ & 1 & 2 & 3 & 4 & 5 & 6 & 7 & 8 & 9 & 10 \\
\hline $\begin{array}{l}\text { 5) Avalie seu GRAU DE CONCORDÂNCIA com } \\
\text { as seguintes afirmativas, com notas de } 1 \text { a } 10 \text { : }\end{array}$ & & rento & & & & & & & $\begin{array}{r}\text { Con } \\
\text { Tota }\end{array}$ & $\begin{array}{r}\text { rdo } \\
\text { iente }\end{array}$ \\
\hline $\begin{array}{l}\text { a) A minha participação na cooperativa tem } \\
\text { proporcionado um aumento na minha renda } \\
\text { familiar. }\end{array}$ & 1 & 2 & 3 & 4 & 5 & 6 & 7 & 8 & 9 & 10 \\
\hline $\begin{array}{l}\text { b) A cooperativa está sempre pronta para me } \\
\text { ajudar. }\end{array}$ & 1 & 2 & 3 & 4 & 5 & 6 & 7 & 8 & 9 & 10 \\
\hline $\begin{array}{l}\text { c) As decisões tomadas pela gestão da cooperativa } \\
\text { (por exemplo, instalar novas unidades e oferecer } \\
\text { novos serviços) demonstram preocupação com o } \\
\text { meu bem-estar financeiro. }\end{array}$ & 1 & 2 & 3 & 4 & 5 & 6 & 7 & 8 & 9 & 10 \\
\hline $\begin{array}{l}\text { d) A cooperativa sempre cumpre com aquilo que } \\
\text { foi acordado em assembleia e está no estatuto. }\end{array}$ & 1 & 2 & 3 & 4 & 5 & 6 & 7 & 8 & 9 & 10 \\
\hline $\begin{array}{l}\text { e) As informações fornecidas pela cooperativa são } \\
\text { confiáveis. }\end{array}$ & 1 & 2 & 3 & 4 & 5 & 6 & 7 & 8 & 9 & 10 \\
\hline f) Eu posso confiar nos outros cooperados. & 1 & 2 & 3 & 4 & 5 & 6 & 7 & 8 & 9 & 10 \\
\hline $\begin{array}{l}\text { g) No geral, eu estou satisfeito com a minha relação } \\
\text { com a cooperativa. }\end{array}$ & 1 & 2 & 3 & 4 & 5 & 6 & 7 & 8 & 9 & 10 \\
\hline
\end{tabular}


6) Considerando o total de sua atividade agrícola, assinale o percentual (\%) de VOLUME de negócios que você realiza com a COOPERATIVA:

\begin{tabular}{l}
$\begin{array}{l}\text { a) Produção agrícola entregue na } \\
\text { COOPERATIVA, na safra: }\end{array}$ \\
\hline
\end{tabular}

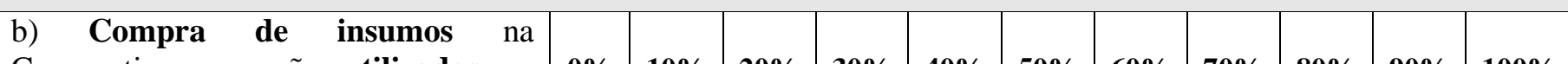
\begin{tabular}{|l|l|l|l|l|l|l|l|l|l|l|l|l|} 
Cooperativa, que são utilizados na & $\mathbf{0 \%}$ & $\mathbf{1 0 \%}$ & $\mathbf{2 0 \%}$ & $\mathbf{3 0 \%}$ & $\mathbf{4 0 \%}$ & $\mathbf{5 0 \%}$ & $\mathbf{6 0 \%}$ & $\mathbf{7 0 \%}$ & $\mathbf{8 0 \%}$ & $\mathbf{9 0 \%}$ & $\mathbf{1 0 0 \%}$ \\
\hline
\end{tabular}

c) Assistência técnica da Cooperativa

utilizada na safra:

\begin{tabular}{|l|l|l|l|l|l|l|l|l|l|l|}
\hline $0 \%$ & $10 \%$ & $20 \%$ & $30 \%$ & $40 \%$ & $50 \%$ & $60 \%$ & $70 \%$ & $\mathbf{8 0} \%$ & $90 \%$ & $100 \%$ \\
\hline
\end{tabular}

7) Avalie o seu GRAU DE CONCORDÂNCIA com as seguintes afirmativas, com notas de 1 a 10 :

\begin{tabular}{|c|c|c|c|c|c|c|c|c|c|}
\hline \multicolumn{2}{|c|}{$\begin{array}{c}\text { Discordo } \\
\text { totalmente }\end{array}$} & \multicolumn{2}{|c|}{ Discordo } & \multicolumn{2}{|c|}{$\begin{array}{c}\text { Não } \\
\text { concordo, } \\
\text { nem } \\
\text { discordo } \\
\end{array}$} & \multicolumn{2}{|c|}{ Concordo } & \multicolumn{2}{|c|}{$\begin{array}{c}\text { Concordo } \\
\text { Totalmente }\end{array}$} \\
\hline 1 & 2 & 3 & 4 & 5 & 6 & 7 & 8 & 9 & 10 \\
\hline
\end{tabular}

a) $\mathrm{Eu}$ vendo a minha produção agrícola para a empresa que oferecer o maior preço.

\begin{tabular}{|l|l|l|l|l|l|l|l|l|l|}
\hline 1 & 2 & 3 & 4 & 5 & 6 & 7 & 8 & 9 & 10 \\
\hline
\end{tabular}

b) Eu compro insumos (fertilizantes, inseticidas, sementes, etc) da empresa que oferecer o menor preço.

c) No futuro, se a cooperativa precisar, eu comprarei mais quotas-partes (capital integralizado).

d) Eu me preocupo com o futuro da cooperativa.

\begin{tabular}{|l|l|l|l|l|l|l|l|l|l|}
1 & 2 & 3 & 4 & 5 & 6 & 7 & 8 & 9 & 10 \\
\hline
\end{tabular}

e) O meu comprometimento com as ações da cooperativa é importante para que a situação econômica de todos os cooperados melhore ao longo do tempo.

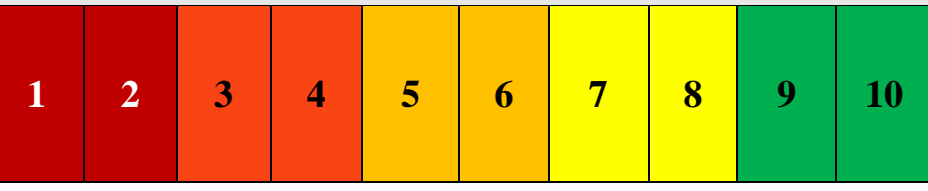

8) Quais tipos de produtos você entrega/vende para a cooperativa? Mais de uma opção pode ser assinalada.
( ) Soja
( ) Milho
( ) Laranja
( ) Canola
( ) Algodão
( ) Café
( ) Trigo
( ) Outros. Quais?
( ) Girassol

9) Avalie a FREQUÊNCIA com que você mantém as seguintes relações com a Cooperativa, com nota de 1 a 10:

a) Utilizo as linhas de crédito da cooperativa.

b) Voto nas eleições para Conselho de Administração e Fiscal.

c) Procuro saber informações sobre assuntos da cooperativa.

d) Frequento as reuniões e assembleias de prestação de contas e acompanhamento das estratégias da cooperativa.

e) Participo de eventos relacionados a informações técnicas (dias de campo, palestras técnicas na unidade, Safratec).

f) Participo de eventos relacionados a esporte, lazer, cuidados com a saúde e educação (Copa, cursos em parceria com Senar, Dia de Vacinação, entre outros).

\begin{tabular}{|c|c|c|c|c|c|c|c|c|c|c|}
\hline \multicolumn{2}{|c|}{ Nunca } & \multicolumn{2}{|c|}{ Raramente } & \multicolumn{2}{|c|}{ Às vezes } & \multicolumn{2}{|c|}{$\begin{array}{c}\text { Quase } \\
\text { sempre }\end{array}$} & \multicolumn{2}{c|}{ Sempre } \\
\hline 1 & 2 & 3 & 4 & 5 & 6 & 7 & 8 & 9 & 10 \\
\hline 1 & 2 & 3 & 4 & 5 & 6 & 7 & 8 & 9 & 10 \\
\hline 1 & 2 & 3 & 4 & 5 & 6 & 7 & 8 & 9 & 10 \\
\hline 1 & 2 & 3 & 4 & 5 & 6 & 7 & 8 & 9 & 10 \\
\hline 1 & 2 & 3 & 4 & 5 & 6 & 7 & 8 & 9 & 10 \\
\hline 1 & 2 & 3 & 4 & 5 & 6 & 7 & 8 & 9 & 10 \\
\hline
\end{tabular}


10) Perfil do respondente:

a) Em qual cidade você reside?

b) Qual é o tamanho da sua propriedade rural?

hectares ou alqueires

c) Qual é a distância da sua propriedade rural a unidade mais próxima da Cooperativa? . $\mathbf{k m}$

d) Qual é a sua idade?
( ) 18 a 30 anos
( ) 31 a 40 anos
( ) 41 a 50 anos
( ) 51 a 50 anos
( ) mais de 60 anos

e) Há quanto tempo você é associado da Cooperativa?
( ) menos de 02 anos
( ) 2 a 5 anos
( ) 6 a 11 anos
( ) 12 a 20 anos
( ) mais de 20 anos

f) Algum outro membro de sua família também é associado da Cooperativa?

( ) Sim. Qual o grau de parentesco? ( $\quad$ Pai ( ) Mãe ( ) Avós ( ) Irmãos ( ) Esposo(a)

( ) Não

g) Assinale o seu nível educacional:

( ) Ensino Fundamental Incompleto ( ) Ensino Médio Incompeto ( ) Ensino Superior Incompleto

( ) Ensino Fundamental Completo ( ) Ensino Médio Completo ( ) Ensino Superior Completo

( ) Pós-Graduação

h) Quantas vezes você já assumiu cargos em conselhos ou comitês da Cooperativa?

( ) Nunca assumi ( ) De 1 a 3 vezes ( ) De 4 a 6 vezes ( ) De 7 a 10 vezes ( ) Mais do que 10 vezes

Se você deseja receber os resultados dessa pesquisa, por favor, informe seu:

Telefone:

E-mail: 
APÊNDICE D - Carta de solicitação para realização da pesquisa.

Coordeasçăo do Programa de Pos-Graduaçào em Controladoria e Contabilidade UNTVERSIDADE DE SĂO PAULO

Ribeirão Preto, 12 de novembro de 2018

Ao Sr.

Gerente do Cooperativismos

Cidade-Estado

Prezado senhor,

Gostariamos de solicitar a permissão para a realização de pesquisa cientifica (entrevista e aplicação de questionários junto aos cooperados) na (nome da cooperativa).

A coleta de dados visa subsidiar o desenvolvimento de um projeto de pesquisa de Mestrado da aluna Vanessa Schaefer do Programa de Pós-Graduação em Controladoria e Contabilidade da Facul dade de Economia, Administração e Contabilidade de Ribeirão Preto-FEA-USP/RP, sob orientação do professor Dr. Amaury José Rezende.

Neste projeto busca-se analisar as interpelações entre as seguintes variáveis: a) nivel de comunicação; b) grau de confiança e comprometimento dos cooperados e c) o impacto sobre o desempenho socioeconômico das cooperativas.

A proposta de pesquisa (questionário) será encaminhada previamente para análise. Comprometemo-nos a realizar um workshop de apresentação, ao final do processo de pesquisa, contendo os principais resultados alcançados.

As informações coletadas não têm fins comerciais e nem visam expor a integridade das operações desta conceituada organização, sendo mantido o anonimato dos respondentes (cooperados), que se dispuser a colaborar, e da cooperativa.

Atenciosamente,

Vanessa Schaefer

Discente do Programa de Pós-Graduação em Controladoria e Contabilidade

Amaury José Rezende

Orientador e Coordenador do Programa de Pós-Graduação em Controladoria e Contabilidade 
ANEXO - CRONOGRAMA DE ATIVIDADES

\begin{tabular}{|c|c|c|}
\hline ATTVIDADE & OBJETTVOS & PERIODO-LOCAL \\
\hline $\begin{array}{c}\text { Entrevista com os } \\
\text { cooperados }\end{array}$ & $\begin{array}{l}\text { Buscar subsídios para a elaboração do } \\
\text { questionário }\end{array}$ & $\begin{array}{l}08 / 12 / 2018 \\
\text { Cooperativa }\end{array}$ \\
\hline $\begin{array}{c}\text { Pré-teste do } \\
\text { questionário com } \\
\text { uma pequena } \\
\text { amostra } \\
\end{array}$ & $\begin{array}{l}\text { Verificar se as pergumtas do questionário } \\
\text { são compreendidas pelos cooperados } \\
\text { Validar as perguntas do questionário }\end{array}$ & $\begin{array}{l}\text { De janeiro à março de } \\
2019 \text {, durante eventos } \\
\text { da cooperativa }\end{array}$ \\
\hline $\begin{array}{l}\text { Qualificação da } \\
\text { dissertação }\end{array}$ & $\begin{array}{l}\text { Validar, junto aos professores da banca, os } \\
\text { dados coletados até o momento } \\
\text { Receber contribuições para melhoria do } \\
\text { questionário }\end{array}$ & $\begin{array}{l}\text { Abril a Maio de 2019, } \\
\text { na FEA-RP/USP }\end{array}$ \\
\hline $\begin{array}{l}\text { Aplicação do } \\
\text { questionário } \\
\text { definitivo }\end{array}$ & Coletar os dados finais da pesquisa & $\begin{array}{l}\text { Julho à Outubro de } \\
2019 \text {, durante eventos } \\
\text { da cooperativa }\end{array}$ \\
\hline $\begin{array}{l}\text { Defesa da } \\
\text { dissertação }\end{array}$ & $\begin{array}{l}\text { Apresentar os resultados finais da pesquisa } \\
\text { para os professores da banca }\end{array}$ & $\begin{array}{lr}\text { Dezembro/2019 } & \text { a } \\
\text { Fevereiro/2020, na } \\
\text { FEA-RP/USP }\end{array}$ \\
\hline $\begin{array}{l}\text { Envio do relatório } \\
\text { final da pesquisa } \\
\text { para a cooperativa }\end{array}$ & $\begin{array}{l}\text { Apresentar os resultados finais da pesquisa } \\
\text { para a cooperativa }\end{array}$ & $\begin{array}{l}\text { Dezembro/2019 } \\
\text { Fevereiro/2020, }\end{array}$ \\
\hline
\end{tabular}

Observaçâo: As datas definitivas de aplicação do pré-teste e do questionánio definitivo serăo agendadas previamente, conforme o calendário de eventos da cooperativa. Além dos eventos, poderão ser utilizadas outras formas de aplicação, desde que alinhadas previamente com a cooperativa. 


\section{APÊNDICE E - Carta de autorização da cooperativa}

\section{TERMO DE AUTORIZAÇÃO PARA REALIZAÇÃO DA PESQUISA}

Informamos que a Cooperativa $\longrightarrow$ autorizou a realização da pesquisa de mestrado que está sendo desenvolvida no âmbito de pós-graduação em Controladoria e Contabilidade da Faculdade de Economia, Administração e Contabilidade de Ribeirão Preto da Universidade de São Paulo, pela aluna de mestrado Vanessa Schaefer, RG 2101285324, sob orientação do professor Dr. Amaury José Rezende. O estudo tem como objetivo analisar as interpelaçōes entre as seguintes variáveis: a) nível de comunicação; b) grau de confiança e comprometimento dos cooperados e c) o impacto sobre o desempenho socioeconômico das cooperativas.

A aluna está autorizada a realizar entrevistas e aplicar questionários aos cooperados da cooperativa, previamente aprovados pela Ressalta-se que as informações recebidas serão utilizadas somente para pesquisa científica e desde já, a aluna se responsabiliza pela preservaçăo da identidade da cooperativa, assim como dos cooperados que aceitarem participar da pesquisa.

07 de dezembro de 2018.

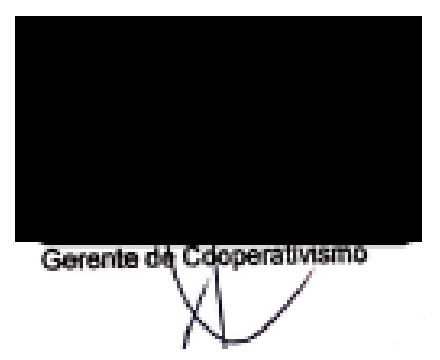




\title{
APÊNDICE F - Termo de Consentimento Livre e Esclarecido
}

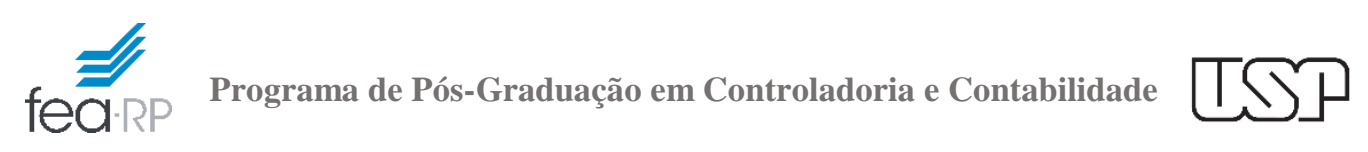

TERMO DE CONSENTIMENTO LIVRE E ESCLARECIDO

\begin{abstract}
Prezado(a) cooperado(a), você está sendo convidado (a) a participar da pesquisa denominada "DESEMPENHO SOCIOECONÔMICO DA COOPERATIVA AGROPECUÁRIA", a qual tem por objetivo verificar se há influência do comportamento do cooperado como proprietário, fornecedor e cliente sobre as suas atitudes perante a cooperativa e no desempenho socioeconômico percebido por ele.

Você responderá a um questionário. A sua participação é voluntária e, em momento algum, esta pesquisa servirá para a identificação e/ou julgamento de suas opiniões. Esta pesquisa é estritamente acadêmica, por isso todas as informações fornecidas são estritamente confidenciais e serão tratadas com sigilo.
\end{abstract}

\footnotetext{
ASSINE AQUI

$\mathrm{Eu}$
}

fui informado(a) dos objetivos da pesquisa, de maneira clara e detalhada e esclareci minhas dúvidas. Sei que em qualquer momento poderei solicitar novas informações e modificar minha decisão se assim desejar. A pesquisadora certificou-me de que minha identidade será preservada. Em caso de dúvidas poderei chamar a pesquisadora responsável, Vanessa Schaefer pelo telefone (51) 99622-9856 ou pelo e-mail vanessaschaefer@usp.br. Declaro que concordo em participar deste estudo, que recebi uma cópia deste TCLE e que me foi dada a oportunidade de ler e esclarecer as minhas dúvidas. 